\title{
PVA, PVA blends and their nanocomposites for biodegradable packaging application
}

\author{
Zainab Waheed Abdullah ${ }^{\mathrm{a}}$, Yu Dong a,*, Ian Jeffery Davies ${ }^{\mathrm{a}}$, Salim Barbhuiya ${ }^{\mathrm{b}}$ \\ ${ }^{a}$ Department of Mechanical Engineering, School of Civil and Mechanical Engineering, \\ Curtin University, Perth, WA 6845, Australia \\ ${ }^{b}$ Department of Civil Engineering, School of Civil and Mechanical Engineering, Curtin \\ University, Perth, WA 6845, Australia
}

\begin{abstract}
This review exclusively addresses material systems primarily based on poly (vinyl-alcohol) (PVA), one of the most popular water soluble biopolymers, for their use in packaging applications with the primary objective of reducing petro-based plastic waste. In addition, some typical PVA blends and nanocomposites are discussed as comparative studies for material packaging. Structural characteristics, mechanical, thermal and barrier properties, in addition to biodegradation of these multiple material systems, are summarised in a systematic manner. Finally, associated fabrication processing methods together with the most popular theoretical models used for the permeability of PVA nanocomposites are also reviewed in detail.
\end{abstract}

KEYWORDS: Poly (vinyl-alcohol) (PVA); biodegradation; PVA blends; PVA nanocomposites; material packaging.

\section{Introduction}

Large quantities of petro-based synthetic polymers are used globally for alternative applications such as packaging, appliances, building and construction. Within the global polymer market, approximately $42 \%$ of polymers are used for packaging of products such as food, chemicals, cosmetics and pharmaceuticals with this amount increasing $5 \%$ annually ${ }^{[1-3]}$. Polymeric materials have been used in recent history as a replacement for metals, glass and ceramics in packaging applications owing to their remarkable properties ${ }^{[4-6]}$. Indeed, their excellent mechanical and barrier properties, easy processability, relatively low cost and large

* Corresponding author. Tel.: +61 8 92669055; fax: +61 892662681.

E-mail address: Y.Dong@curtin.edu.au (Y. Dong). 
availability of synthetic polymers such as polystyrene (PS), polyethylene terephthalate (PET), polyamide (PA), polyvinylchloride (PVC), polypropylene (PP) and polyethylene (PE), have led to the widespread use in packaging applications since the middle of the twentieth century. Nonetheless, the relatively poor biodegradability of synthetic polymers is a major obstacle to the widespread future use of these materials ${ }^{[1,2,4]}$. Significant research work has been motivated by growing concerns of the environmental impact from un-degradable polymers with the hope of finding a solution in order to reduce plastic waste. Many approaches have been used to eliminate this environmental issue, which encompasses landfill to store the waste, incineration and recycling of plastic waste. However, the increasing growth of urbanisation, global warming, high costs and energy consumption inevitably hinder attempts for any further reduction in plastic wastes in an eco-friendly manner. Therefore, researchers have proposed the replacement of non-degradable polymers with fully biodegradable alternatives as a more realistic solution ${ }^{[7-12]}$. As illustrated in Figure 1, there has been a significant increase in the number of publications associated with this research area since 2000. According to the global market data for polymers, biodegradable polymers were responsible for approximately $1 \%$ of total consumed plastics in 2009, but this may reach $20 \%$ by $2020^{[13]}$. Although many bio-based polymers such as poly lactic acid (PLA) and aliphatic polyesters are categorised as biodegradable polymers, currently they are just employed in niche applications such as beverage cups and containers due to their less cost-effectiveness when compared to petro-based synthetic polymers ${ }^{[7,14,15]}$.

The main purpose of the packing process is to save manufactured products from the deterioration through transportation, storage and display steps, as well as to improve food quality and prolong shelf life in food packaging sectors. Accordingly, any suitable biopolymers (or their blends or composites) could exhibit sufficient barrier, optical, thermal and mechanical properties together with eco-friendly characteristics ${ }^{[7,8,16,17]}$, as demonstrated in Figure 2. Unfortunately, the poor material performance of most biopolymers, especially in terms of their barrier properties, high cost and material processing problems, has so far limited their application as neat packaging materials. Instead, biopolymers are typically blended with other synthetic polymers or else reinforced with different nanofillers in order to overcome this limitation $^{[4,16,18,19]}$. PVA is one of the most popular synthetic biopolymers for packaging applications and is the fundamental subject of this review due to its good biodegradability, compatibility, processability and acceptable mechanical and thermal properties. The morphological structure, processing methods and properties of pure PVA, its blends and 
nanocomposites are comprehensively reviewed, together with explicit descriptions of permeability modelling for resulting barrier properties of their nanocomposites.

\section{Biodegradable polymers}

\section{Concept of Biodegradability}

Biodegradability can be defined as the process to break down any organic substance by the enzymatic action of living organisms such as fungi, yeast and bacteria under suitable environmental conditions (defined by factors such as oxygen availability, temperature and humidity) in order to produce $\mathrm{CO}_{2}$, biomass and water in aerobic conditions or else methane in anaerobic conditions without the presence of toxic residues at the final step of degradation [1, 2, 7, 16]. ASTM standard D-5488-94d, European norm (EN) 13432, DIN 103.2 and ISO 472 give similar definitions for biodegradability ${ }^{[20-23]}$. In addition to environmental factors such as organism type, $\mathrm{pH}$ level, temperature and humidity, other important factors are known to influence the biodegradability of polymers such as polymer crystallinity, functional groups, molecular weight and polymer additives such as plasticisers ${ }^{[1,2,21]}$. Under suitable environmental conditions, the biodegradation process may take 6-12 weeks to finalise, depending on many factors such as polymer structure, morphology, molecular weight and chemical treatment ${ }^{[2,23]}$.

The biodegradation process for polymers may consist of several steps ${ }^{[21,24,25]}$ as shown below:

- In the biodeterioration step, polymers are fragmented into smaller pieces by the action of microbial communities. Biodeterioration is dependent on the microorganisms growing on the surface or inside of polymeric materials and uses mechanical, chemical and enzymatic means to complete its job.

- Depolymerisation is the second step, in which polymeric molecules are cleaved into oligomers and monomers by the microorganisms.

- During the assimilation step, transported molecules are used to produce new biomass, energy and storage vesicles in the cytoplasm.

- The final step is mineralisation, in which simple molecules such as $\mathrm{H}_{2} \mathrm{O}, \mathrm{CO}_{2}, \mathrm{CH}_{4}$ and salts are released into the environmental after being completely oxidised.

The biodegradation of polymers can be evaluated by several methods ${ }^{[21,24]}$ as follows: 
- Surface morphology: Many surface characteristics are changed when biodeterioration occurs such as an increase in surface roughness, change in colour and the presence of cracks or holes.

- Weight loss: The weight of polymeric materials decreases with time when buried in soil or enzymatic solutions as an indicator of biodegradation.

- Changes of properties: Changes in dynamic, mechanical, chemical and thermal properties reflect the biodegradation of polymeric materials.

- Product formation: Some products such as glucose from cellulose polymeric materials or carbon dioxide $\left(\mathrm{CO}_{2}\right)$ can be used to evaluate the biodegradation of polymers.

\section{Classification of biopolymers}

Biodegradable polymers or biopolymers can be divided into groups, depending on their raw materials sources and manufacturing methods ${ }^{[2,4,12,16-18,26]}$, as shown in Figure 3:

- Polymers extracted from biomass include plant polysaccharides (e.g., agar, starch and cellulose) and animal or plant proteins (e.g., collagen, gelatine, soy protein and corn zein).

- Polymers produced from renewable bio-based monomers or mixed sources of biomass and petroleum using classical chemical synthesis methods (e.g., PLA, bio-polyester and PVA).

- Polymers produced by bacteria or micro-organisms (e.g., polyhydroxybutyrate (PHB) and xanthan $)^{[2,4,16-19]}$.

Despite the excellent biodegradability, most biopolymers possess low mechanical and barrier properties that do not meet the end users' requirements for many applications. As such, polymer blends or nanocomposites are alternative material systems used to overcome these drawbacks $^{[27-29]}$.

\section{PVA biopolymers}

\section{Structure}

Water-soluble synthetic polymers are man-made polymers that can be dissolved, dispersed and swollen in water with natural, semi-synthetic or synthetic origins ${ }^{[30,31]}$. As one of these polymers, PVA is biocompatible, biodegradable, non-toxic and odourless. It also possesses good chemical resistance and high mechanical properties although its disadvantages include 
limited barrier and thermal properties and relatively high cost ${ }^{[30,32-35]}$. PVA is available in many forms such as fibre, powder and film without the insolation of monomers ${ }^{[9,36,37]}$. PVA is a semicrystalline polymer comprising mainly amorphous phases with only a small amount of crystallinity ${ }^{[38,39]}$ and consists of 1, 3-diol units or 1, 2-diol units, depending on the hydrolysis degree of poly (vinyl-acetate) (Figure 4). The properties of PVA generally depend on its molecular weight and degree of hydrolysis with the molecular weight of PVA generally ranging between 20,000-400,000 and based on the length of vinyl acetate used to produce PVA - the degree of hydrolysis is typically in the range of $80-99 \%$. For example, tensile strength, water, block and solvent resistance are found to increase with increasing molecular weight and degree of hydrolysis; whereas the flexibility, solubility and water sensitivity decrease $\mathrm{e}^{[3,40,41]}$, as shown in Figure 5. The presence of many hydroxyl groups on the PVA surface makes it one of the most hydrophilic polymers with high moisture sensitivity, and hence its resulting blends and composite materials have become popular for packaging applications ${ }^{[42,43]}$, as demonstrated in Table 1. In general, full-hydrolysis PVA is not considered to be a thermoplastic polymer mainly due to its melting temperature being very close to the degradation temperature in the absence of plasticisers. Therefore, it is essential to use plasticisers for PVA in order to control the relevant melting temperature, fluidity and thermal stability, especially for screw extrusion and injection moulding processes widely used for packaging applications (Table 1$)^{[33,44,45]}$. As mentioned by Jang and Lee ${ }^{[46]}$ and Negim et al. ${ }^{[47]}$, the addition of plasticiser to PVA can decrease its melting temperature, brittleness and improve the flexibility and processability, as a result of increasing the segment mobility and reducing the crystallinity. However, the use of excessive plasticiser is known to result in phase separation due to the increase of hydrogen bonding between plasticiser and polymer molecules. On the other hand, partial-hydrolysis PVA contains residual acetate groups, sometimes known as a copolymer of vinyl acetate and vinyl alcohol. These groups can restrict the creation of hydrogen bonding with adjacent -OH groups, resulting in increased blend solubility, water uptake and permeability. As such, partialhydrolysis PVA is not preferred for packaging applications ${ }^{[48-51]}$. Roohani et al. ${ }^{[48]}$ compared $^{[0}$ thermal properties of full-hydrolysis and partial-hydrolysis PVA/cellulose nanowhisker (CNW) composite films. Thermal stability of full-hydrolysis PVA/CNW nanocomposites was found to be higher than that of partial-hydrolysis counterparts owing to strong interactions between polymer matrices and nanofillers restricting chain mobility. In addition, Giannakas et $a l .{ }^{[52]}$ reported that hydrogen bonds were less likely to be formed when low-molecular-weight PVA was blended with chitosan, leading to a reduction in strength and stiffness, while simultaneously increasing elongation, as a result of phase separation. According to Grande et 
al. ${ }^{[53]}$, PVA may be used as a compatibiliser for other biopolymer blend systems. For example, PVA has been added to chitosan/PLA blends in order to improve their miscibility and formability in the presence of glycerol as a plasticiser due to plasticised PVA acting as a dispersion medium for other polymers ${ }^{[53,54]}$. Therefore, the use of PVA and its blends and composites for packaging applications has increased dramatically in recent years due to their high material performance, as illustrated in Figure 6.

\section{Material synthesis}

PVA was first synthesised using the saponification process of poly (vinyl-acetate) (PVAc) in 1924. Since PVA could not be produced through the direct polymerisation of PVAc, Herrmann and Haehnel ${ }^{[55]}$ prepared PVA by mixing ethanol solutions containing potassium hydroxyl and polyvinyl acetate at room temperature, which were then boiled in the presence of hydraulic acid for 1-2 h. The saponification mechanism was interpreted according to the following chemical reactions ${ }^{[31,56]}$ :

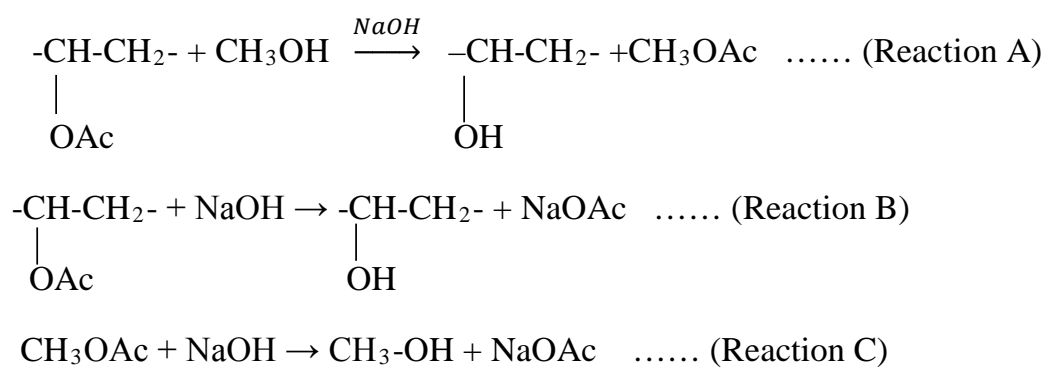

where Reaction A is expressed as the alcoholysis of polyvinyl acetate. Reaction B represents the saponification of polyvinyl acetate; whereas methyl acetate was produced in Reaction $\mathrm{C}^{[55]}$. Within industries, acetylene or ethylene are used as base materials to produce vinyl acetate in the presence of acetic acid and/or oxygen. Subsequently, heat is used to initiate the polymerisation process of purified vinyl acetate in the presence of a methanol solution. More than $70 \%$ of monomers are generally converted to polyvinyl acetate during the polymerisation process in order to produce polyvinyl alcohol via saponification ${ }^{[31,52]}$, depicted in Figure 7. PVA is currently prepared by partially or completely replacing ester groups from polyvinylacetate with hydroxyl groups during the hydrolysis process in the presence of sodium hydroxide or anhydrous sodium methylate (Figure 4$)^{[32,35]}$. The degree of hydrolysis can be controlled by the concentration of catalyst and hydrolysis temperature ${ }^{[31]}$. PVA can be processed easily from the suspension, water and melt via extrusion or injection moulding at lower costs, as compared with other biodegradable polymers ${ }^{[36]}$. PVA films for packaging 
applications can be produced by casting from water solution, injection moulding and blow extrusion though limitations exist due to the high heat sensitivity of PVA (The use of plasticisers and lubricants are a promising solution to overcome this main drawback $)^{[57,58]}$. The melting temperature and viscosity of PVA can be reduced by adding plasticisers in order to restrict thermal degradation during the extrusion process ${ }^{[16]}$.

\section{Properties}

The tensile test is predominantly used to characterise mechanical properties of biopolymers with tensile strength, elongation at break and Young's modulus being determined according to ASTM D882 and ASTM D638 standards for thin plastic sheets and general plastics, respectively. Moreover, impact and compression tests can also be used to characterise material properties depending on their application (e.g., building construction and infrastructure $)^{[2,56]}$. As mentioned previously, tensile properties of pure PVA are generally a function of molecular weight and degree of hydrolysis (Figure 5) ${ }^{[33,41]}$. Gaaz et al. ${ }^{[41]}$ reported that full-hydrolysis PVA possessed a tensile strength of 1.6 GPa, Young's modulus of $48 \mathrm{GPa}$ and elongation at break of 6.5\%; whereas Loryuenyong et al. ${ }^{[59]}$ found values of 25.4 MPa, 27.6 MPa and 260\%, respectively, for partial-hydrolysis PVA. In addition, mechanical properties of PVA can be significantly changed when crosslinked with chemicals such as boric acid, citric acid and hexamethylene diisocyanate due to the change of PVA structure ${ }^{[43,60]}$. Finally, the presence of plasticisers such as polyol is known to improve elongation at break at the expense of reduced tensile strength and Young's modulus due to the increase in mobility of polymer molecules $^{[43,61]}$.

Barrier properties of polymers are an important issue to maintain product quality and estimate package shelf life. In general, all biodegradable polymers have a wide range of permeability levels against small molecules such as oxygen and water vapour ranging from high to low permeability rates ${ }^{[2]}$. The barrier property against oxygen can be expressed by the oxygen permeability coefficient (OPC), which is defined as the amount of oxygen transfer through a packaging material per unit of area and time $\left(\mathrm{kg} \cdot \mathrm{mm}^{-2} \cdot \mathrm{s}^{-1} \cdot \mathrm{Pa}^{-1}\right)$, or by the oxygen transmission rate $(O T R)$ that is measured in units of $\mathrm{cm}^{3} \cdot \mathrm{m}^{-2} \cdot \mathrm{s}^{-1}$ and related to the $O P C$ by the following equation $^{[2,62]}$ :

$$
O P R=O T R \cdot \frac{l}{\Delta P}
$$


Where $l$ is the film thickness $(\mathrm{m})$ and $\Delta P$ is the difference in oxygen pressure across the film ${ }^{[2]}$. The water vapour permeability coefficient (WVPC) is used to express the barrier property against water, which is referred to as the amount of water vapour transfer through a packaging material per unit of area and time and is correlated to the water vapour transmission rate $(W V T R)$ through an equation similar to Equation $1^{[2,63]}$. The mechanism of permeability through polymeric films is a complex process that can include several sub-processes ${ }^{[64,65]}$. First of all, the molecules (e.g., gas or water vapour) are absorbed on the film surface where they dissolve inside the film. Following this, dissolving molecules diffuse through the film and finally desorption of diffusing molecules takes place on other film surfaces ${ }^{[18,66]}$. Many factors are known to affect the permeability of polymers. For example, permeability decreases dramatically with increasing the degree of polymer crystallinity as crystalline regions tend to be more resistant against diffusive molecules when compared to their amorphous counterparts. Furthermore, permeability increases at higher temperatures due to the increase in mobility of polymeric chains, leading to the production of a larger free volume for diffusive molecules ${ }^{[67]}$. However, the presence of poor barrier properties in a polymer film for material packaging applications can be improved by several methods including co-extrusion with other polymers, coating with hydrophobic materials, surface modification, blending with renewable or synthetic polymers and development of bionanocomposites ${ }^{[18]}$. PVA, as a typical water-soluble polymer, has relatively high water permeability, but very low oxygen permeability as a result of its crystalline structure and strong interaction between molecules ${ }^{[43,68]}$. Krumova et al. ${ }^{[58]}$ reported that barrier properties of PVA could be significantly improved when crosslinked with 3-5\% boric acid due to the creation of a new hydrogen bond between -OH groups on PVA and boric acid. Furthermore, the permeability level of PVA was found to be dependent on the boric acid content.

Thermal characterisation of biodegradable polymers in order to determine the melting temperature $\left(T_{m}\right)$ and glass transition temperature $\left(T_{\mathrm{g}}\right)$ can be carried out by differential scanning calorimetry (DSC) according to ASTM D3418. In addition, DSC can be used to determine the melting enthalpy $(\Delta H)$, onset (i.e., start of melting event) and end-point temperature (i.e., completion of melting event). In contrast to this, the decomposition temperature can be determined by thermogravimetric analysis (TGA) according to ASTM E1131-03 ${ }^{[2,57,67]}$. Whilst pure PVA has a $T_{m}$ of $230{ }^{\circ} \mathrm{C}$, the value of $T_{g}$ is known to depend on the degree of hydrolysis with values of $85{ }^{\circ} \mathrm{C}$ for $98-99 \%$ hydrolysed PVA and $58{ }^{\circ} \mathrm{C}$ for $87-$ $89 \%$ hydrolysed $\mathrm{PVA}^{[62]}$. In general, the $T_{g}$ of PVA decreases linearly with increasing relative 
humidity as a result of the plasticising effect of water on the PVA structure ${ }^{[49]}$. Holland and Hay ${ }^{[69]}$ characterised the thermal degradation of PVA in solid and molten states. It was found that, in a molten state, the degradation process happened due to random scission that produced volatile products such as acetaldehyde in addition to ketones. However, the degradation process in the solid state occurred through the elimination of water at a temperature below the melting point to produce carboxyl groups in addition to water. Cano et al. ${ }^{[70]}$ detailed the thermal degradation of PVA and noted that PVA lost water at approximately $100^{\circ} \mathrm{C}$ to start the degradation process. In the second step, PVA lost approximately $80 \%$ of its weight due to the dehydration, chain scission and decomposition occurring at approximately 206-357 ${ }^{\circ} \mathrm{C}$. Finally, by-product degradation took place at $387-450^{\circ} \mathrm{C}$ to complete the degradation process.

It should be noted that PVA is not a completely biodegradable polymer in all environments as some of the necessary conditions may be missing such as types of microorganism, temperature, $\mathrm{pH}$ level and relative humidity ${ }^{[31,71]}$. According to Kopčilová et al. ${ }^{[7]}$, PVA was completely biodegradable in activated sludge; whereas its biodegradation rate was very low in other environments such as soil and compost. Furthermore, Corti et al. ${ }^{[72]}$ showed that the biodegradability of PVA and PVA blends with other polymers such as lignocellulos and gelatine under soil burial conditions was extremely limited due to the lack of specific microorganisms required to attack PVA. Similarly, Chiellini et al. ${ }^{[24]}$ detected that during burial tests, the degradation rate of PVA based films varied from 8-9\% in 74 days to $13 \%$ in 21 days under aerobic conditions. Therefore, PVA blended with polysaccharide polymers such as starch and cellulose can enhance the biodegradation rate. According to Chiellini ${ }^{[30]}$, the molecular weight and degree of hydrolysis of PVA do not have a significant effect on biodegradation rate. This result was also in good agreement with that obtained from Solaro et al. ${ }^{[73]}$, which investigated the biodegradation rate of PVA membranes with different degrees of hydrolysis (98, 88 and 72\%) and molecular weights (20.3, 44.9 and $9.5 \mathrm{kD}$ ) and found that the biodegradation rates were essentially independent of environment. Under a suitable environment, most biopolymers follow a definite procedure during the biodegradation process. This starts with water uptake by the polymer to hydrolyse its bonds into fragmented oligomers, followed by further solubilisation of oligomers and finally mineralisation into $\mathrm{CO}_{2}$ and $\mathrm{O}_{2}{ }^{[17]}$. The biodegradability of PVA involves two steps, consisting of the enzymatic oxidation of alcohol groups into ketone groups and then hydrolysis of ketone groups to cleavage. The biodegradability of PVA is known to be affected by hydroxyl groups on its surface ${ }^{[23,74]}$. Gaaz 
et al. ${ }^{[41]}$ indicated that the biodegradability of PVA was improved during the hydrolysis process due to the presence of hydroxyl groups on carbon atoms.

UV-vis spectrometry is used to characterise the optical properties of pure polymers, blends and composite materials. In general, PVA is considered to be a completely transparent polymer with a transparency level of approximately $91 \%$ to visible light though this value may decrease when PVA is blended or else reinforced with additive and filler ${ }^{[59,75]}$. The transparency of polymers is a function of its crystallinity, which decreases significantly with increasing the degree of crystallinity ${ }^{[76]}$.

\section{PVA blends}

Blending techniques provide a good opportunity to improve material properties and costeffectiveness for particular applications in medical science and material packaging. Polymers generally possess similar solubility parameters that lead to enhanced compatibility and miscibility in blending due to the formation of strong hydrogen bonds rather than weak van der Waals forces ${ }^{[20,77,78]}$. The resulting polymer blends may possess unusual properties that are completely different from individual component polymers ${ }^{[9]}$. PVA has a relatively high material cost and low biodegradable rate, and thus it has to be blended with other polymers. Moreover, PVA possesses high compatibility with several natural polymers such as starch, chitosan, cellulose and lignocellulose that can be exploited for packaging applications ${ }^{[32,45]}$.

\section{PVA/starch blends}

Starch, belonging to polysaccharide family, is abundant in nature. It is water soluble, odourless, tasteless, colourless, transparent, non-toxic, with low oxygen permeability, completely biodegradable in water and soil and cost-effective ${ }^{[20,22,40,58]}$. Starch granules are typically 0.5$175 \mu \mathrm{m}$ in size, depending on their source such as tubers (e.g. potato and cassava), cereal grains (e.g. wheat, corn and rice) and legumes (e.g. lentils and pea) ${ }^{[20,22,40,80-82]}$, as illustrated in Figure 8. Starch with a chemical formula $\left(\mathrm{C}_{6} \mathrm{H}_{10} \mathrm{O}_{5}\right)_{n}$ consists of two major types of macromolecules, namely 20-30\% amylose and 70-80\% amylopectin with small amounts of lipids, phosphate, protein, amino acid and gluten, obtained from the manufacturing process. Amylose is a linear carbohydrate in which D-glucose units are linked by $\alpha(1-4)$ bonds with a molecular weight of $10^{5}-10^{6}$. In contrast to this, amylopectin is a more highly branched polymer based on $\alpha(1-4)$ and $\alpha(1-6)$ bonds to link D-glucose with a molecular weight of $10^{7}-10^{9}$ (Figure 9) ${ }^{[20,40,80-82]}$. Starch is a semicrystalline polymer with a degree of crystallinity in range from $15-45 \%$, 
depending on amounts of amylose and amylopectin ${ }^{[22,83,84]}$. Starch is hard to process as a pure polymer because its decomposition temperature $\left(T_{d}=220{ }^{\circ} \mathrm{C}\right)$ is very close to the melting temperature $\left(T_{m}=220-240{ }^{\circ} \mathrm{C}\right)$. The presence of many H-bonds between macromolecules also prevents the mobility of these polymeric molecules ${ }^{[20,56,85,86]}$. Therefore, plasticisers such as water, polyols, glycerol and urea as low molecular weight and low volatile organic agents, can overcome this limitation in addition to increases in flexibility and processability, as well as reductions of brittleness and $T_{g}$ for native starch by decreasing its intermolecular forces ${ }^{[8,40,83,87]}$. Sreedhar et al. ${ }^{[88]}$ has concluded that starch does not have a specific $T_{g}$ because of its semicrystalline and hygroscopic nature. In addition, Zou et al. ${ }^{[89]}$ has also suggested that starch does not have a definite $T_{g}$ since the moisture content, amorphous segments surrounded by crystalline counterparts and physical forces can restrict the movement of amorphous segments. Plasticised starch or thermoplastic starch (TPS) was produced by a gelatinisation process in order to improve starch fluidity and processability via extrusion or injection moulding ${ }^{[20,22,32,33]}$. The gelatinisation process can be defined as the process to disrupt and swell highly organised starch granules in the presence of heat, water and plasticisers in order to produce viscous starch pastes with lower $T_{m}$ and $T_{g}$ values ${ }^{[10,27,90,91]}$. Poor mechanical properties and high water sensitivity are the main drawbacks of TPS. However, PVA/TPS blends have been used to improve the biodegradability and reduce the material cost of PVA, in addition to the reduction of high water sensitivity and improvement of TPS mechanical properties $^{[40,42,92,93]}$. Tânase et al. ${ }^{[94]}$ tested the biodegradability of PVA/starch films using soil burial tests with the effect of starch content on biodegradation being investigated. Their results showed that the biodegradation rate was increased by $32.45 \%$ with increasing the starch content from 0 to $20 \mathrm{wt} \%$. However, the biodegradability was reduced by $11 \%$ upon increasing the starch content to $30 \mathrm{wt} \%$ with their results being explained in terms of water absorption accompanied by biodegradation. Very close solubility parameters for glycerol (21.1 $\left.\mathrm{MPa}^{1 / 2}\right)$, PVA (22.5 $\mathrm{MPa}^{1 / 2}$ ) and starch (23.4 $\mathrm{MPa}^{1 / 2}$ ) have suggested that glycerol is a suitable plasticiser that can produce better system integrity ${ }^{[44]}$, Table 1 . In addition, glycerol content is an important factor to attain required material structures. For instance, a high glycerol content of more than $27 \%$ can give rise to phase separation of polymer matrices; whereas a lower content can lead to a hardening rather than plasticising effect for matrices ${ }^{[22]}$. PVA and starch have acceptable compatibility in the presence of plasticisers owing to chemical interactions between -OH groups and their formation of hydrogen bonds (Figure 10). Park et al. ${ }^{[95]}$ studied the effect of three different types of plasticisers on PVA/starch films, denoted as glycerol (GL), sorbitol (SO) and citric acid (CA). In general, these plasticisers reduced the tensile strength and 
increased the elongation at break and solubility of blends, as observed in Figure 11. Similarly, Yun et al. ${ }^{[96]}$ investigated the effect of different additives such as GL, SO, CA, succinic acid (SA), malic acid (MA) and tartaric acid (TA) with different hydroxyl and carboxyl groups on mechanical properties of PVA/starch films. The tensile strength decreased and elongation at break increased with increasing most of these additive contents from 10 to $50 \mathrm{wt} \%$ despite an opposite effect of SA due to its different hydrophobicity. Overall the blends were found to possess good film properties such as odourless, non-toxic, transparent and fully biodegradable material features but at the expense of limited mechanical properties ${ }^{[1,34,97,98]}$. In general, PVA/starch blend films have some limitations such as high hydrophilicity and weak mechanical properties. In particular, tensile and barrier properties decrease with increasing the starch content, resulting from their partial compatibility, especially in the absence of plasticisers. Consequently, main approaches to overcome these limitations comprise the use of chemicals (such as cross-linkers and surfactants) to modify the compatibility during blending, the use of modified PVA and starch instead of native PVA and starch, respectively, as well as the incorporation of nanofillers to improve their properties ${ }^{[99]}$. Zhao et al. ${ }^{[100]}$ modified starch to tackle this problem by using methylated corn-starch (MCS) and then blended it with PVA. The water absorption capacity of PVA/MCS decreased by a factor of two when compared with that of PVA/native starch. This finding was attributed to the increase in film hydrophobicity owing to the substitution of - $\mathrm{OH}$ groups on starch with methyl-groups. In addition, mechanical properties were noted to improve linearly with increasing the degree of substitution. On the other hand, Jayasekara et al. ${ }^{[101]}$ modified surface compatibility of PVA/starch films with the aid of chitosan since the surface roughness of PVA was lower than that of starch. However, PVA/starch blend surfaces had an intermediate roughness between those of individual PVA and starch, which remained unchanged with the addition of chitosan. In addition, no clear changes in Fourier transformation infrared (FTIR) and X-ray diffraction (XRD) results were observed when chitosan was added to the blend, suggesting no sign of newly formed bonds. Notwithstanding that starch is often used as a biopolymer matrix to reduce environmental pollution by improving the biodegradation of other polymers, it can also be used in the form of particles or platelets as reinforcements ${ }^{[82,102,103]}$. Eaysmine et al. ${ }^{[104]}$ used potato starch as reinforcing particles for PVA and PLA to improve their properties. Starch loading of less than $6 \mathrm{wt} \%$ was found to decrease the tensile strength due to insufficient reinforcement; whereas a higher loading at $9 \mathrm{wt} \%$ conversely yielded improved tensile strength due to good interfacial bonding between matrices and starch particles. Chen et al. ${ }^{[99]}$ also revealed that the addition of pea starch nanocrystals (PSN) to PVA produced higher properties when compared with PVA 
blended with native pea starch (NPS). PVA/PSN films have shown better mechanical and optical properties than PVA/NPS films due to higher dispersibility, homogenous structure and strong interaction of PSN relative to NPS (Figure 12). According to Lawton ${ }^{[105]}$, the property stability of PVA/starch films during storage conditions depended on the amylose content of starch. This result was detected when PVA/starch films were prepared from six different types of starch, namely normal corn starch, waxy corn starch, high amylose corn starch, potato starch, tapioca starch and wheat starch. The resulting mechanical properties indicated that starch with a high amylose content such as waxy corn starch (50 \% amylose) and high amylose corn starch (70\% amylose) possessed improved stability under storage conditions in comparison with other starch types. In general, relative humidity is also known to affect the properties of PVA/starch films. Zanela et al. ${ }^{[106]}$ reported that increasing the relative humidity from 33 to 75\% reduced tensile strength and Young's modulus by 20 and 43\%, respectively, arising from the plasticising effect of water molecules on the films.

\section{PVA/chitosan blends}

Chitosan is a natural biodegradable polymer that has high antimicrobial activity, low oxygen permeability, good film formability and nontoxicity, in addition to its cost-effectiveness and widely availability. These attractive properties result from the presence of strong hydrogen bonds between molecular chains and the presence of hydroxyl and amine groups ${ }^{[13,107,108]}$. Chitosan is generally regarded as a hydrophilic biopolymer, even though it is insoluble in water, and can be dissolved in many acidic solvents and plasticisers ${ }^{[13,77,109]}$. It is a semicrystalline copolymer produced by more than $75 \%$ deacetylation of chitin and regarded as the second most abundant polysaccharide in nature after cellulose, which can be found in the cell walls of fungi, exoskeletons of insects and crustaceans such as shrimps ${ }^{[9,13,52,58,110,111]}$. Chitosan consists of glucosamine and $\mathrm{N}$-acetylglucosamine units with different molecular weights ranging from $100-1100 \mathrm{~kg} / \mathrm{mol}^{[16,74,112]}$. Many factors are known to influence antibacterial properties of chitosan including its molecular weight, activity of cationic groups and degree of deacetylation, in addition to environmental conditions such as temperature, $\mathrm{pH}$ level and bacteria type ${ }^{[9,13,107]}$. Since chitosan degrades before it melts, it is considered to be a non-thermoplastic polymer. However, it can be blended with other thermoplastic polymers to overcome this limitation. Meanwhile, the addition of chitosan to un-degradable polymers can increase the biodegradability of these polymers; whereas antimicrobial blends can occur when it is added to biodegradable polymers ${ }^{[13]}$. The combination of good mechanical properties and hydrophilicity of PVA with the biological activity of chitosan offers a good opportunity to 
produce beneficial blend films with high antimicrobial effects, high formability, good strength and high barrier proprieties, despite that the elongation at break may be a limiting factor for packaging and medical applications ${ }^{[77,108,113]}$. Many studies have used nanofillers to reinforce PVA/chitosan blends in order to enhance their mechanical properties. For instance, Butnaru et al. ${ }^{[5]}$ used Cloisite 30B nanoclays to improve thermal stability and mechanical properties of PVA/chitosan blends for packaging films. The addition of Cloisite 30B nanoclays increased the onset degradation temperature and reduced the mass loss as compared with neat PVA and typical PVA/chitosan blends. Moreover, tensile properties were mostly enhanced at a nanoclay loading of $5 \mathrm{wt} \%$. In addition, Khoo et al. ${ }^{[110]}$ found that thermal degradation and water uptake of PVA/chitosan could be decreased with the incorporation of halloysite nanotubes (HNTs).

\section{PVA/PLA blends}

Poly (lactic-acid) (PLA) is a natural, biodegradable, biocompatible and nontoxic aliphatic polyester, derived from agro resources such as corn, potato and sugar beet as a linear polymer. PLA is synthesised from lactic acid monomers through the ring-opening polymerisation (ROP) or condensation by two routes ${ }^{[9,40,114]}$. Copolymers of poly (L-lactide) with D-lactide are commercial material grades for PLA. Notwithstanding its good thermal and mechanical properties, the highly hydrophobic nature of PLA leads to low hydrolytic degradation rates. In general, hydrophobicity means the poor ability for holding-up water. As water uptake is an essential step to degradation process, PLA thus possesses the low hydrolytic degradation rate ${ }^{[17}$, 114]. Hence, it is often blended with synthetic biopolymers such as PVA in order to enhance its biodegradability $^{[9,21,114]}$. Li et al. ${ }^{[115]}$ suggested that the blending of PVA with PLA could lead to promising ecofriendly materials for packaging applications with high performance such as good mechanical properties and thermoplasticity. In addition, Gajria et al. ${ }^{[116]}$ found that there was high physical miscibility and compatibility between PVA and PLA due to the presence of a single $T_{g}$ peak observed in DSC results. It was also shown that tensile strength significantly increased with increasing PVA amounts in blends, which is attributed to increases in hydrogen bonding and chemical interactions between polymers. Moreover, Hu et al. ${ }^{[117]}$ added PLA to PVA/starch films to improve their miscibility, enhance mechanical and thermal properties and reduce their water absorption. In-situ polymerisation was used to prepare films by modifying starch with lactic acid graft copolymers to produce starch-g-PLA that was then blended with PVA to manufacture composite films. Tensile strength and elongation of PVA/starch-g-PLA films were increased from 11.80 to $19.96 \mathrm{MPa}$ and from 113.10 to $208.35 \%$, respectively, after 
the addition of PLA. On the other hand, water absorption was decreased from 142.30 to 70.59\%. The overall improvement in properties was believed to stem from strong interactions between polymers. Furthermore, Shuai et al. ${ }^{[118]}$ stated that L-PLA was immiscible with PVA with completely different $T_{g}$ peaks being observed from DSC results, which is ascribed to the absence of hydrogen bonding in amorphous regions.

\section{PVA/PEO blends}

Poly (ethylene oxide) (PEO) is a synthetic, water soluble and thermoplastic polymer with a chemical formula $\left(-\mathrm{CH}_{2}-\mathrm{CH}_{2}-\mathrm{O}\right)_{n}$. PEO has been well known and widely utilised since 1859 when Lourenco synthesised polyethylene glycol ${ }^{[119]}$. It has a wide range of molecular weights, starting from the lowest molecular weight known as ethylene glycol to more than a million. Many properties vary with the change of molecular weight. For example, the viscosity ranges from fluid-like for lower-molecular-weight polymers to thermoplastic polymers with high molecular weight ${ }^{[119]}$. PEO possesses versatile and multifunctional properties such as hydrophilicity, nonpolarity, biocompatibility and nontoxicity, so it can be used for many medical and packaging applications. However, the main disadvantage of PEO is that it is not miscible with many polymers ${ }^{[78,120]}$. Gupta et al. ${ }^{[78]}$ showed that PVA/PEO blends were immiscible because of the lack of bonding between ether groups on PEO and hydroxyl groups on PVA, leading to phase separation of the blends. Therefore, using a stabiliser such as carboxymethyl cellulose (CMC) was essential to improve the miscibility between polymers, and further enhance the transparency, tensile strength and thermal stability of the blends. Mishra and $\mathrm{RaO}^{[50]}$ explained this miscibility of PVA/PEO blends according to their polymeric structures. The compatibility between PVA and other polymers is produced from hydrogen bonding between $-\mathrm{OH}$ groups of PVA and other polymers. However, PEO has simple molecular chains connected through etheric linkages instead of - $\mathrm{OH}$ groups so that the chance of forming hydrogen bonds is very low. In addition, the backbone of PEO consists of C-O-C with the straight angle making the formation of hydrogen bonds difficult to achieve. This arises from the difficult attachment between -OH groups in PVA and etheric oxygen in PEO. PVA/PEO blends have been used for packaging films and bottles because PEO is a nonpolar polymer with good barrier properties against water, in contrast to PVA films with low permeability to water but high permeability to oxygen ${ }^{[76]}$. 


\section{Manufacturing Process}

Solution casting, extrusion and thermoforming are major material preparation methods of PVA blends (Table 1). Solution casting has been studied as a primary processing method for PVA blends since the 1980s. However, this method is considered unacceptable from an economic viewpoint due to its relatively high processing cost and limited efficiency as compared with other techniques ${ }^{[33,112]}$. According to Tang and Alavi ${ }^{[33]}$, solution casting can be used in a wide range to process PVA because it is completely dissolved in water. Moreover, Gaaz et al. ${ }^{[41]}$ stated that the dissolution of PVA took $30 \mathrm{~min}$ in water at about $90{ }^{\circ} \mathrm{C}$ as a relatively low processing temperature. In contrast, the extrusion processing of PVA is difficult due to its processing temperature being close to the degradation and melting temperatures. In general, PVA starts to degrade at $150^{\circ} \mathrm{C}$, depending on the degree of hydrolysis and this temperature is close to melting points at $230^{\circ} \mathrm{C}$ and $180-190{ }^{\circ} \mathrm{C}$ for full-hydrolysis PVA and partial-hydrolysis PVA, respectively ${ }^{[31,62]}$. Water is the first product released during the degradation process with many changes in structure and properties occurring owing to the water soluble behaviour of PVA. Hence, the structure of PVA may be altered during extrusion process. ${ }^{[31]}$ Several studies $^{[112,114]}$ have shown that PVA/starch blends are difficult to be synthesised by twin screw extrusion due to their unique rheology. Tânase et al. ${ }^{[32]}$ prepared PVA/starch films by single screw extrusion and evaluated the effect of starch content on processing parameters. Their results showed that an increase in the starch content caused an increase in melt viscosity for PVA/starch blends, which made processability of the blends harder during mixing. In addition, the power consumption for mixing increased linearly with increasing the starch content from 10-30 wt\%. On the other hand, Wang et al. ${ }^{[80]}$ demonstrated that extrusion blow moulding could be a highly productive and efficient process, similar to industrial manufacturing methods, when PVA films were prepared with two different types of starches, namely hydroxypropyl distarch phosphate (HPDSP) and cationic starch. Moreover, the mixing time of PVA with other polymers influences the colour and properties of resulting blends. This result was achieved by Priya et al. ${ }^{[57]}$ when the mixing time of PVA/starch blends was changed from 0-45 min with the optimal mixing time of $10 \mathrm{~min}$. Their findings showed that blend colour was altered, tensile strength was decreased and elongation at break was increased with increasing the mixing time due to the disruption of internal polymeric structures during the mixing process. 


\section{Morphological structure}

Many advanced techniques can be used to characterise polymeric structures such as wide and small angle X-ray diffraction (WAXRD and SAXRD, respectively), scanning electron microscopy (SEM), transmission electron microscopy (TEM) and infrared spectroscopy $(\mathrm{IR})^{[3,4]}$. Cano et al. ${ }^{[121]}$ used SEM to characterise morphological structure of PVA/starch blends. Good PVA morphology was evident when blended with other hydrophilic polymers. Globular structures were formed in PVA/starch blend surfaces as a result of distributing one polymeric phase into other continuous counterpart, as shown in Figure 13. Crystalline zones of PVA and interpenetrated networks of PVA/starch blends were identified clearly through cross sectional micrographs of PVA/starch blends (Figure 14). SEM results obtained by Ismail and Zaaba $^{[36]}$ depicted smoother surfaces of PVA/starch blends in the presence of glycerol as a plasticiser when compared with corresponding blends without glycerol. Such results were a good indication for high compatibility between PVA and starch in the presence of plasticisers. Meanwhile, an excess of plasticiser may cause blooming/blushing, which is a white appearance on blend surfaces, leading to typical phase separation (Figure 15). As compared with pure PVA, PVA/starch blends possess irregular and rougher surfaces, especially when the PVA amount in the blends is equal or more than that of starch. Cano et al. ${ }^{[70]}$ discussed this behaviour as a result of the formation of PVA-rich and starch-rich phases when the amount of PVA was equal or higher than the starch content, which was mixed in a different way at the surfaces. Similarly, Cano et al. ${ }^{[97]}$ observed two similar phases on the surfaces in addition to crystalline and amorphous phases within the cross sections. Furthermore, blending PVA with chitosan in the presence of glycerol did not change single phase structure of PVA as a result of high compatibility and miscibility between the polymers ${ }^{[53]}$. Meanwhile, Giannakas et al. $^{[52]}$ believed that good intercalation between PVA and chitosan could be observed via XRD analysis because of the hydrophilic nature of both polymers. This finding was in good accordance with Tripathi et al. ${ }^{[111]}$ when PVA/chitosan films were prepared for packaging applications. Hu and Wang ${ }^{[122]}$ used SEM to show that PVA had smooth surfaces and continuous cross sections with maintained PVA morphology when blended with 5-20 wt\% N(2-hydroxy) propyl-3-trimethyl ammonium chloride chitosan (HTCC). However, when the HTCC content was increased to $30 \mathrm{wt} \%$, the surface appeared to become rougher, resulting from the increase of chitosan molecules that disrupted the uniform PVA structures (Figure 16). Gupta et al. ${ }^{[78]}$ increased the compatibility between PVA/PEO blends when using CMC as a 
stabiliser. SEM results revealed that PVA/PEO morphology was changed from elongated porous structures to denser but less porous structures with the addition of CMC.

\section{Blend properties}

\section{Mechanical properties}

Theoretically, tensile strength and elongation of PVA should decrease with increasing the starch content in PVA/starch blends, which is attributed to the increase in brittleness in conjunction with an improvement of Young's modulus ${ }^{[99]}$. This hypothesis was proven experimentally by Ramaraj ${ }^{[123]}$ when physiochemical properties of crosslinked PVA/starch films were studied. The results showed that tensile strength and elongation at break decreased by 65 and 2.6\%, respectively, when increasing the starch content from 10 to $50 \mathrm{wt} \%$, though Young's modulus was increased by $75 \%$. In a similar manner, Azahari et al. ${ }^{[124]}$ found that both tensile strength and elongation at break decreased linearly with increasing the starch content in PVA/starch blends due to the amorphous nature of starch. Nevertheless, Young's modulus of blends was increased as compared with that of pure PVA. Crosslinking agents such as borax, boric acid, glutaraldehyde and tetraethylene glycol diacrylate are used to modify PVA/starch blend systems by reacting with hydroxyl groups and forming intermolecular linkages to improve the properties of the material blend system. Zhou et al. ${ }^{[42]}$ used crosslinked PVA/TPS blends with sodium benzoate as a crosslinking agent with the aid of ultraviolet irradiation to improve their mechanical properties and water contact angle. Generally, mechanical properties of the films were improved by increasing the crosslinking density. As compared with unmodified PVA/TPS films, crosslinked blends possessed a 3-fold increase in tensile strength and an 11-fold increase in Young's modulus despite a decrease in elongation at break. Moreover, the water contact angle increased linearly with a progressive crosslinking reaction because more hydroxyl groups were used by the crosslinking agent. A similar result was achieved by Das et al. ${ }^{[125]}$ when the effect of four different cross-linkers, comprising borax, formaldehyde, epichlorohydrin and $\mathrm{ZnO}$, on mechanical properties of PVA/starch films was studied. Shi et al. ${ }^{[84]}$ indicated that some of cross-linkers possessed a toxic nature, which could limit their applications as biomass materials. Therefore, citric acid was used as a crosslinking agent to improve mechanical properties of PVA/starch films. Tensile strength was shown to be increased by $123 \%$ for a low content of citric acid (less than $5 \mathrm{wt} \%$ ); whereas increasing the citric acid content above $5 \mathrm{wt} \%$ was found to decrease tensile strength by $87.5 \%$. Similarly, elongation at break was increased by $203 \%$ due to the esterification phenomenon. In 
comparison, Priya et al. ${ }^{[57]}$ found that increasing the citric acid content reduced tensile strength of PVA/starch films by $33.6 \%$ but increased elongation at break by $181 \%$. This was explained by the plasticisation of citric acid instead of its cross-linking effect. Yoon et al. ${ }^{[126]}$ and Reddy and Yang ${ }^{[127]}$ obtained similar results when the effect of citric acid was compared with other crosslinking agents on mechanical properties of PVA/starch films. The use of plasticisers could reduce tensile strength and Young's modulus of PVA/starch blends but increase their elongation at break and flexibility, which is attributed to the penetration of plasticiser molecules between blend components and the existence of hydrogen bonding to weaken the interaction between PVA and starch ${ }^{[36,65]}$. Tudorachi et al. ${ }^{[74]}$ studied the effect of glycerol and urea as plasticisers on mechanical properties of PVA/starch blends with their tensile strength and Young's modulus decreasing linearly with increasing the plasticiser content up to $40 \%$ in blends. Conversely, elongation at break was found to increase with increasing glycerol and urea contents. This behaviour can be explained by the increase in the mobility of macromolecules for both PVA and starch. In addition, Yoon et al. ${ }^{[92]}$ achieved similar results when the effect of plasticiser and cross linkers on properties of PVA/corn starch blends was investigated. Similarly, Mao et al. ${ }^{[128]}$ noted that the tensile strength decreased when the glycerol content was increased by more than $20 \mathrm{wt} \%$ while elongation at break increased continuously beyond this amount. The enhancement of PVA tensile properties resulted from the interaction of -OH groups between PVA and other polymers. Giannakas et al. ${ }^{[52]}$ observed that the significant increase in tensile strength of PVA/chitosan came from the interaction between $-\mathrm{OH}$ groups on PVA as well as $-\mathrm{NH}_{2}$ and $-\mathrm{OH}$ groups on chitosan. This increase was associated with a reduction in elongation at break. Furthermore, Li et al. ${ }^{[115]}$ found that tensile strength of PVA/PLA blends was increased by $11.8 \%$ through increasing the PLA content; whereas elongation at break was decreased by $87 \%$ due to the low flexibility and high rigidity of PLA.

\section{Barrier properties}

The permeability of blends depends on many factors such as the surrounding relative humidity, temperature, film thickness, water and plasticiser contents in addition to the nature of blend components ${ }^{[129]}$. In general, film permeability increases linearly with increasing the temperature and plasticiser content. High temperature and plasticiser content can enhance diffusivity through the films as a result of accelerating the mobility of polymer segments, leading to an increase in the permeability coefficient ${ }^{[129]}$. PVA/starch blends possess moderate water vapour permeability (WVP) between water soluble PVA and water sensitive starch. Cano 
et al. ${ }^{[70]}$ showed that the WVP of PVA/starch blends was enhanced by increasing the starch content within blends and could be changed slightly with storage time. Similarly, Azahari et al. ${ }^{[124]}$ concluded that the WVP of PVA/starch films increased with increasing the starch content when compared with pure PVA owing to the hydrophilicity of starch. In addition, the water solubility level and water uptake of the films increased with increasing starch content. Plasticisers and cross-linking agents are always used to modify the compatibility and mechanical properties of PVA/starch blends. Most of these materials have a hydrophilic nature, and thus their use increases the WVP and water absorption of resulting films. Ismail and Zaaba $^{[36]}$ found that the water permeability of PVA/starch blends increased linearly with increasing the glycerol content. On the other hand, Li et al. ${ }^{[108]}$ reported that blending PVA with chitosan reduced the oxygen permeability (OP) of PVA/cellulose nanowhisker (CNW)/chitosan composites to produce food packaging films with a high level of protection against oxidation.

\section{Biodegradability}

The biodegradability of PVA blends increases slightly with increasing PVA molecular weight; whereas the biodegradation rate is much higher in a moist environment when compared to dry condition ${ }^{[48]}$. The biodegradation rate of biopolymers also increased with increasing the temperature and relative humidity. In addition, the biodegradability of blends was dependent on blend mixtures and nature of microorganism species ${ }^{[2,74]}$. Shuai et al. ${ }^{[118]}$ suggested that the biodegradability of PVA blends depended on not only the biodegradability of blend components but also the miscibility between these components. Biodegradability results have shown that starch, plasticiser (especially glycerol) and PVA amorphous phases were consumed completely by the microorganisms in PVA/starch blends though PVA crystalline phases were unaffected $^{[1,93,130,131]}$. When PVA/starch films were attacked by organisms, starch was consumed first, and pores behind that made the film structure weaker and accelerated the fragmentation process. This phenomenon depended on starch type and content within the films and took approximately 5- 45 days according to environmental conditions ${ }^{[2]}$. Based on research work by Taghizadeh et al. ${ }^{[85]}, \alpha$-amylose with free mobility first degraded from starch. Therefore, the biodegradability of PVA/starch blends was found to increase in the presence of $\alpha$-amylose with free mobility. Enzymatic solution results showed that the biodegradation rate of PVA/starch blends with a low starch content was higher than with a high starch content of over $50 \mathrm{wt} \%$. This finding is associated with an increase in material compaction, leading to the hindrance of free mobility of $\alpha$-amylase in blend films. Chen et al. ${ }^{[132]}$ found that PVA/starch 
films degraded much faster than pure PVA but more slowly than pure starch. Most of these observations were confirmed by Azahari et al. ${ }^{[124]}$ when the biodegradability of PVA/starch films in an enzymatic solution and soil was investigated. In an enzymatic solution, the biodegradability rate of PVA/starch blends was increased with increasing the starch content when compared with that of pure PVA to reach a maximum weight loss at the starch content of $70 \%$. This was attributed to the presence of increased $\alpha$-amylose in the blend, which was preferentially attacked by enzymes. In the soil, the biodegradability rate of the same films also increased with increasing the starch content and burial time. The maximum weight loss was $85 \%$ after 8 weeks for films containing $70 \%$ starch. Siddaramaiah et al. ${ }^{[98]}$ also detected that the weight loss was enhanced to $40 \%$ when the starch content was increased to $50 \%$ in PVA/starch blends.

\section{Thermal properties}

Molecular weight and residual weight of PVA blends are main factors that influence their thermal stability. In addition, the weight loss of PVA blends decreases with increasing the PVA content in blends ${ }^{[48]}$. Most PVA/starch blends have similar thermal decomposition steps with slight differences. Cano et al. ${ }^{[121]}$ identified three general steps of thermal decomposition for PVA/starch blends, depending on TG and DTG results. Approximately 10\% of blend weight was lost in the initial step at approximately $100^{\circ} \mathrm{C}$ due to the evaporation of bonded water and plasticiser. Additionally, $70 \%$ of blend weight was lost at the second step at temperatures ranging from 150 to $380^{\circ} \mathrm{C}$ due to a series of processes such as dehydration, scission and decomposition. The remaining blend weight was lost at the third step through the generation of by-products between $380-500^{\circ} \mathrm{C}$. PVA/starch blends do not have a clear $T_{g}$ as compared with neat PVA, which results from the increase in segment mobility when starch and plasticiser are added. With only low intermolecular interactions, it requires relatively little energy to break the bonds ${ }^{[134]}$. On the other hand, Jose et al. ${ }^{[135]}$ believed that the presence of starch increased the $T_{g}$ and $T_{m}$ of PVA, which was attributed to their interaction with the resulting formation of additional hydrogen bonding. Othman et al. ${ }^{[136]}$ reported that the high melting temperature in the presence of starch ensured a high thermal stability for the blends though this was still less than the thermal stability of pure PVA. The high plasticiser content decreased both $T_{g}$ and $T_{m}$ for PVA/blends, as observed by Aydın and Ilberg ${ }^{[134]}$ when PVA/starch was prepared with different types of polyol based plasticisers. A similar result obtained by Ramaraj ${ }^{[123]}$ was explained that plasticiser molecules were much smaller than those of polymer matrices. Therefore, plasticiser molecules could penetrate into polymer matrices to create strong 
hydrogen bonds between PVA/plasticiser and starch/plasticiser instead of cohesive attraction forces between PVA and starch. Sreedhar et al. ${ }^{[87]}$ attained the same results when the effect of various plasticisers on thermal properties of PVA/starch blends was evaluated. Generally speaking, melting temperature, melting enthalpy $(\Delta H)$ and crystallinity are decreased in the presence of plasticisers and cross linking agents ${ }^{[125]}$. Tripathi et al. ${ }^{[111]}$ reported that PVA/chitosan blend films started to lose weight at low temperatures, as opposed to pure PVA, due to the presence of chitosan. DSC results showed that PVA/chitosan blends degraded in two steps. During the first step, the weight loss was a result of moisture evaporation taking place at $40-120{ }^{\circ} \mathrm{C}$. For the second, weight loss occurred at $170-300^{\circ} \mathrm{C}$ owing to the degradation of chitosan and PVA. In addition, Grande et al. ${ }^{[53]}$ stated that the $T_{g}$ of PVA/chitosan blends decreased linearly from $61-44^{\circ} \mathrm{C}$ when increasing the chitosan content from 0-50 wt\%.

\section{Optical Properties}

Optical properties can be affected in two different ways for packaging applications. First of all, contained products should be viewed through packaging materials. Secondly, packaging materials should protect the products from light emission in order to avoid the deterioration ${ }^{[38]}$. Although pure PVA is completely transparent, its transparency can be reduced when blended with other polymers, which depends on polymer properties. Siddaramaiah et al. ${ }^{[98]}$ observed that the light transparency of PVA/starch blends decreased by approximately 78\% with increasing the starch content up to $10 \mathrm{wt} \%$ due to the increase in the haze value with more lights being scattered through the incorporation of starch. Yin et al. ${ }^{[137]}$ detected that the transparency of PVA/starch blends initially increased with the addition of boric acid as a crosslinker, but was further decreased with time. In comparison, Gupta et al. ${ }^{[78]}$ found that PVA/PEO blends were opaque because of the miscibility between them. Ultraviolet spectroscopic results revealed that the transparency of PVA/PEO blends could be enhanced by $133 \%$ after using an additional $20 \mathrm{wt} \%$ of $\mathrm{CMC}$ as a stabiliser to improve polymeric interactions. Sawatari and Kondo ${ }^{[120]}$ stated that the opaqueness of PVA/PEO blend films increased linearly with increasing the PEO content from 25-75 wt\%. This was completed with the phase separation due to the distribution of PEO crystalline structures around PVA amorphous phases. Hu and Wang ${ }^{[122]}$ demonstrated that pure PVA was completely transparent with a transmittance of $91.47 \%$ for visible light. This transparency level was reduced when PVA was blended with chitosan, resulting from the change of light scattering and reflection with the incorporation of high-loading chitosan. 


\section{PVA nanocomposites}

Richard Feynman was the first person to introduce the concept of nanotechnology at an American Physical Society conference in $1959^{[16]}$. This technology aimed to use materials on a nanoscaled level at 1-100 $\mathrm{nm}$ to improve their performance by taking advantage of the high surface area (generally in excess of $750 \mathrm{~m}^{2} / \mathrm{g}$ ) with unique properties ${ }^{[16]}$; Whereas polymer composites have traditionally contained a mixture of polymers (thermoset, thermoplastic or elastomer) and micro-sized organic or nonorganic reinforcements or fillers ${ }^{[16,138,139]}$, polymer nanocomposite (PNCs) normally incorporate fillers on the nanoscaled level $\left(10^{-9} \mathrm{~m}\right)$ with high aspect ratios (i.e. length/ thickness >300). The use of nanotechnology for biodegradable polymers offers excellent opportunities to enhance their properties with improved cost effectiveness $^{[9,16,140]}$. PNCs with small filler loadings $(\leq 5 \mathrm{wt} \%)$ can match the properties of conventional composite with 40-50 wt.\% loading of classical fillers, leading to light-weight composite materials ${ }^{[9,16,138,140,141]}$. However, PNCs have several limitations in relation to material processing and property with the incorporation of nanofillers. Particle agglomeration during filler dispersion, high viscosity when using relatively high filler loadings and high modulus and low strength resulting from high brittleness are the main disadvantages of $\mathrm{PNCs}^{[138]}$, as illustrated in Figure 17. PVA is one of the most popular biodegradable polymers reinforced with nanofillers in order to enhance its thermal and barrier properties, especially for food packaging ${ }^{[30]}$.

\section{Polymer/clay nanocomposites}

Polymer/clay nanocomposites (PCNs) were studied for the first time in 1961 to make polymerised vinyl monomers intercalated into montmorillonite, which was further systematically developed and commercialised by Toyota Central Research Laboratories during the $1980 \mathrm{~s}^{[4,135,136,138]}$. PCN is a class of hybrid material consisting of nanoclay fillers such as montmorillonite (MMT), halloysite nanotubes (HNTs), saponite and hectrite dispersed into organic polymers $^{[8]}$. Low cost, availability and simple processability are the most attractive properties of nanoclays required to work as effective fillers for polymer nanocomposites ${ }^{[142]}$. Such nanocomposites provide unique properties different from their base materials such as remarkable improvements of mechanical and barrier properties, elimination of solvent uptake, weight reduction and enhancement of biodegradation rate by using low filler loadings ${ }^{[16,139]}$. Any improvement in the properties depends on uniform dispersion of nanofillers within polymer matrices together with high aspect ratios and large surface area in addition to the types 
of polymers and nanoclays used ${ }^{[16,143]}$. PCNs have a wide range of applications in industrial sectors such as building construction, aerospace, automobile and food packaging ${ }^{[143]}$. For this review study, PVA/clay nanocomposites are only covered as a typical example of PCNs in next section.

\section{PVA/MMT nanocomposites}

MMT clays consist of stacked nanoscaled platelets based on aluminium and magnesium silicates with a typical thickness of $1 \mathrm{~nm}$, diameter of 100-500 nm and aspect ratio of 50-1000. MMT has shared oxygen between $\mathrm{Al}$ and $\mathrm{Si}$ with many - $\mathrm{OH}$ groups at the edges and its chemical formula is given by $(\mathrm{Na}, \mathrm{Ca})_{0.33}(\mathrm{Al}, \mathrm{Mg})_{2}\left(\mathrm{Si}_{4} \mathrm{O}_{10}\right)(\mathrm{OH})_{2} \cdot n \mathrm{H}_{2} \mathrm{O}$. The MMT unit includes one alumina octahedron crystal embedded between two silica tetrahedron crystals $^{[4,8,35]}$, as shown in Figure 18. MMT possesses several important properties such as availability, high aspect ratio, natural occurrence and eco-friendliness. The hydrophilic nature of MMT, resulting from the presence of hydrated potassium or sodium ions, makes it miscible only with hydrophilic polymers such as PVA, PEO and natural biopolymers like protein and $\operatorname{starch}^{[8,35]}$. The dispersion of solid layered MMT clays in continuous polymer matrices can produce three different dispersion statuses, namely, tactoid, intercalation and exfoliation, as illustrated in Figure 19. As for tactoids, MMT are dispersed within polymer matrices without any separation or interaction between polymer matrices and clay particles, resulting in conventional microcomposites instead of nanocomposites. With respect to the intercalation, monomer molecules or polymer chains diffuse between clay layers to broaden the $d$-spacing (i.e., the distance between two layers or two platelets $\left(d_{001}\right)$ ) with the formation of well-ordered stacks of layered structures. As for exfoliation, individual clay particles are dispersed uniformly within polymer matrices and $d$-spacing becomes much higher at 5-10 $\mathrm{nm}$ as compared with intercalated tactoids ${ }^{[4,8,10,16,143]}$. The presence of ions in unmodified MMT such as $\mathrm{Na}^{+}$ promotes the interaction between MMT and water soluble polymers like PVA due to ion-dipole interactions between MMT and water molecules. PVA/MMT nanocomposites have been studied for a considerable time due to their excellent properties and a wide range of applications ${ }^{[144]}$. Sapalidis et al. ${ }^{[35]}$ prepared PVA/MMT nanocomposites with different MMT contents of 5, 10 and $20 \mathrm{wt} \%$ in order to investigate resulting morphological structures. TEM results indicated that exfoliation took place with the MMT inclusion of $20 \mathrm{wt} \%$. Li et al. ${ }^{[145]}$ reported that intercalated structures became more evident with increasing the MMT loading; whereas exfoliated structures were conversely decreased for PVA/MMT nanocomposites. In addition, the crystallisation of PVA became more difficult to achieve with the incorporation of 
MMT due to the excessive affinity between PVA and MMT to prevent PVA molecules from the crystallisation. Furthermore, Young's modulus of nanocomposites was found to increase linearly with increasing $d$-spacing values as a result of larger numbers of polymeric molecules diffusing between clay platelets, which represented good clay intercalation and subsequent effective filler dispersion ${ }^{[90,146]}$. Higher MMT contents have a greater effect on properties of PVA and PVA blends than lower contents in relation to $d$-spacing values. This result was evidenced by Majdzadeh-Ardakani and Nazari ${ }^{[147]}$ when PVA/starch/MMT nanocomposites were prepared with nanoclay loadings of 0,4 and $8 \mathrm{wt} \%$. The results showed that tensile strength and Young's modulus were enhanced by increasing the MMT content above $4 \mathrm{wt} \%$.

\section{PVA/HNT nanocomposites}

Halloysite nanotubes (HNTs) are natural clays resulting from hydrothermal changes in aluminosilicate deposits. Their chemical formula is $\mathrm{Al}_{2} \mathrm{Si}_{2} \mathrm{O}_{5}(\mathrm{OH})_{4} \cdot n \mathrm{H}_{2} \mathrm{O}$ consisting of 21.76\% for $\mathrm{Si}, 20.90 \%$ for $\mathrm{Al}$ and $1.56 \%$ for $\mathrm{H}_{2}$. Omalius d'Halloy ${ }^{[40]}$ first discovered this mineral in 1826 as a dioctahedral 1:1 clay mineral. According to the variation of $n$ value, HNTs can be classified as hydrated HNTs ( $n=2$ and interlayer spacing of $10 \AA$ ) and dehydrated HNTs ( $n=0$ and interlayer spacing of $7 \AA)^{[40,41,46,110,139]}$. Depending on the crystallisation and geological conditions, different shapes of halloysite can be observed including tubular, spherical and plate-like formations. The tubular form is the most common with typical dimensions of $2 \mathrm{~nm}-150 \mu \mathrm{m}$ in length, $5-30 \mathrm{~nm}$ in inner diameter and $20-100 \mathrm{~nm}$ in outer diameter. HNTs are chemically similar to kaolinite with a monolayer of water between halloysite sheets. HNTs have good dispersibility in many polymers and solvents because lower hydroxyl groups exist on their surfaces to minimise the interactions between tubes ${ }^{[40,41,46,110,148]}$. The crystalline structure of HNTs comprises - $\mathrm{OH}$ groups in tetrahedral silicon-oxygen sheets and other -OH groups in octahedral aluminium-oxygen sheets (Figure 20) ${ }^{[51,148-151]}$. In general, the incorporation of HNTs into continuous polymer matrices greatly improves thermal stability, barrier and mechanical properties of resulting nanocomposites. This is attributed to the high aspect ratios of HNTs and enhanced interactions between fillers and matrices ${ }^{[51,152-}$ ${ }^{154]}$. Gaaz et al. ${ }^{[41]}$ reported that the incorporation of HNTs into PVA matrices produced superior nanocomposite performance including excellent mechanical properties and thermal stability, which makes them suitable for many applications. As compared with carbon nanotubes (CNTs), HNTs are relatively cheap, available and easily dispersed within polymer matrices ${ }^{[46,148,152,155,156]}$. He et al. ${ }^{[157]}$ reported that using HNTs as a suspension in water, ethanol and water/ethanol solutions was better than as dry fillers in terms of eliminating the 
agglomeration issue, resulting from the polar functional groups and high specific areas of halloysite.

\section{PVA/graphene oxide (GO) nanocomposites}

Graphene oxides (GOs) can be synthesised through the chemical oxidation of simple graphite powders based on the Hummers method ${ }^{[158,159]}$. Such graphite powders are cheap and abundant raw materials in the presence of oxidising agents to introduce oxygen contained groups into graphene and further convert them to hydrophilic materials with large interlayer spacings ${ }^{[158,159]}$. Liu et al. ${ }^{[160]}$ prepared PVA/GO films by using GOs with different degrees of oxidation prepared from graphite powders by simply increasing the amount of oxidation agent during the oxidation process. FTIR results showed that increasing the degree of oxidation created more oxygen contained groups on the GOs. These groups help to generate stronger hydrogen bonds with other hydroxyl or carboxyl groups on PVA and other polymers. Such a strong interaction between nanofillers and matrices has led to improved mechanical and barrier properties of resulting nanocomposite films. For example, the tensile strength of PVA/GO nanocomposite films has been found to increase significantly with increasing the degree of oxidation $^{[160]}$. In contrast to this, the oxygen permeability was found to decrease by more than $50 \%$. On the other hand, Liu et al. ${ }^{[161]}$ found that the oxidation process of graphite could produce GOs with the high permeability of small molecules such as hydrogen due to the presence of hole-like defects within the GO planes. Therefore, the modification of GOs with polyethyleneimine (PEI) to produce modified graphene oxide (PEI-mGO) may fill these holes and reduce the hydrogen permeability and gas transmission rate (GTR). This result was confirmed when both PVA/GO and PVA/PEI-mGO nanocomposite films were prepared with the presence of $3 \mathrm{wt} \%$ of PEI-mGO and GO, thus reducing the GTRs of both films by 95 and 90\%, respectively, as compared to pure PVA films ${ }^{[161]}$. In addition, tensile strength and Young's modulus were found to increase by 200 and 20\%, respectively, for the case of 0.3 wt\% PEI-mGO as opposed to those of PVA $^{[161]}$. Overall, mechanical properties of such composites have been found to increase linearly with increasing the nanofiller content. GOs have excellent thermal, mechanical and barrier properties ${ }^{[76,162]}$. In the presence of oxygen on their surfaces, GOs are soluble in water and can be well dispersed in polar media ${ }^{[76,162]}$. Huang ${ }^{[153]}$ stated that PVA is a water soluble polymer and GO nanosheets (GONSs) have high dispersibility in water for a low GO content. As a result, exfoliated structures are often created in PVA/GONS nanocomposites with good transparency and high barrier properties, arising from strong interactions between nanofillers and polymer matrices in addition to the formation 
of tortuous paths when individual GOs are uniformly dispersed. PVA and its blends have been proven to possess good compatibility with graphenes and GOs ${ }^{[76]}$. Jose et al. ${ }^{[135]}$ indicated that $\mathrm{OH}$-groups present on PVA/starch blends decreased with increasing the graphene loading due to the formation of hydrogen bonding between them. In addition, Raheel et al. ${ }^{[162]}$ reported that the presence of exfoliated structures for PVA/MMT/GO nanocomposites were good evidence of the compatibility and excellent dispersion of nanofillers within PVA matrices due to the presence of many oxygen contained groups on GO surfaces.

\section{PVA/CNT nanocomposites}

Carbon nanotubes (CNTs) were discovered in 1991 and comprise cylinders of carbon, resulting from rolling graphite sheets via chemical hydrolysis. CNTs have excellent mechanical, thermal and barrier properties. CNTs are classified as single-walled CNTs (SWCNTs), double-walled CNTs (DWCNTs) and multi-walled CNTs (MWCNTs), depending on the number of wrapped graphite sheets $^{[40,138,163]}$. CNTs are widely used as reinforcing materials to improve overall composite properties such as high mechanical and thermal properties due to their strong C-C bonds ${ }^{[163,164]}$. Liu et al. ${ }^{[165]}$ found that Young's modulus and tensile strength of PVA composite films were increased by 79 and $44.59 \%$, respectively, when increasing the SWCNT loading from 0.3 to $0.8 \mathrm{wt} \%$. This improvement in properties was related to the inherently high mechanical characteristics of SWCNTs (i.e., 1 TPa for Young's modulus and 50-150 MPa for tensile strength). As a result of their high aspect ratios, CNT agglomeration is a critical issue during composite manufacturing containing high-loading fillers ${ }^{[40,138]}$. When PVA/MWCNT composite membranes were prepared ${ }^{[166]}$, SEM micrographs showed a spherical trace that appeared to result from more severe CNT agglomeration with increasing the MWCNT loading,

Figure 21. Zhao et al. ${ }^{[167]}$ overcame this problem by treating MWCNTs with acid and then sodium hydroxide. Following this, PVA/CNT composite films were prepared from pristine CNTs treated with CNT-COOH and CNT-COONa. The results revealed that tensile strength of composite films was increased by 3 and 85\% when using CNT-COOH and CNT-COONa, respectively, as compared with that of pristine CNTs. Furthermore, Basiuk et al. ${ }^{[168]}$ found that SWCNTs possessed higher dispersibility than MWCNTs when using glutaraldehyde as a crosslinker to prepare PVA/CNT composite films reinforced with both SWCNTs and MWCNTs. Ryan et al. ${ }^{[169]}$ reported that Young's modulus and tensile strength of PVA nanocomposites were improved by 3 and 2 fold, respectively, relative to those of pristine PVA when incorporated with $1 \mathrm{wt} \%$ SWCNTs and $5 \mathrm{wt} \%$ MWCNTs, respectively. Shaffer and Windle $^{[170]}$ reported that the addition of CNTs into PVA matrices improved the resulting 
PVA/CNT composites with a significantly increased density, as evidenced by their higher density of $\sim 1.75 \mathrm{~g} / \mathrm{cm}^{3}$ with respect to that of pristine PVA at $\sim 1.3 \mathrm{~g} / \mathrm{cm}^{3}$. The current limited applications of CNTs are related to their high material cost as opposed to other nanofillers such as HNTs with similar tubular nanostructures, as well as their low solubility and dispersibility in organic solvents ${ }^{[163,165,166]}$.

\section{PVA/cellulose nanocomposites}

Cellulose nanocrystals (CNCs), cellulose nanowhiskers (CNWs) and cellulose nanofibres (CNFs) are biodegradable and biocompatible nanofillers with large surface areas, high aspect ratios, high elastic modulus, low density and low cost. They are used as ecofriendly fillers for a wide range of polymers such as PVA and $\operatorname{starch}^{[112,139,171]}$. Cellulose is a linear polymer that consists of $\beta$-(1 $\rightarrow 4)$-D-glucopyranose connected in long chains to form polysaccharide polymers. Wood, cotton, flax, hemp, recycled paper and bacterial cellulose are considered to be main sources to produce cellulose in the powder form. CNCs can be prepared from pure cellulose subjected to strong acid hydrolysis under controlled conditions ${ }^{[9,26,40,121]}$. Due to their hydrophilic nature, CNCs are more compatible with hydrophilic polymers such as PVA and they tend to form 3-dimensional networks within polymer matrices. As a result of this, strong H-bonding between hydroxyl groups can improve the properties of nanocomposite films. However, such properties can decrease when using CNCs with high loadings due to the increase in intermolecular interactions that may prevent filler dispersion within matrices and further cause CNC aggregation in nanocomposites ${ }^{[9,26]}$. A similar result was achieved by Frone et $a l^{[172]}$ when PVA/starch films were reinforced with 1,3 and $5 \mathrm{wt} \%$ CNCs. SEM results suggested that the inclusion of $5 \mathrm{wt} \%$ CNCs presented a high degree of aggregation compared with $3 \mathrm{wt} \%$ counterparts. However, the films containing $1 \mathrm{wt} \%$ CNCs were well dispersed within matrices. This problem can be overcome by using chemical modifications such as the use of coupling agents and polymer grafting ${ }^{[171]}$. CNCs are utilised as fillers for polymers in packaging applications because of their sustainability and natural abundance, as well as their corresponding good properties ${ }^{[121]}$. Cai et al. ${ }^{[75]}$ stated that the incorporation of CNFs improved mechanical and optical properties of PVA because of more highly adhesive interfaces between fibres and polymer matrices, resulting from the interaction of -OH groups. Similarly, Qua et al. ${ }^{[173]}$ found that Young's modulus of PVA nanocomposites was improved by $100 \%$ relative to that of pristine PVA with the incorporation of $5 \mathrm{wt} \%$ CNFs. This improvement was associated with several factors such as inherently high mechanical properties of CNFs (10 GPa for tensile strength and 150 GPa for Young's modulus), homogenous CNF distribution within 
matrices, high interfacial surface areas and good compatibility between nanofillers and matrices. Moreover, high compatibility and strong interaction between PVA and CNFs appeared to increase the $T_{g}$ of nanocomposites owing to hindered mobility of polymeric segments by slightly agglomerated nanofillers ${ }^{[173]}$. On the other hand, Cho and Park ${ }^{[174]}$ detected that a small CNF loading in the range of 1-3 wt\% had a minor impact on mechanical properties of PVA nanocomposites. However, when the CNF loading was increased to $5 \mathrm{wt} \%$, Young's modulus and tensile strength of resulting nanocomposites were enhanced by 60 and 28\%, respectively. It appeared that a CNF loading of $7 \mathrm{wt} \%$ became a threshold at which mechanical properties of PVA nanocomposites tended to decline because of noticeable filler agglomeration. However, thermal stability of PVA was still improved, as explained by the insulation behaviour of CNFs.

\section{Material fabrication}

The main fabrication methods for polymer nanocomposites can be summarised as follows:

- In situ polymerisation: Sometimes known as interlamellar polymerisation, in which nanoclays are first swollen in a monomer solution or liquid monomer with the monomer diffusing into nanoclay layer galleries, subjected to the polymerisation within intercalated layers, as shown in Figure 22(a). Polymerisation can be initiated by using suitable organic initiators, heat or radiation ${ }^{[3,8,9,139,143]}$. This method is more suitable for insoluble or thermally unstable polymers with the use of solvents or heat ${ }^{[158]}$.

- Melt intercalation: Sometimes known as direct melt intercalation, in which nanocomposites are produced by incorporating nanoclays into a molten polymer above its melting point (Figure 22(b)). This method has been shown to be widely used for the preparation of bionanocomposites due to its environmental ecofriendliness and cost effectiveness in the absence of solvents ${ }^{[3,8,9,143]}$. This method is more viable for thermoplastic polymers owing to its dependence on high temperature processing and suitability for commercial production. However, its disadvantage is that resulting nanocomposite properties are strongly dependent on processing parameters ${ }^{[163,175]}$.

- Solution mixing: The dissolved polymer is gradually mixed with nanoclay suspension to allow polymer molecules to diffuse between nanoclay layers. Intercalated/exfoliated nanocomposites can then be obtained after solvent removal ${ }^{[3,8,143]}$, as depicted in Figure 22(c). This method is suitable for the production of thin films of little or non-polar 
polymers at the laboratory scale. However, its use at the commercial level is limited because of environmental concerns associated with the use of chemical solvents $^{[9,139,175]}$. The success of this method relies on the effective dispersion of nanofiller by means of mechanical, magnetic or sonication techniques with the dispersion time and intensity being optimised to minimise any structural damage to nanofillers ${ }^{[163]}$.

Qiu and Netravali ${ }^{[176]}$ found that good nanofiller dispersion during manufacturing is the key to producing nanocomposite films with superior properties. Mechanical stirring, ultrasonication, the use of surfactants and control of the solution $\mathrm{pH}$ level are the main techniques used to tackle nanofiller aggregation and achieve well-dispersed nanofillers. Therefore, all previous synthetic methods play an important role in the property enhancement of fabricated nanocomposites ${ }^{[8]}$.

\section{Nanocomposite properties}

\section{Mechanical properties}

Mechanical properties of bionanocomposites depend primarily on the nanofiller content and their dispersion within polymer matrices. The improvement of these properties is attributed to the high affinity between nanofiller and polymer matrices through their interfaces as well as high aspect ratios of dispersed nanofillers ${ }^{[17]}$. In general, tensile strength and Young's modulus increase while elongation at break is reduced when a low nanofiller loading is utilised, which is in a opposite trend to those at high loadings, as shown in Table 2. Jose et al. ${ }^{[135]}$ found that increasing the graphene loading decreased mechanical properties of PVA/starch/GO nanocomposites, resulting from graphene agglomeration that weakened the adhesion between matrices and nanofillers. The same results were reported by Cao et al. ${ }^{[51]}$ when graphene nanosheets were added to improve mechanical properties of PVA. In addition, Loryuenyong et al. ${ }^{[59]}$ reported that mechanical properties of PVA/GO nanocomposites at low GO contents of 0.3-2 wt\% were improved compared to those containing up to $2 \mathrm{wt} \%$ GOs. Similarly, Kim et $a l .{ }^{[76]}$ showed that the addition of small amounts of GOs at 0.7 wt \% could enhance tensile strength and Young's modulus of PVA/GO nanocomposites by 62 and 76\%, respectively, as opposed to those of pristine PVA. Sadhu et al. ${ }^{[177]}$ discussed the reduction of mechanical properties of PVA/starch/nanoclay composite films when over 1 wt\% of Cloisite 30B nanoclays was used, which was due to their poor dispersion into polymer matrices. On the other hand, Gaaz et al. ${ }^{[41]}$ reported that well dispersed HNTs with a small particle loading, achieved 
by means of combined vigorous stirring and sonication, increased tensile strength of PVA/HNT nanocomposites. Similarly, Khoo et al. ${ }^{[110]}$ found that the addition of $0.25-0.5 \mathrm{wt} \%$ of HNTs improved tensile strength and Young's modulus of PVA/chitosan films by 20 and 55\%, respectively. However, when the HNT content was increased to 1-5 wt\%, tensile strength and Young's modulus were reduced as a result of HNT agglomeration. Furthermore, agglomerated HNTs can easily act as stress concentration sites to hinder effective load transfer between polymer matrices and fillers. Qiu and Netravali ${ }^{[176]}$ found that Young's modulus increased significantly by $90.2 \%$ by increasing the HNT loading from 0 to $20 \mathrm{wt} \%$. This result benefited from the inherently high modulus of inorganic HNT particles and tortuous path generated by dispersed particles. However, respective fracture strength and elongation at break of nanocomposites were reduced by 35.8 and $52.67 \%$ under the same conditions, which was attributed to the adverse effect of nanoparticle agglomeration. Liu et al. ${ }^{[178]}$ investigated the effect of CNFs on mechanical properties of PVA/CNF nanocomposite films. The Young's modulus was found to increase by a factor of five compared with that of pure PVA whilst tensile strength increased by $87.2 \%$ upon increasing the CNF loading from 0 to $60 \mathrm{wt} \%$. These results were associated with high aspect ratios of CNFs, high crystallinity of PVA and good compatibility between CNFs and PVA. The elongation at break was initially increased by $13 \%$ when incorporated with $3 \mathrm{wt} \%$ CNFs. However, this value was reduced by $92.5 \%$ when the CNF loading was increased further from 5 to $60 \mathrm{wt} \%$. The trend in elongation at break was explained in terms of the increase of film rigidity and limited mobility of polymeric molecules. Raheel et al. ${ }^{[162]}$ suggested that the use of hybrid fillers may result in significantly improved mechanical properties due to the strong interaction between matrices and nanofillers restricting the mobility of polymer chains. Additionally, Cai et al. ${ }^{[75]}$ reported that tensile strength of PVA was enhanced by $56 \%$ with the addition of $32 \mathrm{wt} \%$ CNFs. Moreover, Young's modulus also increased from $129 \mathrm{MPa}$ to $1.1 \mathrm{GPa}$ due to the formation of strong hydrogen bonds between $\mathrm{OH}$ groups of fillers and matrices.

\section{Barrier properties}

Gas/liquid permeability is an important factor for packaging applications because it provides product protection against environmental or transportation deterioration ${ }^{[112]}$. Uniform nanofiller dispersion with high aspect ratios in polymer matrices generate tortuous paths or maze structures within nanocomposite films, which tends to force the gas and water molecules to diffuse along zig-zag pathways, leading to a decrease in permeabilities of oxygen and water $^{[140,143]}$, as illustrated in Figure 23. In addition, the presence of nanofillers restricts the 
mobility of polymeric molecules and reduces the free volume of polymers that is used as a transport medium by permeating particles ${ }^{[65,141]}$. According to Nilsen's theory ${ }^{[3]}$, the tortuous path length becomes longer when aspect ratios and contents of nanofillers are increased. In addition, the permeability coefficient decreases with increasing the path length at a constant filler content. Polymer nanocomposites comprise impermeable phases (i.e., nanofillers) embedded within permeable phases (i.e., polymer matrices). Therefore, the permeability tends to decrease with increasing nanofiller loadings ${ }^{[9,64]}$. This phenomenon was noted by Aloui et $a l .{ }^{[171]}$, following the addition of HNTs and CNCs at relatively high contents of 3 and $5 \mathrm{wt} \%$, respectively, within PVA matrices, in which the permeabilities of both water and oxygen dropped as compared with those through pristine PVA. Cano et al. ${ }^{[121]}$ observed that the addition of CNCs to PVA/starch with low loadings of 1-3 wt\% slightly reduced the WVP of resulting nanocomposites. However, a higher filler loading of $5 \mathrm{wt} \%$ increased the permeability due to the high affinity of CNCs to improve the water transport. The layered or platelet structures of nanoclays tend to prevent gas and water molecules from transferring through polymer matrices or films ${ }^{[9,66]}$. Choudalakis and Gotsis ${ }^{[64]}$ reported that the permeability of polymer matrices could be reduced by a factor of 50-500 due to the dispersion of small amounts of nanoclays. Separately, Sapalidis et al. ${ }^{[35]}$ showed that the barrier effect of nanoclays decreased with increasing relative humidity because of the increase in swelling rate of polymer molecules under such conditions. Loryuenyong et al. ${ }^{[59]}$ stated that the permeability of PVA decreased when incorporated with GO particles due to GO layered structures, resulting in a tortuous path for oxygen molecules. Similarly, Kim et al. ${ }^{[76]}$ showed that the permeability of PVA/GO nanocomposite films was reduced by $20 \%$ when adding only 0.3 wt $\%$ of GOs as compared with that of pure PVA films. Strawhecker and Manias ${ }^{[179]}$ found that the WVP of $\mathrm{PVA} / \mathrm{Na}^{+} \mathrm{MMT}$ nanocomposite films decreased by $40 \%$ in comparison to that of pure PVA films with the addition of 4-6 wt\% $\mathrm{Na}^{+} \mathrm{MMT}$ nanoclays. This improvement arose from the development of a mix of exfoliated/intercalated structures, leading to a tortuous diffusion path through films. Selected permeability values of PVA based film systems for packaging applications have been presented in Table 3.

\section{Biodegradability}

With regards to the biodegradability of blends and nanocomposites, as previously mentioned, several methods can be used to determine such key property including enzyme, microbiological and soil burial methods ${ }^{[100]}$. The effect of enzymes on nanocomposite films can be investigated by using surface erosion, diffusion through materials or a combination of simultaneous erosion 
and diffusion ${ }^{[180]}$. On the other hand, the biodegradation mechanism based on the soil burial method involves the following steps: Firstly, composite films tend to swell due to the diffusion of water molecules through films and the growth of microorganisms on their surfaces. Subsequently, films start to lose weight through the action of enzymes that disrupts film structures $^{[100]}$. In general, biodegradability and weight loss decrease in the presence of nanofillers $^{[85]}$. In particular, nanoclays have an alternative effect on biodegradability that depends on the nature of biopolymers. Nanoclays promote the biodegradability of bio-based polyesters owing to their hydrophobic nature. In the case of aliphatic polyesters, nanoclays hinder the biodegradability due to the improvement of their barrier properties ${ }^{[21]}$. Spiridon et al. ${ }^{[130]}$ investigated the effect of three different types of MMTs, namely Nanocore I28, Bentonite and Peruvian clays on the biodegradability of PVA/starch/MMT nanocomposites. The biodegradation rate of PVA/starch/MMT nanocomposites increased significantly when increasing the Nanocore I28 MMT content, which is opposed to Bentonite MMTs. In comparison, increasing the Peruvian MMT content showed little effect on the biodegradation rate. Such differences were believed to be associated with various abilities of nanofillers with respect to water absorption. Taghizadeh et al. ${ }^{[85]}$ found that the addition of carboxymethyl cellulose nanoparticles to PVA/starch nanocomposites reduced the biodegradation rate compared to standard PVA/starch blends due to the restricted mobility of polymeric molecules, which was in good accordance with the later research ${ }^{[180]}$. According to Taghizadeh et al. ${ }^{[180]}$, the biodegradability results showed that increasing the MMT- $\mathrm{Na}^{+}$nanoclay content decreased the biodegradation rate of PVA/TPS/ MMT- $\mathrm{Na}^{+}$nanocomposite films. The remaining weight of nanocomposite films after 72 days decreased by $64,67,70$ and $75 \%$ when the MMT-Na ${ }^{+}$ content increased from 0, 1, 3 to $5 \mathrm{wt} \%$, respectively. Nonetheless, Bin-Dahman et al. ${ }^{\left[{ }^{[3]} \text { stated }\right.}$ that the dissolution of amorphous phases within PVA/starch composites increased with the incorporation of graphene nanoparticles in a natural environment. This finding was believed to be due to the weak hydrogen bonding between PVA and starch, which generated a new bonding system between nanofillers and matrices.

\section{Thermal properties}

The incorporation of nanofillers into polymer matrices can improve the thermal stability of nanocomposites due to excellent barrier effect of nanofillers against heat and mass transport during decomposition ${ }^{[9]}$. Thermal properties are generally dependent on the morphology and structures of fillers. In particular, exfoliated structures can lead to higher thermal stability when compared to their intercalated counterparts. Nistor and Vasile ${ }^{[181]}$ studied the effect of 
unmodified MMTs and modified nanoclays, known as Nanocor I28 and Peruvian nanoclays on the thermal decomposition of PVA/starch nanocomposites. As compared with PVA/starch/Peruvian nanocomposites, PVA/starch/Nanocor I28 nanocomposites possessed higher thermal stability, resulting from improved dispersion of modified MMTs to form exfoliated structures so that thermal decomposition of nanocomposites was hindered. In addition, FTIR results showed that new peaks appeared with increasing the nanoclay content. This result indicated that the formation of a new structure appeared, which differed from the original counterpart. Nistor and Vasile ${ }^{[182]}$ found that a higher decomposition range of nanocomposites occurred when the processing temperature was higher than the temperature for the thermal stability of one or more components within nanocomposites. Additionally, chemical modifiers such as acids used to modify nanoclays have been found to accelerate the thermal decomposition of nanocomposites. These results were achieved when 50/50 (by weight) of PVA/starch nanocomposites were prepared with the inclusion of $2 \mathrm{wt} \%$ Nanocor I28, untreated Bentonite and Peruvian MMTs. TGA and DSC results revealed that the thermal decomposition of PVA/starch nanocomposites started with the release of volatile compounds such as water and carbon dioxide, and was completed with the release of other products such as formaldehyde, formic acid, acetic acid, propionic acid, carbon mono oxide, methane, traces of methanol, $\mathrm{CH}_{4}$, furan, acetone, 2-methylfuran, 2-furaldehyde, 2,5-dimethylfuran, 2propanone and butyraldehyde. In general, the thermal stability of polymer/nanoclay composites is higher than that of pure polymers, as validated by Taghizadeh and Sabouri ${ }^{[183]}$ to investigate the effect of MMTs on the thermal degradation of PVA/starch/carboxymethyl cellulose composites. Sadhu et al. ${ }^{[177]}$ studied thermal properties of PVA/starch with and without the presence of Cloisite 30B nanoclays. XRD and TGA were used to characterise thermal stability of 50/50 of PVA/starch with the addition of 1, 2 and 3 wt\% Cloisite 30B nanoclays. The use of starch was shown to reduce the thermal stability as compared with pure PVA; whereas the addition of 1 and $2 \mathrm{wt} \%$ nanoclays shifted the degradation peaks to a higher temperature. These results could by explained with the aid of XRD, which indicated that a lower content of Cloisite 30B nanoclays gave rise to a high clay dispersion within the composites as compared with the inclusion of $3 \mathrm{wt} \%$ nanoclays, resulting in agglomerated structures. Good nanofiller dispersion within polymer matrices induces better adhesion between the components and further improves the thermal stability of nanocomposites. Qiu and Netravali ${ }^{[176]}$ indicated that the thermal stability of PVA/HNT composite films was improved with increasing the HNT loading from 10 to $20 \mathrm{wt} \%$, as evidenced by a reduction in weight loss of $16 \%$ when the temperature was increased from $286-800{ }^{\circ} \mathrm{C}$. This phenomenon was attributed to the higher thermal stability of 
HNTs. Liu et al. ${ }^{[178]}$ detected that the $T_{g}$ of PVA/CNF composites increased from 77.4 to 83.2 ${ }^{\circ} \mathrm{C}$ when the $\mathrm{CNF}$ loading increased from 0 to $60 \mathrm{wt} \%$. Such results were ascribed to the reduction in the mobility of PVA segments with increasing the nanofiller loading. In addition, the thermal stability of nanocomposites was greatly enhanced by the addition of hybrid nanofillers relative to the use of single nanofillers. Aloui et al. ${ }^{[171]}$ found that the thermal stability of PVA was improved after using additional HNTs due to a reduction in heat transfer within nanocomposites. However, thermal stability was further improved by incorporating CNCs in the presence of HNTs because of additional decrease in PVA molecule mobility. A similar result was achieved by Raheel et al. ${ }^{[162]}$ when the thermal behaviour of PVA/MMT/GO nanocomposites was characterised.

\section{Optical properties}

In general, incident light can be reflected, refracted, transmitted, absorbed or scattered when it strikes filler/matrix interfaces in composite materials ${ }^{[75]}$. As compared with traditional composites, nanocomposites can be highly transparent as a result of ultrafine and uniform dispersion of low-loading fillers and good interfacial adhesion between nanofillers and polymer matrices. Nanocomposite films tend to become opaque with increasing the filler loading due to the rise of light scattering from filler agglomeration (Table 4) ${ }^{[38,140,184,172]}$. Such a trend was noted by Sadhu et al. ${ }^{[177]}$ when a high content of Cloisite 30B nanoclays was incorporated to reinforce PVA/starch blend films. However, Sapalidis et al. ${ }^{[35]}$ reported that the transparency of PVA/MMT nanocomposite films was comparable to that of pure PVA even at high MMT loadings, which stemmed from good nanofiller dispersion within polymer matrices. Similarly, using a low loading of CNFs to reinforce PVA/starch films did not change the transparency; whereas their high loading increased the film transparency owing to more homogenous dispersion of excessive fillers within polymers matrices ${ }^{[172]}$. Loryuenyong et al. ${ }^{[59]}$ stated that the transparency of PVA decreased by $86.8 \%$ when the GO loading increased due to the light scattering by the GO layers. Depending on GO crystalline quality and their number of layers, the transparency can be changed ${ }^{[59]}$. In addition, the transparency of PVA/starch blend films was reduced by $60 \%$ with the addition of $10 \mathrm{wt} \%$ CNCs, which was associated with nonhomogeneous filler dispersion within nanocomposites ${ }^{[172]}$. However, Zhou et al. ${ }^{[185]}$ concluded that the addition of HNTs to PVA did not change the transparency, which was attributed to good filler dispersion and strong interactions between fillers and polymer matrices. According to Cai et al. ${ }^{[76]}$, the transparency of PVA/CNF composite films has not been affected with the addition of CNFs in that their size is much smaller than the wavelength of visible light. 
However, Liu et al. ${ }^{[75]}$ showed that the transparency of PVA/CNF composite films was reduced by $40 \%$ when increasing the CNF loading from 0 to $60 \mathrm{wt} \%$, which was caused by the light scattering effect at high nanofiller contents.

\section{Permeability modelling of nanocomposites}

The permeability coefficient of nanocomposites can be described by the diffusion coefficient and solubility coefficient. Gas/liquid permeability for nanocomposites tends to decrease linearly with increasing the volume fraction of nanofillers within polymer matrices. Owing to longer tortuosity paths in nanocomposites, diffusing molecules have to pass around the nanofiller particles in order to penetrate through polymer matrices ${ }^{[60,63]}$. Moreover, the permeability of nanocomposites can decrease significantly by increasing aspect ratios of nanofiller and their dispersibility ${ }^{[62,186,187]}$. Minelli et al. ${ }^{[141]}$ predicted theoretically that the permeability of nanocomposite films should decrease by increasing the nanofiller loading and aspect ratios. Such results have been validated experimentally by Bhattacharya et al. ${ }^{[65]}$ when different nanofillers including Cloisite 15A nanoclays, sepiolite and carbon nanofillers were used to reinforce rubber membranes. Such results benefited from the increase of tortuosity and reduction in free volume of polymer matrices. The diffusion-solubility model is one of the most popular models used to explain gas permeability through nanocomposite films. It can be expressed in the following equation ${ }^{[60,188]}$ :

$$
P=D S \ldots \ldots(2)
$$

where $P$ is the permeability coefficient that can be defined as a volumetric flow rate of gas through a specific film area under steady state conditions ${ }^{[188]}, D$ is the diffusion coefficient and $S$ is the solubility coefficient. Moreover, the above equation can also be rewritten in a different form as follows ${ }^{[60,188]}$ :

$$
P=\frac{V t_{f}}{A R T \Delta p}\left(\frac{d p}{d t}\right)
$$

where $V$ is the total amount of gas permeation through the film, $t_{f}$ is the film thickness, $A$ is the film area, $R$ is the universal gas constant, $T$ is the absolute temperature, $\Delta p$ is the pressure gradient and $d p / d t$ is the rate of gas transition. The presence of nanofillers creates a tortuous path within nanocomposite films, which restricts the diffusion of molecules through films, thus leading to a decrease in the diffusion coefficient. According to Nielsen's model ${ }^{[64,188]}$, this tortuous path is known as an effective pathway with the calculated effective diffusion coefficient $\left(D_{e}\right)$ given by: 


$$
D e=\frac{D_{o}}{f}
$$

where the $D_{o}$ is the diffusion coefficient of neat polymer. $f$ is the tortuosity factor that depends on the shape and volume fraction of nanofillers ${ }^{[2,63]}$, which can be alternatively expressed below:

$$
f=\frac{l^{\prime}}{l}
$$

where $l$ ' is the distance that dissolved molecules should travel through films. $l$ is the film thickness ${ }^{[62,64]}$. The gas solubility in films can be calculated as ${ }^{[63]}$

$$
S=S_{o}(1-\emptyset)
$$

where $S_{o}$ is the solubility coefficient in neat polymer and $\varnothing$ is the volume fraction of nanofillers. Hence, the effective gas permeability coefficient can be predicted by combining these equations to give:

$$
P_{e}=\frac{D_{o}}{f} S_{o}(1-\emptyset) \text { or } P_{e}=\frac{P_{o}}{f}(1-\varnothing)
$$

The permeability of nanocomposites can also be calculated relative to the permeability of pure polymer matrices as shown below ${ }^{[63,64,188]}$ :

$$
\frac{P}{P_{o}}=\frac{1-\emptyset}{f}
$$

Many models have been developed to predict the tortuosity factor, $f$, depending on aspect ratios and contents of nanofiller embedded in composite membranes, summarised in Table 5. However, in reality, nanofillers have irregular geometries and distributions within composite materials. Nevertheless, most of these models assume that nanofillers have regular shapes and/or dispersion within composite films, and solute molecules pass between them or through pores to simplify the analysis process ${ }^{[186,189]}$. Moggridge et al. ${ }^{[190]}$ predicted theoretically the effect of different shapes of nanofillers including spheres, cylinders and flakes on the permeability of polymer materials. Their results showed that increasing flake loading greatly reduced the relative diffusivity to the spheres and cylinder counterparts, which is associated with their abilities to act as aligned ribbons with long tortuosity paths. Similar results were achieved by Lape et $a l^{[191]}$. The relative permeability of nanocomposites calculated by many models are summarised in Table 6. Most of these models are governed by three main factors: (i) nanocomposites with exfoliated or intercalated structures can be expressed by aspect ratios 
of nanofillers. Regular dispersion of nanofillers throughout polymer matrices, together with extended exfoliated structures, offers more torturous paths in nanocomposites, which thus improves their barrier properties; (ii) the orientation of nanofillers in polymer matrices when fillers are in platelet-like or disk-like shapes in the expression of $S^{\prime}=\left(3 \cos ^{2} \theta-1\right) / 2$. The barrier properties are enhanced remarkably when the orientation of platelet-like fillers are perpendicular to the penetration path because of the increasing tortuosity; and (iii) the distance between filler galleries can be expressed by the volume fraction of fillers. High filler loading is beneficial to create longer tortuosity paths ${ }^{[189,192,193]}$. Gusev and Lusti ${ }^{[194]}$ developed a new model to predict the reduction in permeability as follows:

$$
\frac{P}{P_{\circ}}=\exp \left[-\left(x / x_{o}\right)^{\beta}\right]
$$

where $x=a f$, in which $a$ is the aspect ratio, $f$ is the volume fraction and $\beta$ is a constant. The obtained results were then compared with counterparts obtained from other models. As shown in Table 7, Nielsen model produced more accurate results as compared with other counterparts. This is because it relies on the first order formula while other models are based on a second order formula with lower accuracy. Tan and Thomas ${ }^{[175]}$ believed that Nielsen model is more suitable for the prediction of gas and water vapour permeabilities for polymer/clay nanocomposites. Saritha et al. ${ }^{[195]}$ used more than one model to predict the relative permeability of chlorobutyl rubber/Cloisite 15A nanoclay composites. In general, relative permeabilities of nanocomposites against oxygen, nitrogen and carbon dioxide were significantly reduced with increasing volume fractions and aspect ratios of nanoclays. Moreover, both Nielsen and GusevLusti models agreed well with obtained experimental data; whereas, Cussler's model ${ }^{[195]}$ was in good accordance with experimental data only for the case of low volume fractions and aspect ratios of nanofillers since it was difficult to specify the exact orientation of nanofillers with high loadings. Similarly, Takahashi et al. ${ }^{[196]}$ compared experimental results for the permeability of butyl rubber/vermiculite composite membranes with theoretical prediction determined by different models. The experimental results showed that the permeability was improved three fold by increasing the vermiculite loading from 20 to $30 \mathrm{wt} \%$. In addition, predicted results coincided with experimental data (Figure 24) though slight differences occurred, which were caused by the model assumption of steady state conditions differing from actual experimental conditions. Liu et al. ${ }^{[197]}$ compared experimental data of relative permeability for hydrogen permeated through PVA/GO and PVA/PEI-mGO composites with predicted results based on Nielsen and Cussler models. Overall, theoretical results predicted by 
both models were shown good agreement with experimental data (Figure 25). The experimental data for PVA/GO composite films were between the results of Nielson and Cussler models. On the other hand, Cussler model prediction was much closer to experimental data for PVA/PEImGO composite films, which benefited from similar PEI-mGO morphology to that assumed in Cussler model. Huang et al. ${ }^{[153]}$ also reported that predicted results using Cussler model matched well experimental data of relative permeability against oxygen for PVA/graphene oxide nanosheet (GON) composite films for the same above-mentioned reason (Figure 26). Choudalakis and Gotsis ${ }^{[64]}$ used Nielson's model to predict relative permeabilities of oxygen $\left(\mathrm{O}_{2}\right)$, carbon dioxide $\left(\mathrm{CO}_{2}\right)$ and water vapour $\left(\mathrm{H}_{2} \mathrm{O}\right)$, depending on experimental data collected from previous work for PLA/MMT nanocomposites ${ }^{[9]}$, butyl rubber/vermiculite nanocomposites $^{[196]}$, epoxy/MMT nanocomposites ${ }^{[197]}$ and poly ( $\varepsilon_{\text {-caprolactone)/MMT }}$ nanocomposites $^{[198]}$. These results revealed that the relative permeability was significantly reduced with increasing the volume fraction and aspect ratios of nanofillers due to generated tortuosity paths through nanocomposites, illustrated in Figure 27. In addition, Nielsen's model gave reasonable predictions of relative permeability with experimental data with specific aspect ratios (Figure 28).

\section{Summary}

Plastic wastes are considered to be a significant issue for increasing global warming. The replacement of petro-based plastic wastes by alternative resources is deemed as a viable solution to reduce environmental pollution. Packaging applications are known to be one of main sources of plastic wastes. In particular, the significant attention has been paid to the use of natural and synthetic biopolymers for packaging applications. The most popular example among synthetic biopolymers used for material packaging is PVA as the major subject of this review. The material structure, synthesis methods and properties of PVA have been discussed in detail. PVA is generally blended with other polymers such as starch, PLA, chitosan and PEO in order to improve its biodegradability, reduce its cost and enhance antimicrobial properties. The influence of these polymers on mechanical, thermal and optical properties of PVA blends was also thoroughly investigated. In addition, pure PVA or its blends can be reinforced with nanofillers such as nanoclays, GOs, CNTs and CNWs to produce nanocomposites. Thermal, mechanical and barrier properties of nanocomposites appear to be improved compared with those of pure PVA, which can be attributed to the inherently excellent properties of nanofillers with high tensile strength and insulating characteristics, in addition to the good miscibility between PVA and various nanofillers. Depending on nanofiller shapes, contents and aspect 
ratios, many theoretical models have been developed to predict water and gas permeabilities of PVA nanocomposite films. In short, as far as environmental friendliness is concerned, it is anticipated that more and more PVA, PVA blends and PVA-based nanocomposites can be used as promising materials for packaging applications.

\section{Funding}

The Higher Committee for Developing Education (HCDE) in Iraq is acknowledged to award the PhD scholarship to Mrs. Z. W. Abdullah for her study at Curtin University, Australia.

\section{References}

[1] Shah, A. A.; Hasan, F., Hameed, A.; Ahmed, S. Biological degradation of plastics: A comprehensive review. Biotechnol. Adv. 2008, 26, 246-265.

[2] Siracusa, V.; Rocculi, P.; Romani, S.; Rosa, M. D. Biodegradable polymers for food packaging. Trends Food Sci. Technol. 2008, 19, 634-643.

[3] Silvestre, C.; Duraccio, D.; Cimmino, S. Food packaging based on polymer nanomaterials. Prog. Polym. Sci. 2011, 36, 1766-1782.

[4] Arora, A.; Padua, G. Review: Nanocomposites in food packaging. J. Food Sci. 2010, 75, R43-R49.

[5] Butnaru, E.; Cheaburu, C. N.; Yilmaz, O.; Pricope, G. M.; Vasile, C. Poly(vinylalcohol)/chitosan/montmorillonite nanocomposites for food packaging applications: Influence of montmorillonite content. High Perform. Polym., published online on December 7, 2015 (DoI: 10.1177/0954008315617231).

[6] Ghanbarzadeh, B.; Almasi, H.; Entezami, A. A. Improving the barrier and mechanical properties of corn starch-based edible films: Effect of citric acid and carboxymethyl cellulose. Ind. Crop. Prod. 2011, 33, 229-235.

[7] Avella, M.; Vlieger, J. J.; Errico, M. E.; Fischer, S.; Vacca, P.; Volpe, M. G. Biodegradable starch/clay nanocomposite films for food packaging applications. Food Chem. 2005, 93, 467-474.

[8] Rhim, J.; Ng, P. K. Natural biopolymer-based nanocomposite films for packaging applications. Crit. Rev. Food Sci. Nutr. 2007, 47, 411-433.

[9] Sinharay, S.; Bousmina, M. Biodegradable polymers and their layered silicate nanocomposites: In greeting the $21^{\text {st }}$ century materials world. Prog. Mater. Sci. 2005, 50, 962-1079. 
[10] Avérous, L.; Halley, P. J. Biocomposites based on plasticized starch. Biofuels, Bioprod. Bioref. 2009, 3, 329-343.

[11] Ma, X.; Chang, P. R.; Yu, J.; Stumborg, M. Properties of biodegradable citric acidmodified granular starch/thermoplastic pea starch composites. Carbohyd. Polym. 2009, 75, 1-8.

[12] Mantia, F. L.; Morreale, M. Green composites: A brief review. Compos. Pt. A-Appl. Sci. Manuf. 2011, 42, 579-588.

[13] Broek, L. A.; Knoop, R. J.; Kappen, F. H.; Boeriu, C. G. Chitosan films and blends for packaging material. Carbohyd. Polym. 2015, 116, 237-242.

[14] Kim, M.; Lee, S. Characteristics of crosslinked potato starch and starch-filled linear lowdensity polyethylene films. Carbohyd. Polym. 2002, 50, 331-337.

[15] Sorrentino, A.; Gorrasi, G.; Vittoria, V. Potential perspectives of bio-nanocomposites for food packaging applications. Trends Food Sci. Technol. 2007, 18, 84-95.

[16] Rhim, J.; Park, H.; Ha, C. Bio-nanocomposites for food packaging applications. Prog. Polym. Sci. 2013, 38, 1629-1652.

[17] Mensitieri, G.; Maio, E. D.; Buonocore, G. G.; Nedi, I.; Oliviero, M.; Sansone, L.; Iannace, S. Processing and shelf life issues of selected food packaging materials and structures from renewable resources. Trends Food Sci. Technol. 2011, 22, 72-80.

[18] Romero-Bastida, C. A.; Bello-Pérez, L. A.; García, M. A.; Martino, M. N.; Solorza-Feria, J.; Zaritzky, N. E. Physicochemical and microstructural characterization of films prepared by thermal and cold gelatinization from non-conventional sources of starches. Carbohyd. Polym. 2005, 60, 235-244.

[19] Avérous, L. Biodegradable multiphase systems based on plasticized starch: A review. J. Macromol. Sci. Part C-Polym. Rev. 2004, 44, 231-274.

[20] Fukushima, K.; Camino, G. Polymer nanocomposites biodegradation. In: Dasari, A., Fukushim, K., Eds. Functional and Physical Properties of Polymer Nanocomposites, Wiley: Chichester, 2016, pp. 57-91.

[21] Avérous, L.; Pollet, E. Biodegradable polymers. In: Avérous, L., Pollet, E., Eds. Environmental Silicate Nano-Biocomposites, Springer: London, 2012, pp. 13-39.

[22] Chandra, R.; Rustgi, R. Biodegradable polymers. Prog. Polym. Sci. 1998, 23, 1273-1335.

[23] Lucas, N.; Bienaime, C.; Belloy, C.; Queneudec, M.; Silvestre, F.; Nava-Saucedo, J. Polymer biodegradation: Mechanisms and estimation techniques- A review. Chemosphere 2008, 73, 429-442. 
[24] Chiellini, E.; Corti, A.; Solaro, R. Biodegradation of poly (vinyl-alcohol) based blown films under different environmental conditions. Polym. Degrad. Stabil. 1999, 64, 305-312.

[25] Gáspár, M.; Benkő, Z.; Dogossy, G.; Réczey, K.; Czigány, T. Reducing water absorption in compostable starch-based plastics. Polym. Degrad. Stabil. 2005, 90, 563-569.

[26] Averous, L.; Boquillon, N. Biocomposites based on plasticized starch: Thermal and mechanical behaviours. Carbohyd. Polym. 2004, 56, 111-122.

[27] Follain, N.; Joly, C.; Dole, P.; Bliard, C. Mechanical properties of starch-based materials. I. Short review and complementary experimental analysis. J. Appl. Polym. Sci. 2005, 97, 1783-1794.

[28] Demirgöz, D.; Elvira, C.; Mano, J. F.; Cunha, A. M.; Piskin, E.; Reis, R. L. Chemical modification of starch based biodegradable polymeric blends: Effects on water uptake, degradation behaviour and mechanical properties. Polym. Degrad. Stabil. 2000, 70, 161170.

[29] George, J.; S. N. Sabapathi, S. Water soluble polymer-based nanocomposites containing cellulose nanocrystals. In: Thakur V. K. , Thakur M. K., Eds. Advanced Structured Materials Eco-friendly Polymer Nanocomposites, Springer, New Delhi, 2015, pp. 259293.

[30] Chiellini, E.; Corti, A.; D’Antone, S.; Solaro, R. Biodegradation of poly (vinyl-alcohol) based materials. Prog. Polym. Sci. 2003, 28, 963-1014.

[31] Singha, A. S.; Priya, B.; Pathania, D. Corn starch/poly (vinyl-alcohol) biocomposite blend films: mechanical properties, thermal behavior, fire retardancy, and antibacterial activity. Int. J. Polym. Anal. Charact. 2015, 20, 357-366.

[32] Tânase, E. E.; Popa, M. E.; Râpâ, M.; Popa, O. Preparation and characterization of biopolymer blends based on polyvinyl alcohol and starch. Romanian Biotech. Lett. 2015, 20, 10306-10315.

[33] Tang, X.; Alavi, S. Recent advances in starch, polyvinyl alcohol based polymer blends, nanocomposites and their biodegradability. Carbohyd. Polym. 2011, 85, 7-16.

[34] Xiong, H.; Tang, S.; Tang, H.; Zou, P. The structure and properties of a starch-based biodegradable film. Carbohyd. Polym. 2008, 71, 263-268.

[35] Sapalidis, A. A.; Katsaros, F. K.; Kanellopoulos, N. K. PVA/montmorillonite nanocomposites: Development and properties. In: Cuppoletti, J., Ed. Nanocomposites and Polymers with Analytical Methods, InTech, Rijeka, 2011, pp. 29-50.

[36] Ismail, H.; Zaaba, N. F. Effect of additives on properties of polyvinyl alcohol (PVA)/tapioca starch biodegradable films. Polym.-Plast. Technol. 2011, 50, 1214-1219. 
[37] Shimao, M. Biodegradation of plastics. Curr. Opin. Biotechnol. 2001, 12, 242-247.

[38] Guimarães, M.; Botaro, V. R.; Novack, K. M.; Teixeira, F. G.; Tonoli, G. H. Starch/PVAbased nanocomposites reinforced with bamboo nanofibrils. Ind. Crop. Prod. 2015, 70, $72-$ 83.

[39] Tang, S.; Zou, P.; Xiong, H.; Tang, H. Effect of nano-SiO 2 on the performance of starch/polyvinyl alcohol blend films. Carbohyd. Polym. 2008, 72, 521-526.

[40] Mousa, M. H.; Dong, Y.; Davies, I. J. Recent advances in bionanocomposites: Preparation, properties, and applications. Int. J. Polym. Mater. Polym Biomater. 2016, 65, 225-254.

[41] Gaaz, T.; Sulong, A.; Akhtar, M.; Kadhum, A.; Mohamad, A.; Al-Amiery, A. Properties and applications of polyvinyl alcohol, halloysite nanotubes and their nanocomposites. Molecules 2015, 20, 22833-22847.

[42] Zhou, J.; Ma, Y.; Ren, L.; Tong, J.; Liu, Z.; Xie, L. Preparation and characterization of surface crosslinked TPS/PVA blend films. Carbohyd. Polym. 2009, 76, 632-638.

[43] Rahman, W., Sin, L. T., Rahmat, A., Samad, A. Thermal behaviour and interactions of cassava starch filled with glycerol plasticized polyvinyl alcohol blends. Carbohyd. Polym. 2010, 81, 4, 805-810.

[44] Luo, X.; Li, J.; Lin, X. Effect of gelatinization and additives on morphology and thermal behavior of corn starch/PVA blend films. Carbohyd. Polym. 2012, 90, 1595-1600.

[45] Yuan, P.; Tan, D.; Annabi-Bergaya, F. Properties and applications of halloysite nanotubes: Recent research advances and future prospects. Appl. Clay Sci. 2015, 112-113, 75-93.

[46] Jang, J.; Lee, D. K. Plasticizer effect on the melting and crystallization behavior of polyvinyl alcohol. Polymer 2003, 44, 8139-8146.

[47] Negim, E. S. M.; Rakhmetullayeva, R. K.; Yeligbayeva, G. Zh.; Urkimbaeva, P. I.; Primzharova, S. T.; Kaldybekov, D. B.; Khatib, J. M.; Mun, G. A.; Craig, W. Improving biodegradability of polyvinyl alcohol/starch blend films for packaging applications. Int. J. Basic Appl. Sci. 2014, 3, 263-273.

[48] Roohani, M.; Habibi, Y.; Belgacem, N. M.; Ebrahim, G.; Karimi, A. N.; Dufresne, A. Cellulose whiskers reinforced polyvinyl alcohol copolymers nanocomposites. Eur. Polym. J. 2008, 44, 2489-2498.

[49] Lim, M.; Kwon, H.; Kim, D.; Seo, J.; Han, H.; Khan, S. B. Highly-enhanced water resistant and oxygen barrier properties of cross-linked poly (vinyl-alcohol) hybrid films for packaging applications. Prog. Org. Coat. 2015, 85, 68-75.

[50] Mishra, R.; Rao, K. J. On the formation of poly (ethylene oxide)-poly (vinyl alcohol) blends. Eur. Polym. J. 1999, 35, 1883-1894. 
[51] Cao, Y.; Wei, W.; Liu, J.; You, Q.; Liu, F.; Lan, Q.; Zhang, C.; Liu, C.; Zhao, J. The preparation of graphene reinforced poly (vinyl-alcohol) antibacterial nanocomposite thin film. Int. J. Polym. Sci. 2015, 2015, Article ID 407043, 7 pages.

[52] Giannakas, A.; Vlacha, M.; Salmas, C.; Leontiou, A.; Katapodis, P.; Stamatis, H.; Barkoula, N.; Ladavos, A. Preparation, characterization, mechanical, barrier and antimicrobial properties of chitosan/PVOH/clay nanocomposites. Carbohyd. Polym. 2016, 140, 408-415.

[53] Grande, R.; Pessan, L. A.; Carvalho, A. J. Ternary melt blends of poly (lactic acid)/poly (vinyl alcohol)-chitosan. Ind. Crop. Prod. 2015, 72, 159-165.

[54] Grande, R.; Carvalho, A. J. Compatible ternary blends of chitosan/poly(vinyl alcohol)/poly(lactic acid) produced by oil-in-water emulsion processing. Biomacromolecules 2011, 12, 907-914.

[55] Sakurada, I. Polyvinyl Alcohol Fibres, Marcel Dekker: New York, 1985.

[56] Sadegh-Hassani, F.; Nafchi, A. M. Preparation and characterization of bionanocomposite films based on potato starch/halloysite nanoclay. Int. J. Biol. Macromol. 2014, 67, 458462.

[57] Priya, B.; Gupta, V. K.; Pathania, D.; Singha, A. S. Synthesis, characterization and antibacterial activity of biodegradable starch/PVA composite films reinforced with cellulosic fibre. Carbohyd. Polym. 2014, 109, 171-179.

[58] Krumova, M.; López, D.; Benavente, R.; Mijangos, C.; Pereña, J. Effect of crosslinking on the mechanical and thermal properties of poly (vinyl-alcohol). Polymer 2000, 41, 92659272.

[59] Loryuenyong, V.; Saewong, C.; Aranchaiya, C.; Buasri, A. The improvement in mechanical and barrier properties of poly (vinyl-alcohol)/graphene oxide packaging films. Packag. Technol. Sci. 2015, 28, 939-947.

[60] Cui, Y.; Kumar, S.; Kona, B. R.; Houcke, D. V. Gas barrier properties of polymer/clay nanocomposites. RSC Adv. 2015, 5, 63669-63690.

[61] Nielsen, L. E. Models for the Permeability of Filled Polymer Systems. J. Macromol. Sci. Part A - Chem. 1967, 1, 929-942.

[62] Feldman, D. Polymer Nanocomposite Barriers. J. Macromol. Sci. Part A - Chem. 2013, 50, 441-448.

[63] Sin, L. T.; Rahman, W.; Rahmat, A.; Khan, M. Detection of synergistic interactions of polyvinyl alcohol-cassava starch blends through DSC. Carbohyd. Polym. 2010, 79, 1, 224-226. 
[64] Choudalakis, G.; Gotsis, A. Permeability of polymer/clay nanocomposites: A review. Eur. Polym. J. 2009, 45, 967-984.

[65] Bhattacharya, M.; Biswas, S.; Bhowmick, A. K. Permeation characteristics and modeling of barrier properties of multifunctional rubber nanocomposites. Polymer 2011, 52, 7, 1562 1576.

[66] Eitzman, D. M.; Melkote, R. R.; Cussler, E. L. Barrier membranes with tipped impermeable flakes. AIChE J., 1996, 42, 2-9.

[67] Yeun, J.; Bang, G.; Park, B. J.; Ham, S. K.; Chang, J. Poly(vinyl alcohol) nanocomposite films: Thermooptical properties, morphology, and gas permeability. J. Appl. Polym. Sci., 2006, 101, 591-596.

[68] Ramaraj, B. Crosslinked poly(vinyl-alcohol) and starch composite films: Study of their physicomechanical, thermal, and swelling properties. J. Appl. Polym. Sci., 2006, 103, 1127-1132.

[69] Holland, B. J.; Hay, J. N. The thermal degradation of poly(vinyl-alcohol). Polymer 2001, 42. 6775-6783.

[70] Cano, A. I.; Cháfer, M.; Chiralt, A.; González-Martínez, C. Biodegradation behavior of starch-PVA films as affected by the incorporation of different antimicrobials. Polym. Degrad. Stabil. 2016, 132, 11-20.

[71] Kopčilová, M.; Hubáčková, J.; Růžička, J.; Dvořáčková, M.; Julinová, M.; Koutný, M.; Tomalová, M.; Alexy, P.; Bugaj, P.; Filip, J. Biodegradability and mechanical properties of poly(vinyl alcohol)-based blend plastics prepared through extrusion method. J. Polym. Environ. 2012, 21, 88-94.

[72] Corti, A.; Cinelli, P.; D'antone, S.; Kenawy, E.; Solaro, R. Biodegradation of poly(vinyl alcohol) in soil environment: Influence of natural organic fillers and structural parameters. Macromol. Chem. Phys. 2002, 203, 1526-1531.

[73] Solaro, R.; Corti, A.; Chiellini, E. Biodegradation of poly(vinyl-alcohol) with different molecular weights and degree of hydrolysis. Polym. Adv. Technol. 2000, 11, 873-878.

[74] Talja, R. A.; Helén, H.; Roos, Y. H.; Jouppila, K. Effect of various polyols and polyol contents on physical and mechanical properties of potato starch-based films. Carbohyd. Polym. 2007, 67, 288-295.

[75] Cai, J.; Chen, J.; Zhang, Q.; Lei, M.; He, J.; Xiao, A.; Ma, C.; Li, S.; Xiong, H. Wellaligned cellulose nanofiber-reinforced polyvinyl alcohol composite film: Mechanical and optical properties. Carbohyd. Polym. 2016, 140, 238-245. 
[76] Kim, H. M.; Lee, J. K.; Lee, H. S. Transparent and high gas barrier films based on poly (vinyl-alcohol)/graphene oxide composites. Thin Solid Films 2011, 519, 7766-7771.

[77] Rahmat, A. R.; Rahman, W. A.; Sin, L. T.; Yussuf, A. Approaches to improve compatibility of starch filled polymer system: A review. Mater. Sci. Eng. C, 2009, 29, 2370-2377.

[78] Gupta, B.; Agarwal, R.; Alam, M. S. Preparation and characterization of polyvinyl alcohol-polyethylene oxide-carboxymethyl cellulose blend membranes. J. Appl. Polym. Sci., 2012, 127, 1301-1308.

[79] García, N. L.; Famá, L.; D’Accorso, N. B.; Goyanes, S. Biodegradable starch nanocomposites. In: Thakur V. K., Thakur M. K., Eds. Advanced Structured Materials Eco-friendly Polymer Nanocomposites Springer, New Delhi, 2015, pp.17-77.

[80] Wang, W.; Zhang, H.; Dai, Y.; Hou, H.; Dong, H. Effects of low poly (vinyl-alcohol) content on properties of biodegradable blowing films based on two modified starches. J. Thermoplast. Compos., published online on October 28, 2015 (DOI: 10.1177/0892705715614080).

[81] Corre, D. L.; Bras, J.; Dufresne, A. Starch Nanoparticles: A Review. Biomacromolecules 2010, 11, 1139-1153.

[82] Schmitt, H.; Prashantha, K.; Soulestin, J.; Lacrampe, M.; Krawczak, P. Preparation and properties of novel melt-blended halloysite nanotubes/wheat starch nanocomposites. Carbohyd. Polym. 2012, 89, 920-927.

[83] Song, T.; Tanpichai, S.; Oksman, K. Cross-linked polyvinyl alcohol (PVA) foams reinforced with cellulose nanocrystals (CNCs). Cellulose 2016, 23, 1925-1938.

[84] Shi, R.; Zhang, Z.; Liu, Q.; Han, Y.; Zhang, L.; Chen, D.; Tian, W. Characterization of citric acid/glycerol co-plasticized thermoplastic starch prepared by melt blending. Carbohyd. Polym. 2007, 69, 748-755.

[85] Taghizadeh, M.; Sabouri, N.; Ghanbarzadeh, B. Polyvinyl-alcohol: starch: carboxymethyl cellulose containing sodium montmorillonite clay blends; mechanical properties and biodegradation behavior. Springer Plus 2013, 2, 376 (8 pages).

[86] Xiao, C.; Yang, M. Controlled preparation of physical cross-linked starch-g-PVA hydrogel. Carbohyd. Polym. 2006, 64, 37-40.

[87] Sreedhar, B.; Sairam, M.; Chattopadhyay, D. K.; Rathnam, P. A.; Rao, D. V. Thermal, mechanical, and surface characterization of starch-poly (vinyl-alcohol) blends and boraxcrosslinked films. J. Appl. Polym. Sci. 2005, 96, 1313-1322. 
[88] Sreedhar, B.; Chattopadhyay, D. K.; Karunakar, M. S.; Sastry, A. R. Thermal and surface characterization of plasticized starch polyvinyl alcohol blends crosslinked with epichlorohydrin. J. Appl. Polym. Sci. 2006, 101, 25-34.

[89] Zou, G.; Qu, J.; Zou, X. Optimization of water absorption of starch/PVA composites. Polym. Compos. 2007, 28, 674-679.

[90] Majdzadeh-Ardakani, K.; Navarchian, A. H.; Sadeghi, F. Optimization of mechanical properties of thermoplastic starch/clay nanocomposites. Carbohyd. Polym. 2010, 79, 547554.

[91] Sin, L. T.; Rahmat, A.; Rahman, W.; Sun, Z.; Samad, A. Rheology and thermal transition state of polyvinyl alcohol-cassava starch blends. Carbohyd. Polym. 2010, 81, 737-739.

[92] Yoon, S.; Park, M.; Byun, H. Mechanical and water barrier properties of starch/PVA composite films by adding nano-sized poly (methyl methacrylate-co-acrylamide) particles. Carbohyd. Polym. 2012, 87, 676-686.

[93] Bin-Dahman, O. A.; Jose, J.; Al-Harthi, M. A. Effect of natural weather aging on the properties of poly(vinyl alcohol)/starch/graphene nanocomposite. Starch- Stärke 2016, 68, $1-8$.

[94] Tânase, E. E.; Popa, E. M.; Râpâ, M.; Popa, O.; Popa, I. V. Biodegradation study of some food packaging biopolymers based on PVA. Bull. UASVM Anim. Sci. Biotechnol. 2016, 73, $1-5$.

[95] Park, H.; Chough, S.; Yun, Y.; Yoon, S. Properties of starch/PVA blend films containing citric acid as additive. J. Polym. Environ. 2005, 13, 375-382.

[96] Yun, Y.; Na, Y.; Yoon, S. Mechanical Properties with the Functional Group of Additives for Starch/PVA Blend Film. J. Polym. Environ. 2006, 14, 71-78.

[97] Cano, A. I.; Cháfer, M.; Chiralt, A.; González-Martínez, C. Physical and microstructural properties of biodegradable films based on pea starch and PVA. J. Food Eng. 2015, 167, 59-64.

[98] Siddaramaiah; Raj, B.; Somashekar, R. Structure-property relation in polyvinyl alcohol/starch composites. J. Appl. Polym. Sci. 2004, 91, 630-635.

[99] Chen, Y.; Cao, X.; Chang, P. R.; Huneault, M. A. Comparative study on the films of poly(vinyl alcohol)/pea starch nanocrystals and poly(vinyl alcohol)/native pea starch. Carbohyd. Polym. 2008, 73, 8-17.

[100] Zhang, G.; Liu, Y.; Fang, C.; Zhang, M.; Zhou, C.; Chen, Z. Water resistance, mechanical properties and biodegradability of methylated-cornstarch/poly (vinyl alcohol) blend film. Polym. Degrad. Stabil. 2006, 91, 703-711. 
[101] Jayasekara, R.; Harding, I.; Bowater, I.; Christie, G.; Lonergan, G. Preparation, surface modification and characterisation of solution cast starch PVA blended films. Polym. Test. 2004, 23, 17-27.

[102] Visakh P. M. Starch: State-of-the-Art, New Challenges and Opportunities. In: Visakh, P. M., Long, Y., Eds. Starch-based Blends, Composites and Nanocomposites, RSC, Cambridge, 2016, pp.1-16.

[103] Shi, R.; Bi, J.; Zhang, Z.; Zhu, A.; Chen, D.; Zhou, X.; Zhang, L.; Tian, W. The effect of citric acid on the structural properties and cytotoxicity of the polyvinyl alcohol/starch films when molding at high temperature. Carbohyd. Polym. 2008, 74, 763-770.

[104] Eaysmine, S.; Haque, P.; Ferdous, T.; Gafur, M. A.; Rahman, M. M. Potato starchreinforced poly (vinyl-alcohol) and poly (lactic-acid) composites for biomedical applications. J. Thermoplast. Compos., published online on February 4, 2015 (DOI: 10.1177/0892705715569824).

[105] Lawton, J. Effect of starch type on the properties of starch containing films. Carbohyd. Polym. 1996, 29, 203-208.

[106] Zanela, J.; Olivato, J. B.; Dias, A. P.; Grossmann, M. V.; Yamashita, F. Mixture design applied for the development of films based on starch, polyvinyl alcohol, and glycerol. J. Appl. Polym. Sci. 2015, 132, Article No. 42697, pp. 1-8.

[107] He, Z.; Xiong, L. Evaluation of physical and biological properties of polyvinyl alcohol/chitosan blend films. J. Macromol. Sci.-Part B 2012, 51, 1705-1714.

[108] Li, H.; Chen, S.; Wang, Y. Preparation and characterization of nanocomposites of polyvinyl alcohol/cellulose nanowhiskers/chitosan. Compos. Sci. Technol. 2015, 115, 60-65.

[109] Bari, S. S.; Chatterjee, A.; Mishra, S. Biodegradable polymer nanocomposites: An overview. Polym. Reviews 2016, 56, 287-328.

[110] Khoo, W. S.; Ismail, H.; Ariffin, A. Tensile, swelling, and oxidative degradation properties of crosslinked polyvinyl alcohol/chitosan/halloysite nanotube composites. Int. J. Polym. Mater. Polym. Biomater. 2013, 62, 390-396.

[111] Tripathi, S.; Mehrotra, G.; Dutta, P. Physicochemical and bioactivity of cross-linked chitosan-PVA film for food packaging applications. Int. J. Biol. Macromol. 2009, 45, 372-376.

[112] Zou, G.; Jin, P.; Xin, L. Extruded starch/PVA composites: Water resistance, thermal properties, and morphology. J. Elastom. Plast. 2008, 40, 303-316. 
[113] Castro-Aguirre, E.; Iñiguez-Franco, F.; Samsudin, H.; Fang, X.; Auras, R. Poly (lactic acid)-Mass production, processing, industrial applications, and end of life. Adv. Drug Deliver. Rev., available online 1 April 2016 (DOI: 10.1016/j.addr.2016.03.010).

[114] Zhang, R.; Xu, W.; Jiang, F. Fabrication and characterization of dense Chitosan/polyvinyl-alcohol/poly-lactic-acid blend membranes. Fibers Polym. 2012, 13, 571-575.

[115] Li, H.; Chen, S.; Wang, Y. Thermoplastic PVA/PLA blends with improved processability and hydrophobicity. Ind. Eng. Chem. Res. 2014, 53, 17355-17361.

[116] Gajria, A. M.; Davé, V.; Gross, R. A.; Mccarthy, S. P. Miscibility and biodegradability of blends of poly (lactic acid) and poly (vinyl acetate). Polymer 1996, 37, 437-444.

[117] Hu, Y.; Wang, Q.; Tang, M. Preparation and properties of starch-g-PLA/poly(vinyl alcohol) composite film. Carbohyd. Polym. 2013, 96, 384-388.

[118] Shuai, X.; He, Y.; Asakawa, N.; Inoue, Y. Miscibility and phase structure of binary blends of poly (L-lactide) and poly (vinyl alcohol). J. Appl. Polym. Sci. 2001, 81, 762772.

[119] F.E. Bailey; Jr., Koleske, J. V. Properties of poly (ethylene oxide) In: Poly (ethylene Oxide), Academic Press, New York, 1976, 105-149.

[120] Sawatari, C.; Kondo, T. Interchain hydrogen bonds in blend films of poly (vinyl alcohol) and its derivatives with poly(ethylene oxide). Macromolecules 1999, 32, 1949-1955.

[121] Cano, A.; Fortunati, E.; Cháfer, M.; González-Martínez, C.; Chiralt, A.; Kenny, J. M. Effect of cellulose nanocrystals on the properties of pea starch-poly(vinyl-alcohol) blend films. J. Mater. Sci. 2015, 50, 6979-6992.

[122] Hu, D.; Wang, L. Fabrication of antibacterial blend film from poly(vinyl alcohol) and quaternized chitosan for packaging. Mater. Res. Bull. 2016, 78, 46-52.

[123] Ramaraj, B. Crosslinked poly(vinyl-alcohol) and starch composite films. II. Physicomechanical, thermal properties and swelling studies. J. Appl. Polym. Sci. 2006, 103, 909-916.

[124] Azahari, N. A.; Othman, N.; Ismail H. Biodegradation studies of polyvinyl-alcohol/corn starch blend films in solid and solution media. J. Phys. Sci. 2011, 22, 15-31.

[125] Das, K.; Ray, D.; Bandyopadhyay, N. R.; Gupta, A.; Sengupta, S.; Sahoo, S.; Mohanty, A.; Misra, M. Preparation and characterization of cross-linked starch/poly (vinylalcohol) green films with low moisture absorption. Ind. Eng. Chem. Res. 2010, 49, 21762185. 
[126] Yoon, S.; Chough, S.; Park, H. Preparation of resistant starch/poly (vinyl-alcohol) blend films with added plasticizer and crosslinking agents. J. Appl. Polym. Sci. 2007, 106, 2485-2493.

[127] Reddy, N.; Yang, Y. Citric acid cross-linking of starch films. Food Chem. 2010, 118, 702-711.

[128] Mao, L.; Imam, S.; Gordon, S.; Cinelli, P.; Chiellini, E. Extruded corn starch-glycerolpolyvinyl alcohol blends: Mechanical properties, morphology, and biodegradability. J. Polym. Environ. 2000, 8, 205-211.

[129] Bertuzzi, M.; Vidaurre, E. C.; Armada, M.; Gottifredi, J. Water vapour permeability of edible starch based films. J. Food Eng. 2007, 80, 972-978.

[130] Spiridon, I.; Popescu, M. C.; Bodârlău, R.; Vasile, C. Enzymatic degradation of some nanocomposites of poly (vinyl alcohol) with starch. Polym. Degrad. Stabil. 2008, 93, 1884-1890.

[131] Hu, G.; Chen, J.; Gao, J. Preparation and characteristics of oxidized potato starch films. Carbohyd. Polym. 2009, 76, 291-298.

[132] Chen, L.; Imam, S. H.; Gordon, S. H.; Greene, R. V. Starch- polyvinyl alcohol crosslinked film-performance and biodegradation. J. Environ. Polym. Degrad. 1997, 5, 111-117.

[133] Julkapli, N. M.; Bagheri, S.; Sapuan, S. M. Multi-functionalized carbon nanotubes polymer composites: Properties and applications. In: Thakur, V. K., Thakur, M. K., Eds., Advanced Structured Materials Eco-friendly Polymer Nanocomposites, Springer, New Delhi, 2015, pp.155-214.

[134] Aydın, A. A.; Ilberg, V. Effect of different polyol-based plasticizers on thermal properties of poly vinyl-alcohol: starch blends. Carbohyd. Polym. 2016, 136, 441-448.

[135] Jose, J.; Al-Harthi, M. A.; Alma'adeed, M. A.; Dakua, J. B.; De, S. K. Effect of graphene loading on thermomechanical properties of poly(vinyl-alcohol)/starch blend. J. Appl. Polym. Sci. 2015, 132, Article No. 41827, pp. 1-8.

[136] Othman, N.; Azahari, N. A.; Ismail, H. Thermal properties of polyvinyl alcohol (PVOH)/corn starch blend film. Malaysian Polym. J. 2011, 6, 147-154.

[137] Yin, Y.; Li, J.; Liu, Y.; Li, Z. Starch crosslinked with poly(vinyl-alcohol) by boric acid. J. Appl. Polym. Sci. 2005, 96, 1394-1397.

[138] Soheilmoghaddam, M.; Pour, R. H.; Wahit, M. U.; Balakrishnan, H. Bionanocomposites of regenerated cellulose reinforced with halloysite nanoclay and graphene nanoplatelets: Characterizations and properties. In: Thakur, V. K., Thakur, M. K., Eds. Advanced 
Structured Materials Eco-friendly Polymer Nanocomposites, Springer, New Delhi, 2015, pp. 295-321.

[139] Youssef, A. M. Polymer nanocomposites as a new trend for packaging applications. Polym.-Plast. Tech. Eng. 2013, 52, 635-660.

[140] Cano, A.; Fortunati, E.; Cháfer, M.; Kenny, J.; Chiralt, A.; González-Martínez, C. Properties and ageing behaviour of pea starch films as affected by blend with poly (vinylalcohol). Food Hydrocolloid. 2015, 48, 84-93.

[141] Minelli, M., Baschetti, M. G., Doghieri, F. Analysis of modelling results for barrier properties in ordered nanocomposite systems. J. Membrane Sci. 2009, 327, 1-2, 208-215.

[142] Azeredo, H. M. Nanocomposites for food packaging applications. Food Res. Int. 2009, 42, 1240-1253.

[143] Ray, S.; Quek, S. Y.; Easteal, A.; Chen, X. D. The Potential Use of Polymer-Clay Nanocomposites in Food Packaging. Int. J. Food Eng. 2006, 2, Article 5 (DOI: 10.2202/1556-3758.1149).

[144] Dean, K. M.; Do, M. D.; Petinakis, E.; Yu, L. Key interactions in biodegradable thermoplastic starch/poly (vinyl alcohol)/montmorillonite micro- and nanocomposites. Compos. Sci. Technol. 2008, 68, 1453-1462.

[145] Li, Y.; Tian, H.; Jia, Q.; Niu, P.; Xiang, A.; Liu, D.; Qin, Y. Development of polyvinyl alcohol/intercalated MMT composite foams fabricated by melt extrusion. J. Appl. Polym. Sci. 2015, 132, Article No. 42706, pp. 1-7.

[146] Chiou, B.; Yee, E.; Glenn, G. M.; Orts, W. J. Rheology of starch-clay nanocomposites. Carbohyd. Polym. 2005, 59, 467-475.

[147] Majdzadeh-Ardakani, K.; Nazari, B. Improving the mechanical properties of thermoplastic starch/poly (vinyl alcohol)/clay nanocomposites. Compos. Sci. Technol. 2010, 70, 1557-1563.

[148] Rawtani, D; Agrawal, Y.K. Multifarious applications of halloysite nanotubes: A review. Rev. Adv. Mater. Sci. 2012, 30, 282-295.

[149] Tully, J., Fakhrullin, R., Lvov, Y. Halloysite clay nanotube composites with sustained release of chemicals. In: Bardosova, M., Wagner, T., Eds. Nanomaterials and Nanoarchitectures, Springer, Dordrecht, 2015, pp. 87-118.

[150] Schmitt, H.; Creton, N.; Prashantha, K.; Soulestin, J.; Lacrampe, M.; Krawczak, P. Preparation and characterization of plasticized starch/halloysite porous nanocomposites possibly suitable for biomedical applications. J. Appl. Polym. Sci. 2014, 132, Article No. 41341, pp. 1-9. 
[151] Meira, S. M.; Zehetmeyer, G.; Scheibel, J. M.; Werner, J. O.; Brandelli, A. Starchhalloysite nanocomposites containing nisin: Characterization and inhibition of Listeria monocytogenes in soft cheese. LWT - Food Sci. Technol. 2016, 68, 226-234.

[152] Xie, Y.; Chang, P. R.; Wang, S.; Yu, J.; Ma, X. Preparation and properties of halloysite nanotubes/plasticized Dioscorea opposita Thunb. Starch composites. Carbohyd. Polym. 2011, 83, 186-191.

[153] Huang, H.; Ren, P.; Chen, J.; Zhang, W.; Ji, X.; Li, Z. High barrier graphene oxide nanosheet/poly (vinyl alcohol) nanocomposite films. J. Membrane Sci. 2012, 409-410, 156-163.

[154] Alipoormazandarani, N.; Ghazihoseini, S.; Nafchi, A. M. Preparation and characterization of novel bionanocomposite based on soluble soybean polysaccharide and halloysite nanoclay. Carbohyd. Polym. 2015, 134, 745-751.

[155] Zhang, Y.; Tang, A.; Yang, H.; Ouyang, J. Applications and interfaces of halloysite nanocomposites. Appl. Clay Sci. 2016, 119, 8-17.

[156] Tully, J.; Yendluri, R.; Lvov, Y. Halloysite clay nanotubes for enzyme immobilization. Biomacromolecules 2016, 17, 615-621.

[157] He, Y.; Kong, W.; Wang, W.; Liu, T.; Liu, Y.; Gong, Q.; Gao, J. Modified natural halloysite/potato starch composite films. Carbohyd. Polym. 2012, 87, 2706-2711.

[158] Sellam, C.; Zhai, Z.; Zahabi, H.; Picot, O. T.; Deng, H.; Fu, Q.; Bilotti, E.; Peijs, T. High mechanical reinforcing efficiency of layered poly (vinyl-alcohol)-graphene oxide nanocomposites. Nanocomposites 2015, 1, 89-95.

[159] Schmitt, H.; Creton, N.; Prashantha, K.; Soulestin, J.; Lacrampe, M.; Krawczak, P. Meltblended halloysite nanotubes/wheat starch nanocomposites as drug delivery system. Polym. Eng. Sci. 2014, 55, 573-580.

[160] Liu, D.; Bian, Q.; Li, Y.; Wang, Y.; Xiang, A.; Tian, H. Effect of oxidation degrees of graphene oxide on the structure and properties of poly (vinyl alcohol) composite films. Compos. Sci. Technol. 2016, 129, 146-152.

[161] Liu, H.; Bandyopadhyay, P.; Kim, N. H.; Moon, B.; Lee, J. H. Surface modified graphene oxide/poly (vinyl alcohol) composite for enhanced hydrogen gas barrier film. Polym. Test. 2016, 50, 49-56.

[162] Raheel, M.; Yao, K.; Gong, J.; Chen, X.; Liu, D.; Lin, Y.; Cui, D.; Siddiq, M.; Tang, T. Poly (vinyl-alcohol)/GO-MMT nanocomposites: Preparation, structure and properties. Chin. J. Polym. Sci. 2015, 33, 329-338. 
[163] Lemes, A. P.; Montanheiro, T. L.; Passador, F. R.; Durán, N. Nanocomposites of polyhydroxyalkanoates reinforced with carbon nanotubes: Chemical and biological properties. In: Thakur, V. K., Thakur, M. K. Eds. Advanced Structured Materials Ecofriendly Polymer Nanocomposites, Springer, New Delhi, 2015, pp.79-108.

[164] Kumar, B. R.; Crasta, V.; Praveen, B. M.; B, S. Enhancement of micro structural properties of PVA doped with MWCNT's and metal oxide nanocomposites films. AIP Conf. Proc. 2015, 1665, 140002-1.

[165] Liu, L.; Barber, A. H.; Nuriel, S.; Wagner, H. D. Mechanical properties of functionalized single-walled carbon-nanotube/poly (vinyl alcohol) nanocomposites. Adv. Funct. Mater. 2005, 15, 975-980.

[166] Samal, S. K.; Fernandes, E. G.; Chiellini, F.; Chiellini, E. Thermal analysis of PVA/CNTs 2D membrane. J. Therm. Anal. Calorim. 2009, 97, 859-864.

[167] Zhao, B.; Wang, J.; Li, Z.; Liu, P.; Chen, D.; Zhang, Y. Mechanical strength improvement of polypropylene threads modified by PVA/CNT composite coatings. Mater. Lett. 2008, 62, 4380-4382.

[168] Basiuk, E. V.; Anis, A.; Bandyopadhyay, S.; Alvarez-Zauco, E.; Chan, S. L.; Basiuk, V. A. Poly (vinyl alcohol)/CNT composites: An effect of cross-linking with glutaraldehyde. Superlatt. Microstruct. 2009, 46, 379-383.

[169] Ryan, K.P.; Cadek, M.; Nicolosi, V.; Blond, D.; Ruether, M.; Armstrong, G.; Swan, H.; Fonseca, A.; Nagy, J. B.; Maser, W. K.; Blau, W. J.; Coleman, J. N. Carbon nanotubes for reinforcement of plastics? A case study with poly (vinyl alcohol). Compos. Sci. Technol. 2007, 67, 1640-1649.

[170] Sam, S. T.; Nuradibah, M. A.; Chin, K. M.; Hani, N. Current application and challenges on packaging industry based on natural polymer blending. In: Olatunj, O. Ed. Natural Polymers: Industrial Techniques and Applications, Springer, New York, 2015, pp.163184.

[171] Aloui, H.; Khwaldia, K.; Hamdi, M.; Fortunati, E.; Kenny, J. M.; Buonocore, G. G.; Lavorgna, M. Synergistic effect of halloysite and cellulose nanocrystals on the functional properties of PVA based nanocomposites. ACS Sustain. Chem. Eng. 2016, 4, 794-800.

[172] Frone, A. N.; Nicolae, C. A.; Gabor, R. A.; Panaitescu, D. M. Thermal properties of water-resistant starch-polyvinyl alcohol films modified with cellulose nanofibers. Polym. Degrad. Stabil. 2015, 121, 385-397. 
[173] Qua, E. H.; Hornsby, P. R.; Sharma, H. S.; Lyons, G.; Mccall, R. D. Preparation and characterization of poly(vinyl alcohol) nanocomposites made from cellulose nanofibers. J. Appl. Polym. Sci. 2009, 113, 2238-2247.

[174] Cho, M.; Park, B. Tensile and thermal properties of nanocellulose-reinforced poly (vinyl alcohol) nanocomposites. J. Ind. Eng. Chem. 2011, 17, 36-40.

[175] Tan, B.; Thomas, N. A review of the water barrier properties of polymer/clay and polymer/graphene nanocomposites. J. Membrane Sci. 2016, 514, 595-612.

[176] Qiu, K.; Netravali, A. N. Halloysite nanotube reinforced biodegradable nanocomposites using noncrosslinked and malonic acid crosslinked polyvinyl alcohol. Polym. Compos. 2013, 34, 799-809.

[177] Sadhu, S.; D., Soni, A.; Varmani, S. G.; Garg, M. Preparation of starch-poly vinyl alcohol (PVA) blend using potato and study of its mechanical properties. Int. J. Pharm. Sci. 2014, 3, 33-37.

[178] Liu, D.; Sun, X.; Tian, H.; Maiti, S.; Ma, Z. Effects of cellulose nanofibrils on the structure and properties on PVA nanocomposites. Cellulose 2013, 20, 2981-2989.

[179] Strawhecker, K. E.; Manias, E. Structure and properties of poly(vinyl alcohol)/Na montmorillonite nanocomposites. Chem. Mater. 2000, 12, 2943-2949.

[180] Taghizadeh, M. T.; Abbasi, Z.; Nasrollahzade, Z. Study of enzymatic degradation and water absorption of nanocomposites starch/polyvinyl alcohol and sodium montmorillonite clay. J. Taiwan Inst. Chem. Eng. 2011, 43, 120-124.

[181] Nistor, M.; Vasile, C. Influence of the nanoparticle type on the thermal decomposition of the green starch/poly (vinyl-alcohol)/montmorillonite nanocomposites. J. Therm. Anal Calorim. 2012, 111, 1903-1919.

[182] Nistor, M.; Vasile, C. TG/FTIR/MS study on the influence of nanoparticles content upon the thermal decomposition of starch/poly(vinyl-alcohol) montmorillonite nanocomposites. Iran Polym. J. 2013, 22, 519-536.

[183] Taghizadeh, M. T.; Sabouri, N. Study of enzymatic degradation and water absorption of nanocomposites polyvinyl alcohol/starch/carboxymethyl cellulose blends containing sodium montmorillonite clay nanoparticle by cellulose and $\alpha$-amylase. J. Taiwan Inst. Chem. Eng. 2013, 44, 995-1001.

[184] Yeun, J.; Bang, G.; Park, B. J.; Ham, S. K.; Chang, J. Poly(vinyl alcohol) nanocomposite films: Thermooptical properties, morphology, and gas permeability. J. Appl. Polym. Sci. 2006, 101, 591-596. 
[185] Zhou, W. Y.; Guo, B.; Liu, M.; Liao, R.; Rabie, A. B.; Jia, D. Poly(vinylalcohol)/halloysite nanotubes bionanocomposite films: Properties and in vitro osteoblasts and fibroblasts response. J. Biomed. Mater. Res. 2010, 93A, 1574-1587.

[186] Rayleigh, L. On the influence of obstacles arranged in rectangular order upon the properties of a medium. Philos. Mag. Ser. 5, 1892, 34, 481-502.

[187] Picard, E.; Vermogen, A.; Gerard, J.; Espuche, E. Barrier properties of nylon 6montmorillonite nanocomposite membranes prepared by melt blending: Influence of the clay content and dispersion state Consequences on modelling. J. Membrane Sci. 2007, 292, 133-144.

[188] Xu, B.; Zheng, Q.; Song, Y.; Shangguan, Y. Calculating barrier properties of polymer/clay nanocomposites: Effects of clay layers. Polymer 2006, 47, 2904-2910.

[189] Fredrickson, G. H.; Bicerano, J. Barrier properties of oriented disk composites. J. Chem. Phys. 1999, 110, 2181.

[190] Moggridge, G.; Lape, N. K.; Yang, C.; Cussler, E. Barrier films using flakes and reactive additives. Prog. Org. Coat. 2003, 46, 231-240.

[191] Lape, N. K.; Nuxoll, E. E.; Cussler, E. Polydisperse flakes in barrier films. J. Membrane Sci. 2004, 236, 29-37.

[192] Yun, Y.; Na, Y.; Yoon, S. Mechanical properties with the functional group of additives for starch/PVA blend film. J. Polym. Environ. 2006, 14, 71-78.

[193] Cussler, E.; Hughes, S. E.; Ward, W. J.; Aris, R. Barrier membranes. J. Membrane Sci. 1988, 38, 161-174.

[194] Gusev, A. A.; Lusti, H. R. Rational design of nanocomposites for barrier applications. Adv. Mater. 2001, 13, 1641-1643.

[195] Saritha, A.; Joseph, K.; Thomas, S.; Muraleekrishnan, R. Chlorobutyl rubber nanocomposites as effective gas and VOC barrier materials. Compos. Pt. A-Appl. Sci. Manuf. 2012, 43, 864-870.

[196] Takahashi, S.; Goldberg, H.; Feeney, C.; Karim, D.; Farrell, M.; O'leary, K.; Paul, D. Gas barrier properties of butyl rubber/vermiculite nanocomposite coatings. Polymer 2006, 47, 3083-3093.

[197] Yeh, J.; Huang, H.; Chen, C.; Su, W.; Yu, Y. Siloxane-modified epoxy resin-clay nanocomposite coatings with advanced anticorrosive properties prepared by a solution dispersion approach. Surf. Coat. Tech. 2006, 200, 2753-2763. 
[198] Tortora, M.; Vittoria, V.; Galli, G.; Ritrovati, S.; Chiellini, E. Transport properties of modified montmorillonite-poly(E-caprolactone) nanocomposites. Macromol. Mater. Eng. 2002, 287, 243-249.

[199] Cano, A. I.; Cháfer, M.; Chiralt, A.; González-Martínez, C. Physical and microstructural properties of biodegradable films based on pea starch and PVA. J. Food Eng. 2015, 167, 59-64.

[200] Yoon, S.; Chough, S.; Park, H. Properties of starch-based blend films using citric acid as additive. II. J. Appl. Polym. Sci. 2006, 100, 2554-2560.

[201] Aris, R. On a problem in hindered diffusion. Arch. Rational Mech. Anal. 1986, 95, 8391.

[202] DeMerlis, C.C.; Schoneker, D.R. Review of the oral toxicity of polyvinyl alcohol (PVA). Food. Chem. Toxicol. 2003, 41, 319-326.

[203] John F. Robyt. Starch: Structure, Properties, Chemistry, and Enzymology. In: Glycoscience. Fraser-Reid B, Tatsuta K, Thiem J. EDS. Springer-Verlag Berlin Heidelberg, 2008, pp. 1437-1472 


\section{List of Figures}

Figure 1. The number of published research work in biodegradable polymers.

Figure 2. Required properties for biopolymer packaging materials.

Figure 3. Classification of biopolymers ${ }^{[16]}$.

Figure 4. Poly (vinyl-alcohol) (PVA) chemical structures: (A) partially-hydrolysed and (B) fully-hydrolysed ${ }^{[202]}$.

Figure 5. Effect of degree of hydrolysis and molecular weight on PVA properties ${ }^{[33]}$.

Figure 6. Published research for the use of PVA in packaging applications over forty years.

Figure 7. Flow chart of PVA industrial manufacturing ${ }^{[55]}$ (Interpreted from text).

Figure 8. SEM micrographs of native starch: (A) potato, (B) rice, (C) wheat, (D) mung bean, (E) maize, (F) waxy maize, (G) tapioca, $(\mathrm{H})$ shoti, and (J) leaf starch ${ }^{[203]}$.

Figure 9. Chemical structure of starch: (a) amylose structure and (b) amylopectin structure $\mathrm{f}^{[79]}$. Figure 10. Chemical interaction between PVA and starch in PVA/starch blends ${ }^{[98]}$.

Figure 11. Effect of plasticiser content on tensile strength, elongation and solubility of PVA/starch films ${ }^{[95]}$.

Figure 12. Mechanical and optical properties of PVA, PVA/NPS and PVA/PSN films ${ }^{[99]}$.

Figure 13. SEM micrograph of PVA/starch blend surfaces ${ }^{[121]}$.

Figure 14. SEM micrographs on the cross sections of PVA/starch blends ${ }^{[121]}$.

Figure 15. SEM micrographs of PVA/tapioca starch with a blooming/blushing phenomenon $^{[36]}$.

Figure 16. SEM micrographs of pure and blend PVA with HTCC: (a-e) upper surfaces and (fj) cross-sections ${ }^{[122]}$.

Figure 17. Pros and cons of PNCs ${ }^{[133]}$.

Figure 18. Montmorillonite structure ${ }^{[35]}$.

Figure 19. Dispersion status of layered silicates in polymer nanocomposites ${ }^{[142]}$.

Figure 20. Crystalline structures of HNTs ${ }^{[155]}$. 
Figure 21. SEM micrographs of (a) PVA/MWCNT nanocomposites at 0.025 g MWCNT, (b) PVA/MWCNT nanocomposites at 0.05 g MWCNT, (c) MWCNTs and (d) PVA/MWCNT nanocomposites at $0.05 \mathrm{~g}$ MWCNT after pyrolysis ${ }^{[166]}$.

Figure 22. Synthetic methods of PNCs: (a) in situ polymerisation, (b) melt intercalation and (c) solution casting ${ }^{[60]}$.

Figure 23. Tortuous paths in (a) conventional polymer composites and (b) polymer/layered silicate nanocomposites ${ }^{[8]}$.

Figure 24. Comparison of experimental data and predicted results for relative permeability of rubber/vermiculite composite membranes ${ }^{[196]}$.

Figure 25. Comparison between experimental data and theoretical results of relative permeability of (a) PVA/PEI-mGO composite films and (b) PVA/GO composite films ${ }^{[161]}$.

Figure 26. Comparison between experimental data and predicted results by Cussler model for the relative permeability of PVA/GON composite films ${ }^{[153]}$.

Figure 27. Effect of aspect ratios and volume fractions of nanofillers on relative permeability predicted by Nielsen's models ${ }^{[64]}$.

Figure 28. Comparison of predicted permeabilities by Nielsen model with experimental data (a) $\mathrm{O}_{2}$ in epoxy/MMT nanocomposites (b) $\mathrm{H}_{2} \mathrm{O}$ in poly(e-caprolactone)/MMT nanocomposites; (c) $\mathrm{CO}_{2}$ in butyl rubber/vermiculite nanocomposites; (d) $\mathrm{O}_{2}$ in PLA/MMT nanocomposites. Note: $K_{\text {comp }} / K_{m}$ is relative permeability of composites (i.e. $P_{\text {composites }} / P_{\text {matrice }}$ in Equation (8)) and $L / W$ is the aspect ratio ${ }^{[64]}$. 


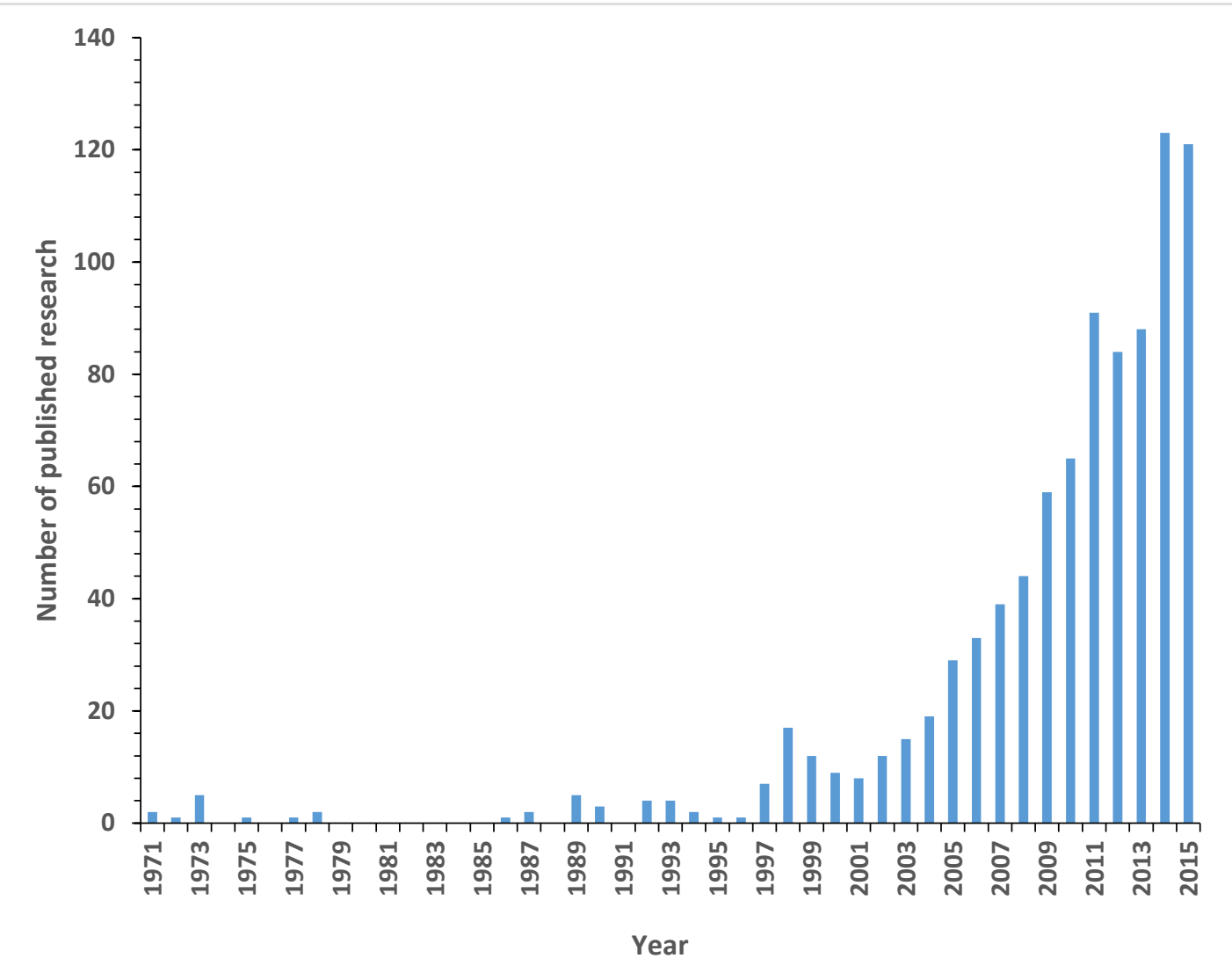

Figure 1. 


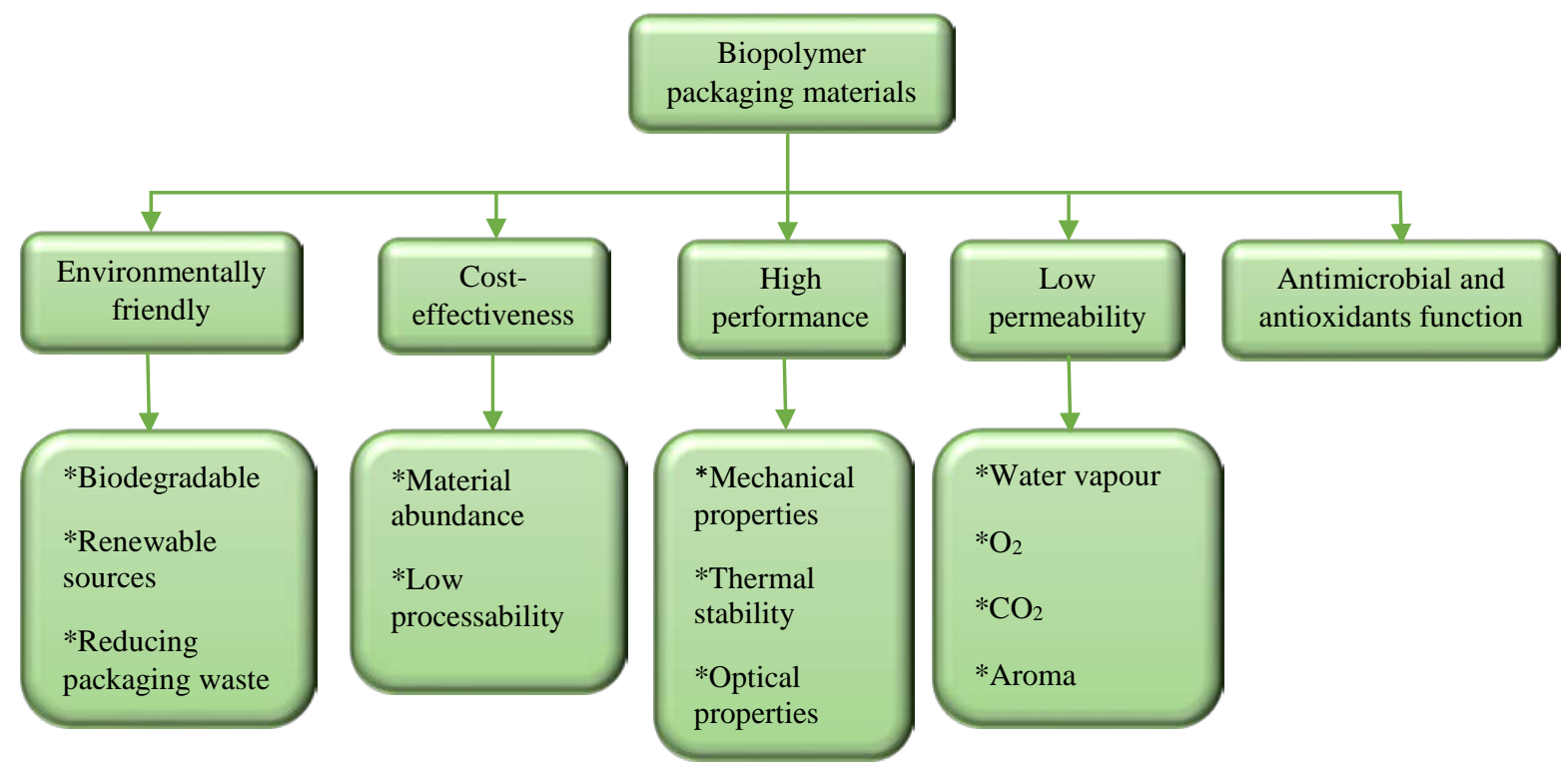

Figure 2. 


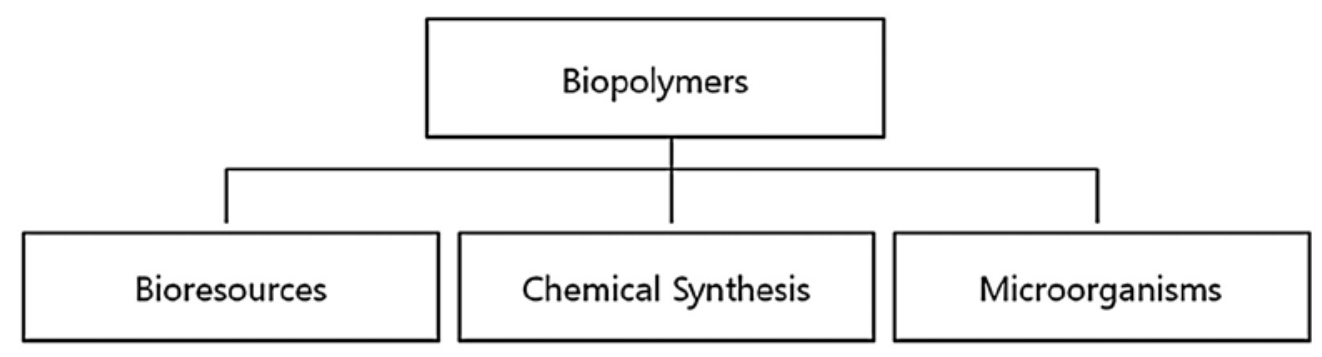

\begin{tabular}{|l|l|l|}
\hline - Protein & • from biomass & - polyester \\
SPI, WPI, cornzein, wheat & PLA & PHAs (PHB, PHBV) \\
gluten, gelatin etc. & - from petrochemicals & • carbohydrates \\
- Carbohydrates & PCL \\
starch, cellulose, chitosan, & PVA \\
agar, carrageenan etc. & PGA & \\
- Lipids & \\
wax, fatty acids. & \\
\hline
\end{tabular}

Figure 3. 
(A)

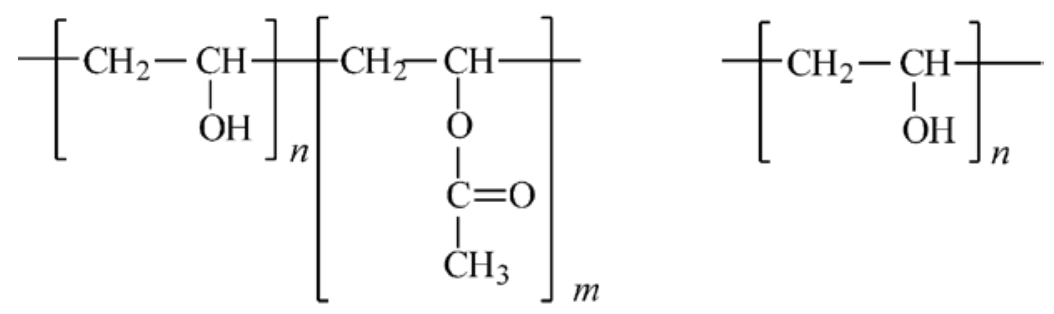

Figure 4. 


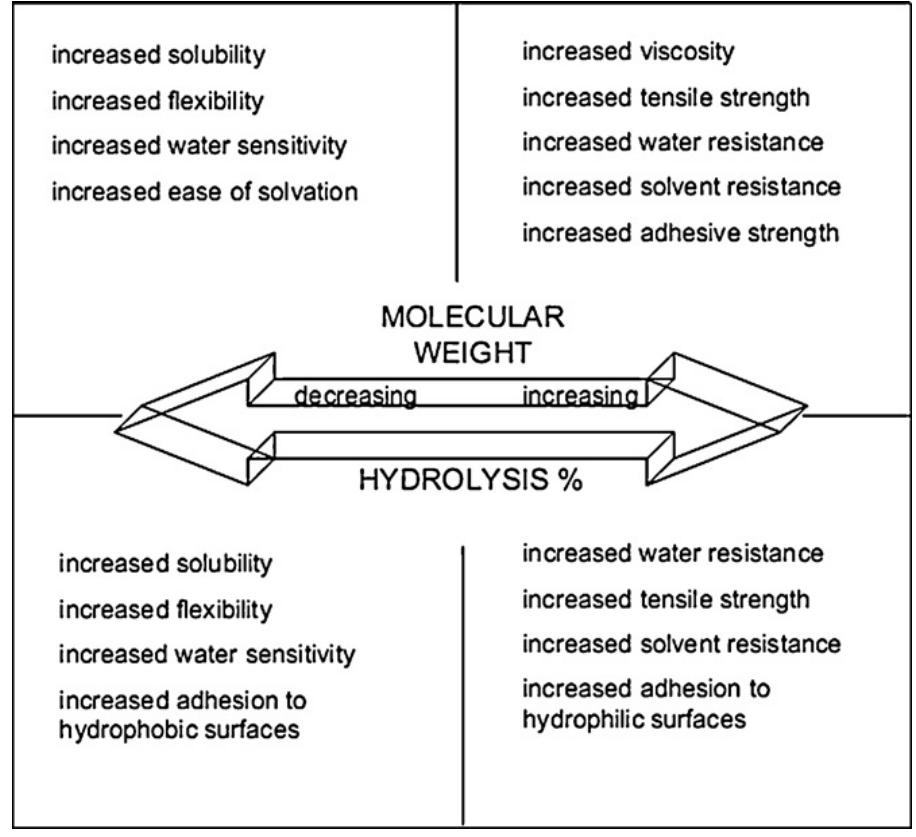

Figure 5. 


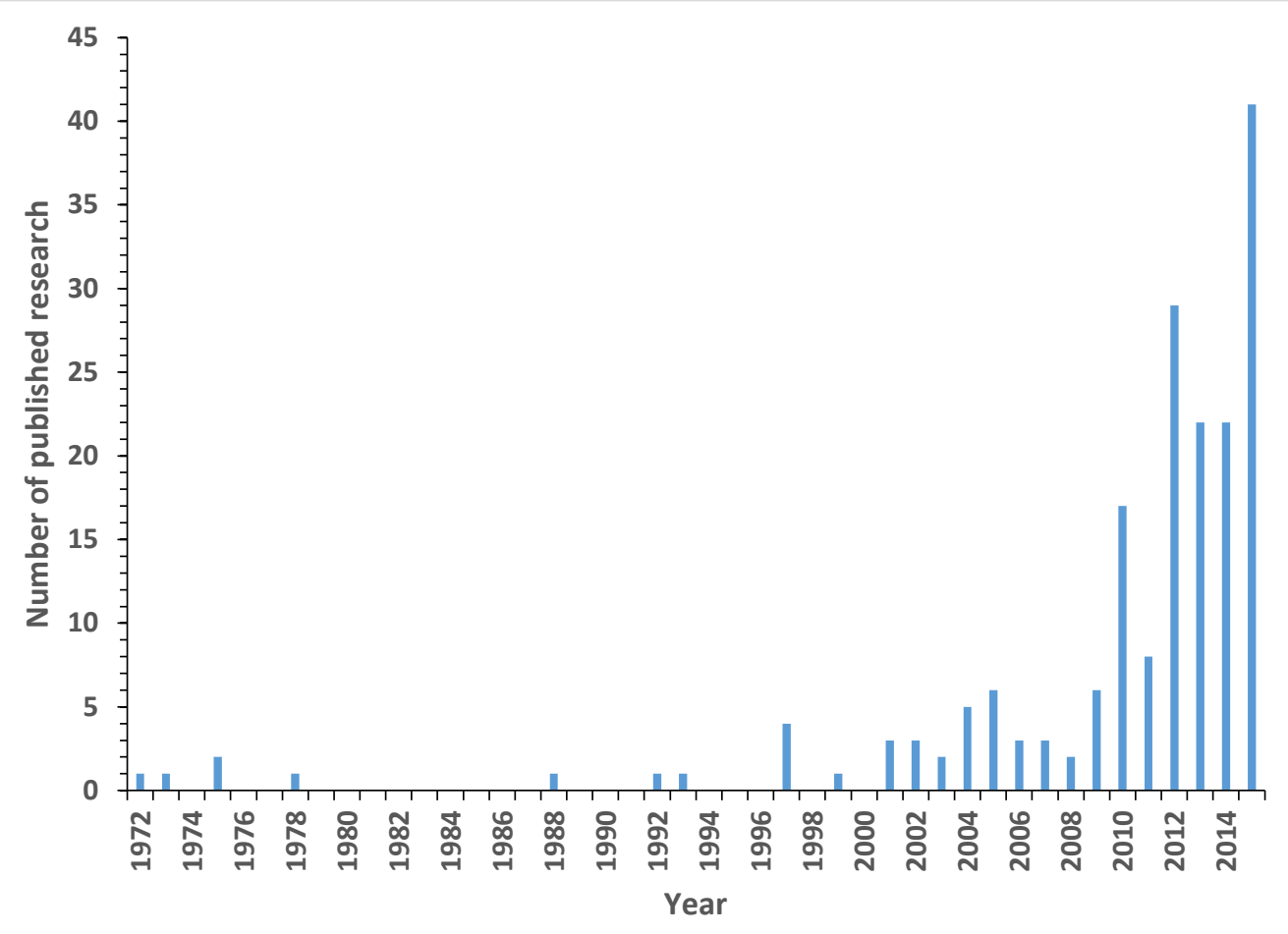

Figure 6. 


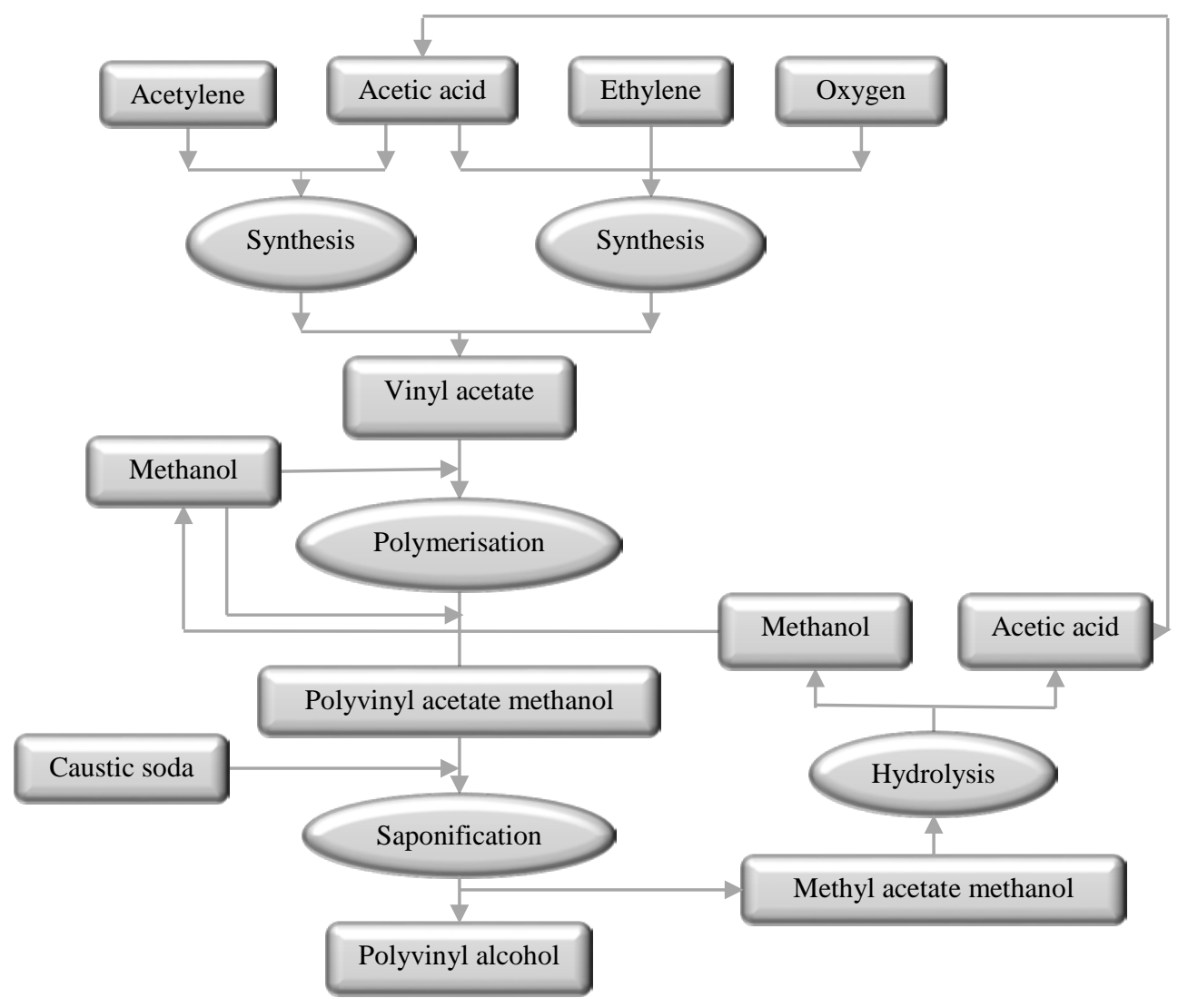

Figure 7. 

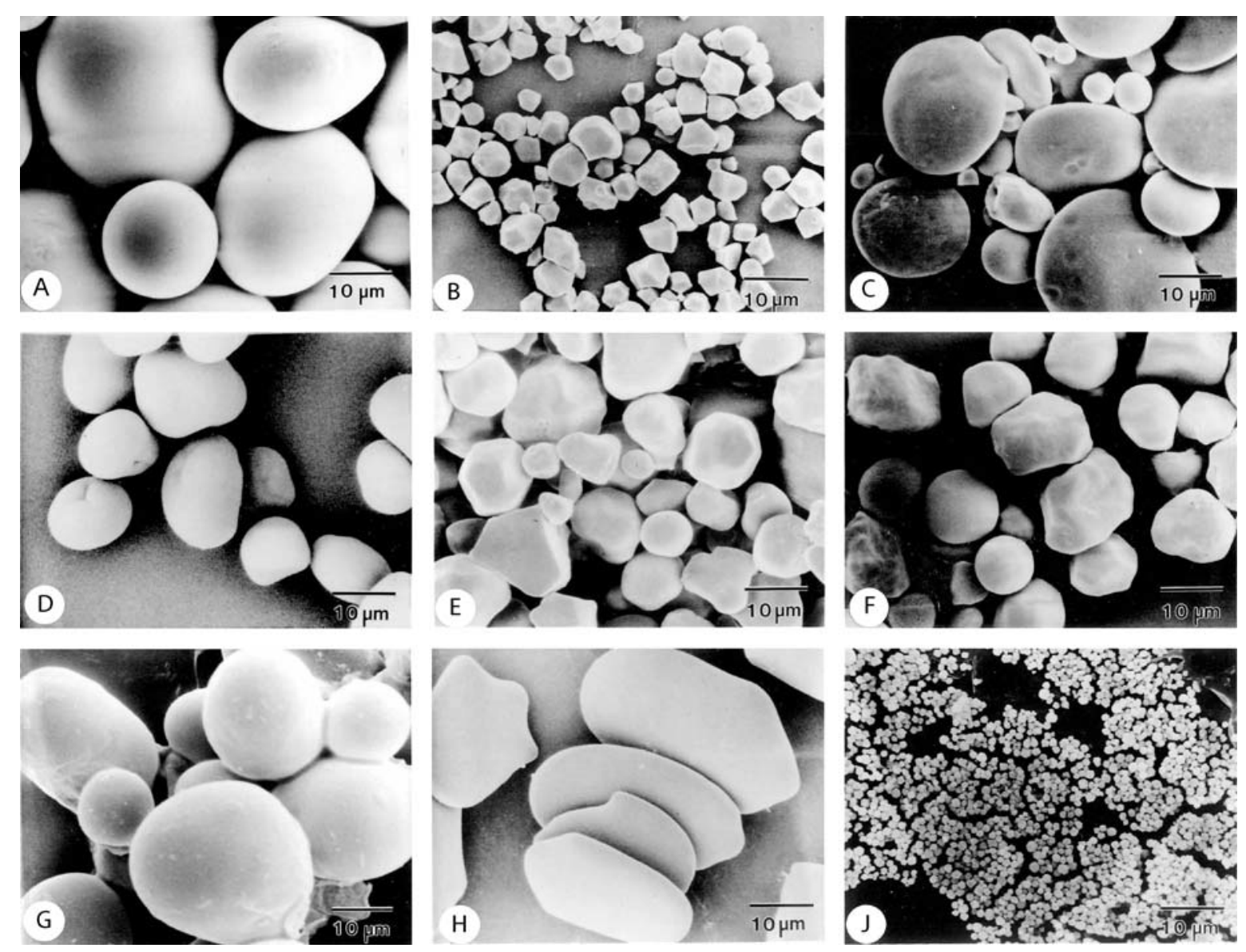

Figure 8. 

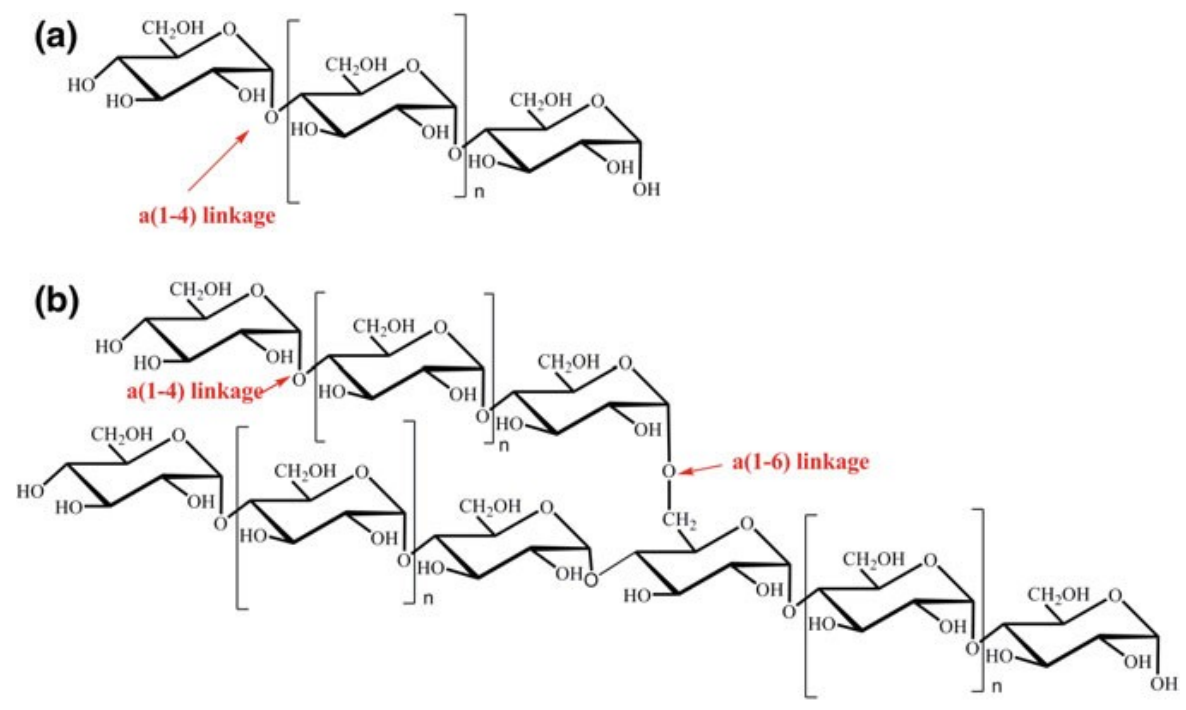

Figure 9. 


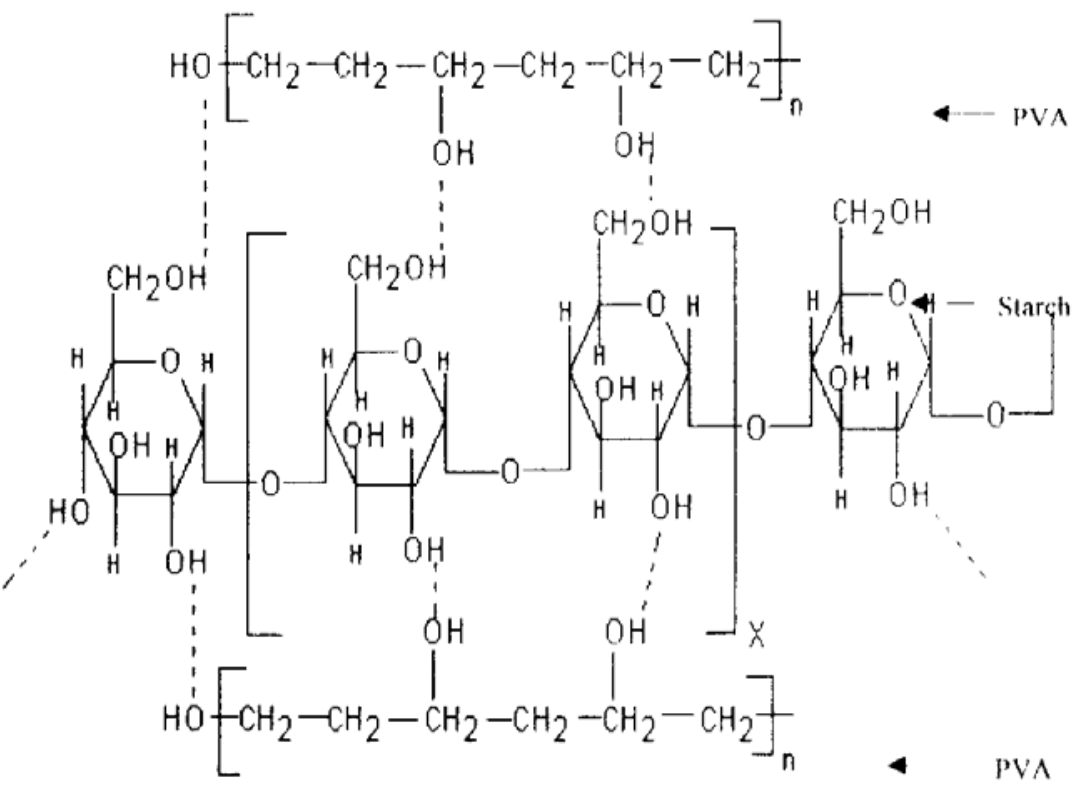

Figure 10. 

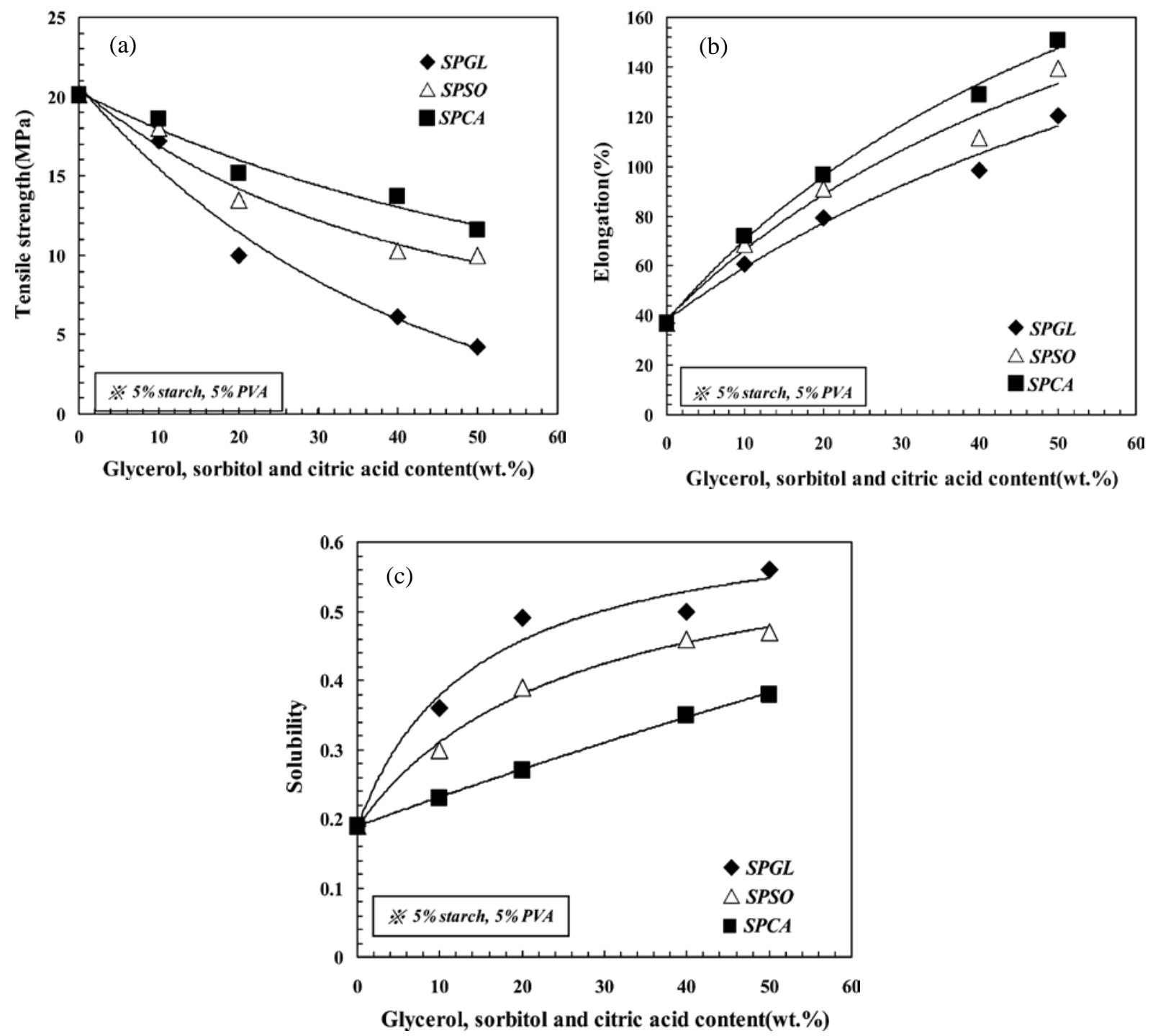

Figure 11. 

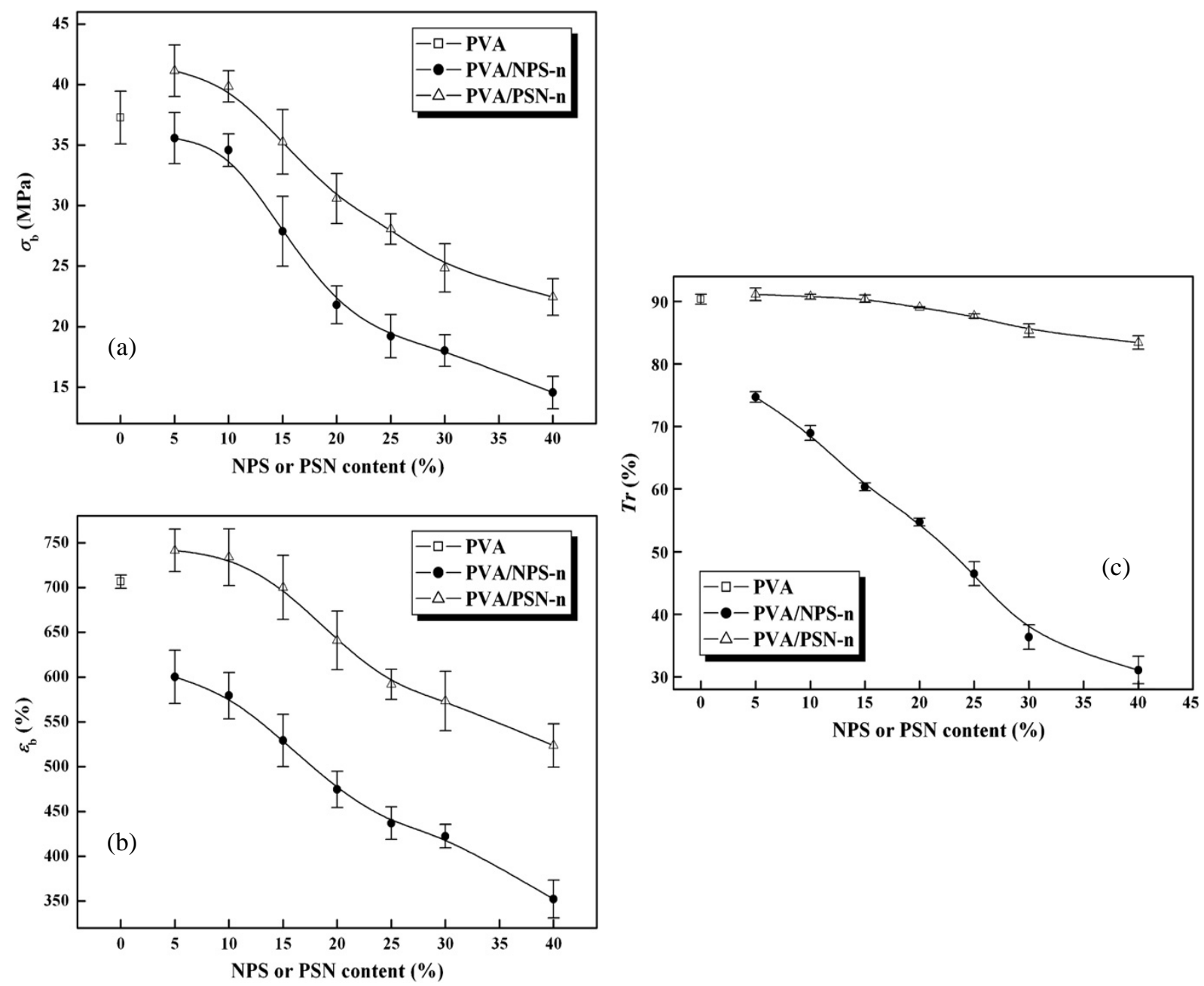

Figure 12. 


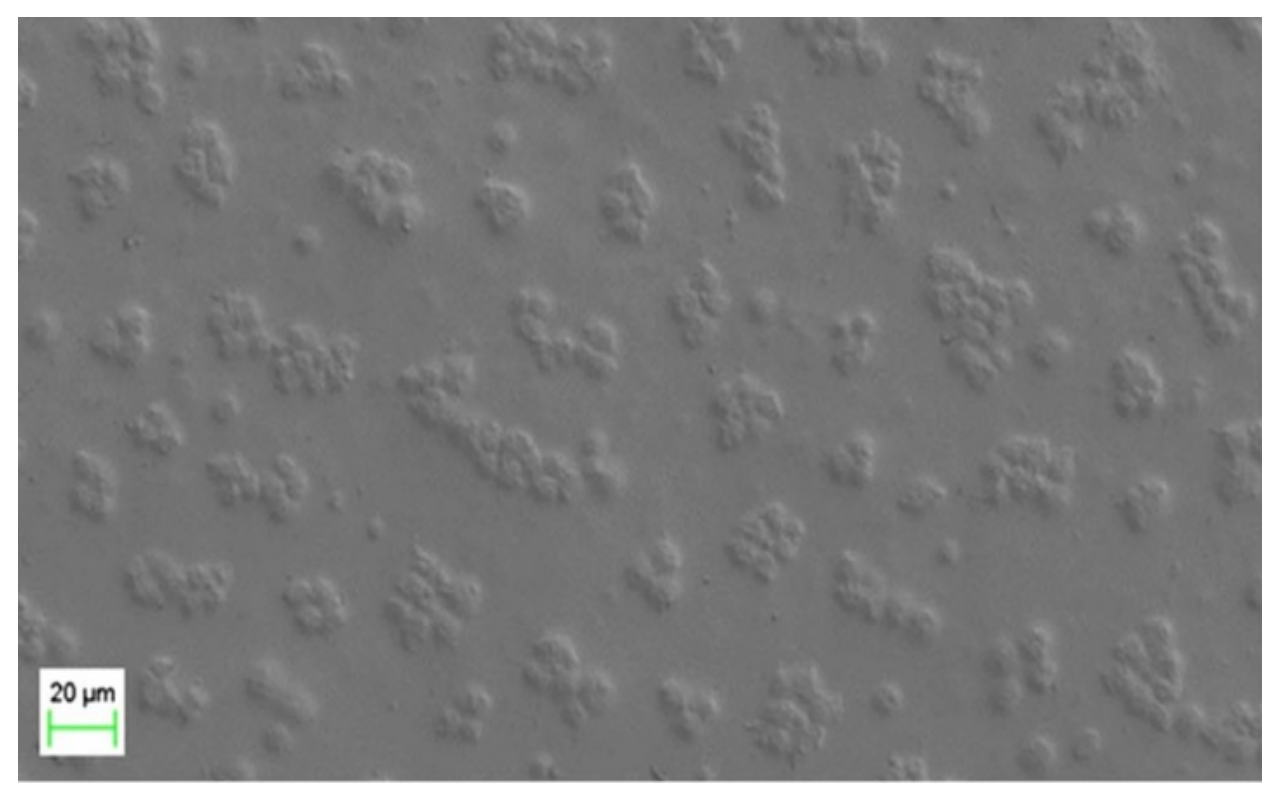

Figure 13. 

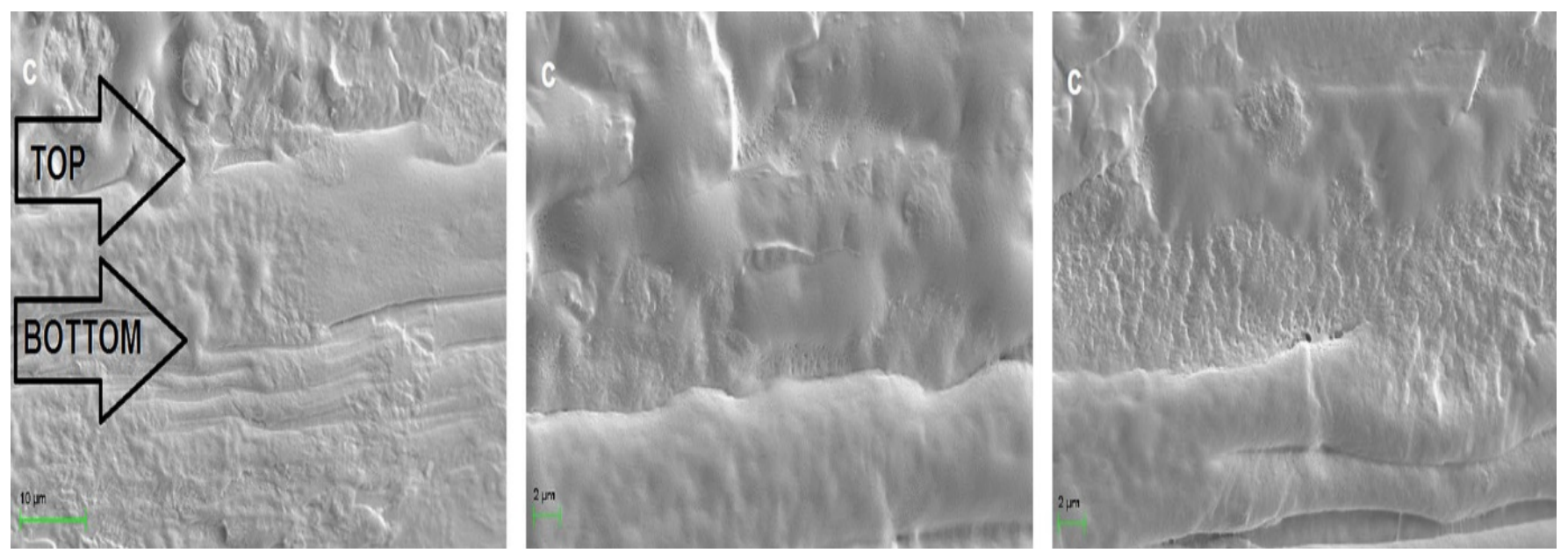

Figure 14. 


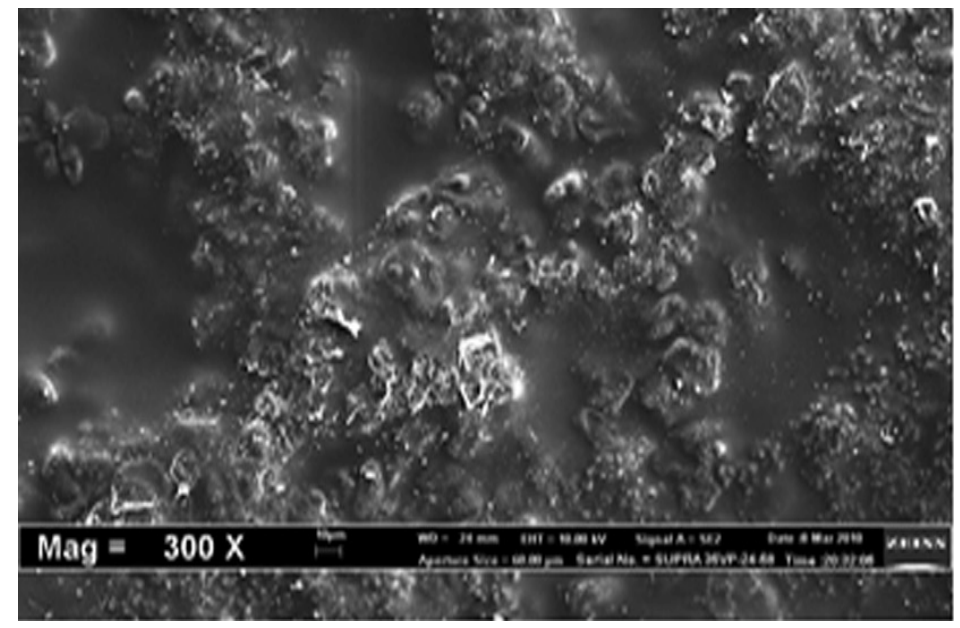

Figure 15. 

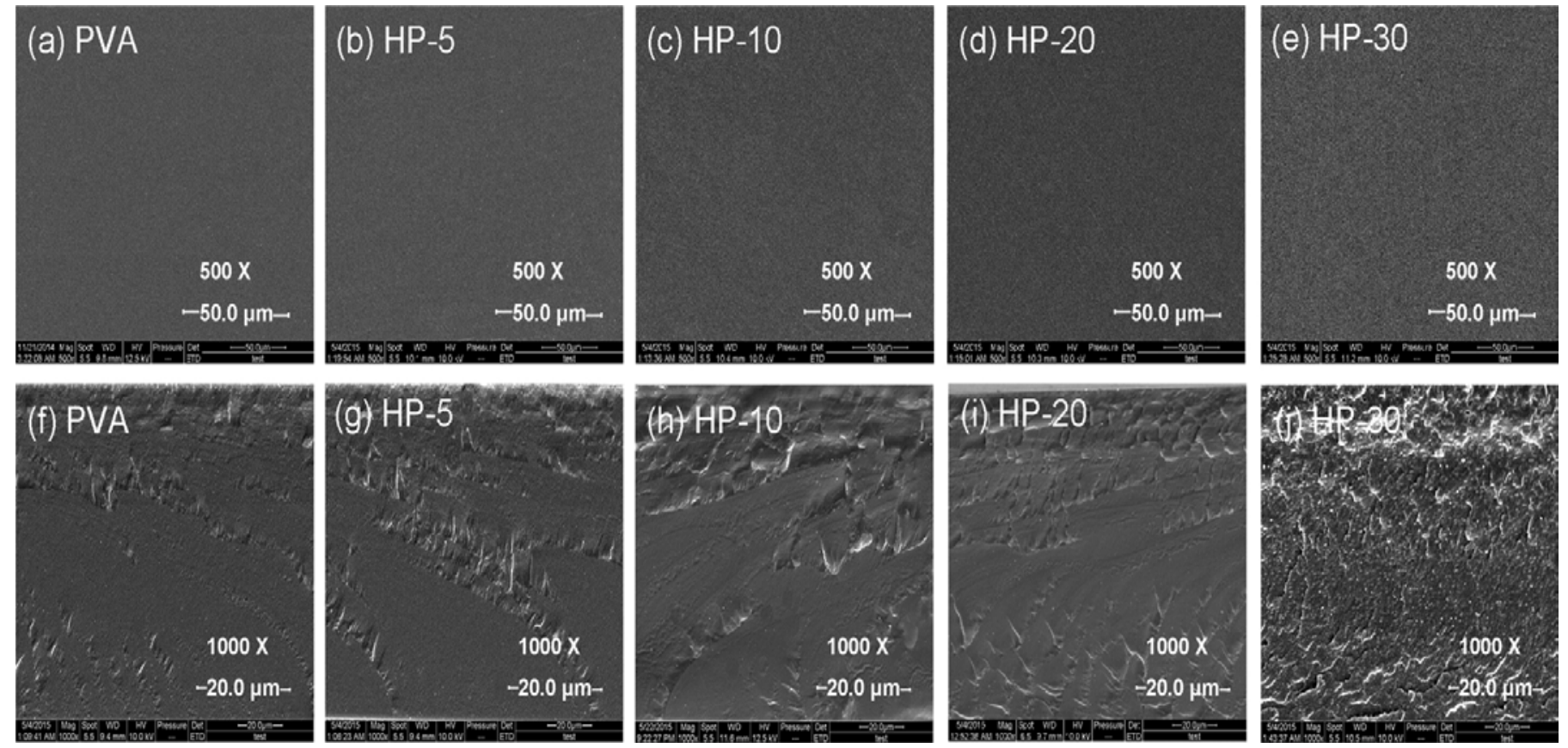

Figure 16. 


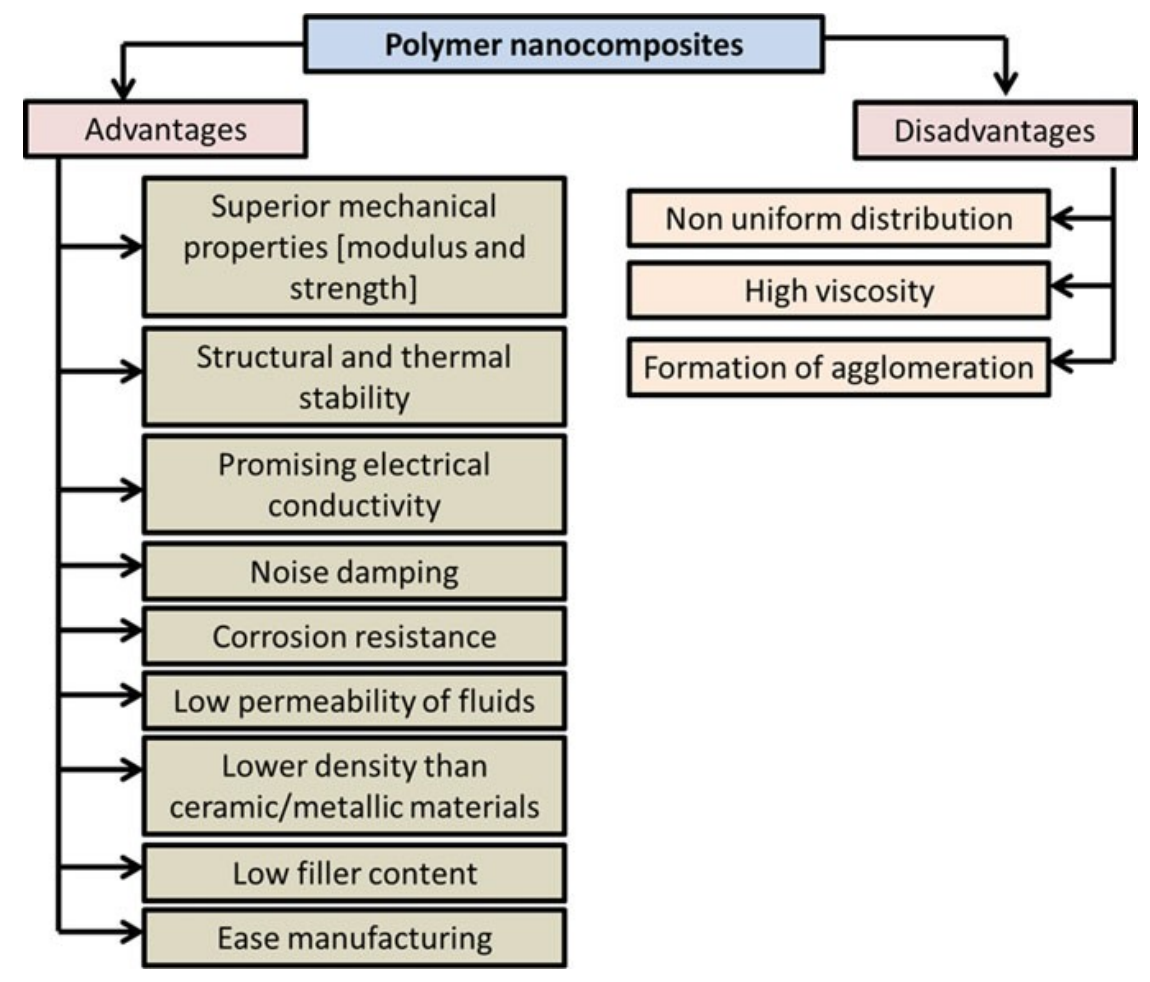

Figure 17. 


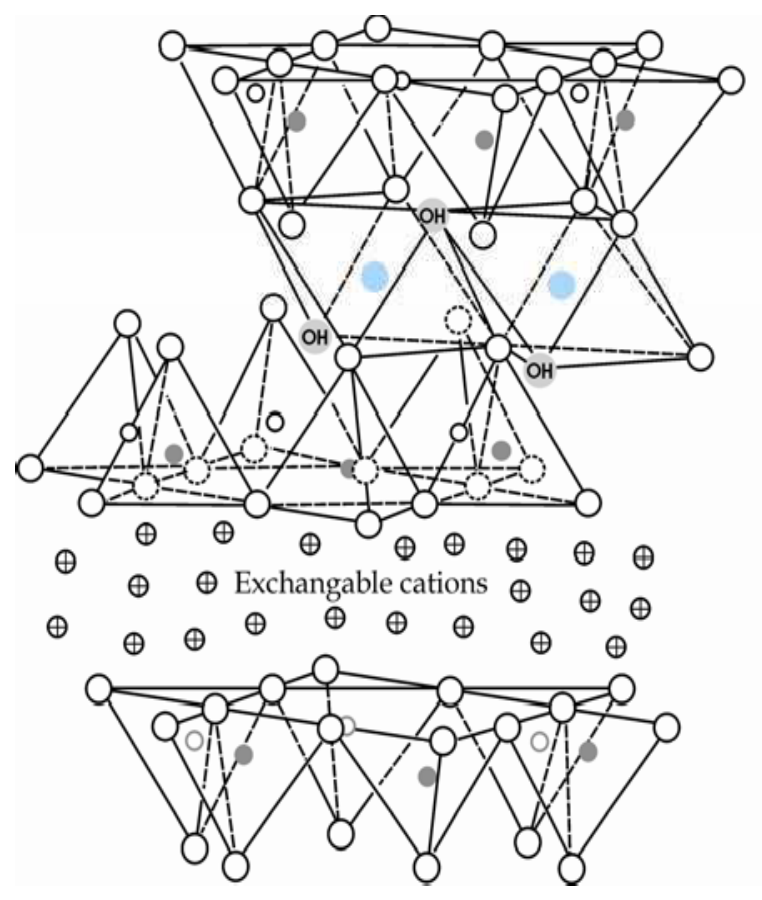

$\bigcirc$ Oxygen

- 0 Silicon(or occasionally Aluminiun

$\mathrm{OH}$ Hydroxyl group

Aluminium, iron magnesium etc

$\oplus$ Exchangable cations

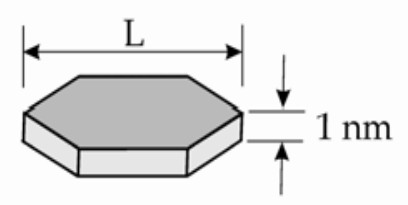

Figure 18. 


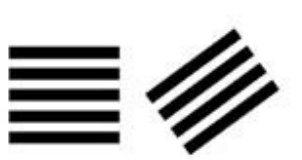

Layered silicate

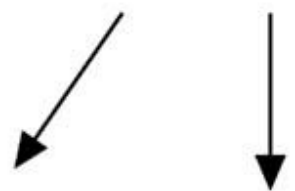

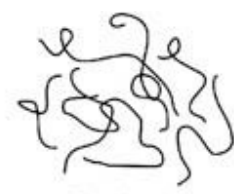

Polymer

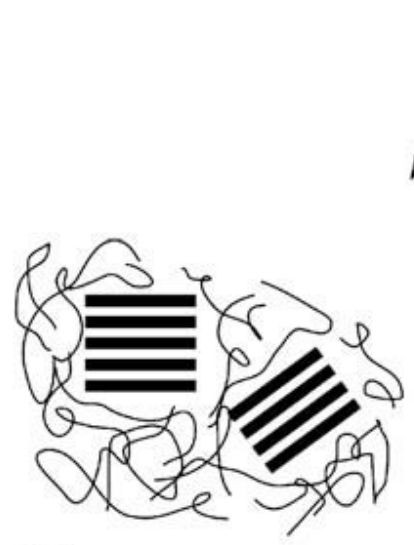

(a)

Phase separated (microcomposite)

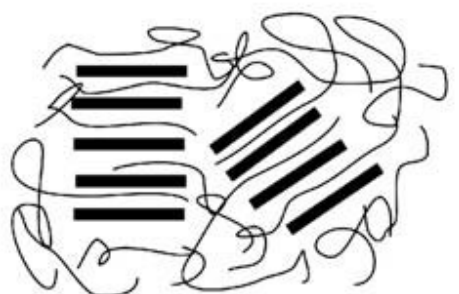

(b)

Intercalated (nanocomposite)

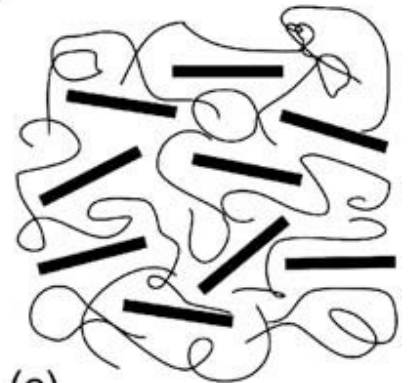

(c)

$$
\begin{gathered}
\text { Exfoliated } \\
\text { (nanocomposite) }
\end{gathered}
$$

Figure 19. 


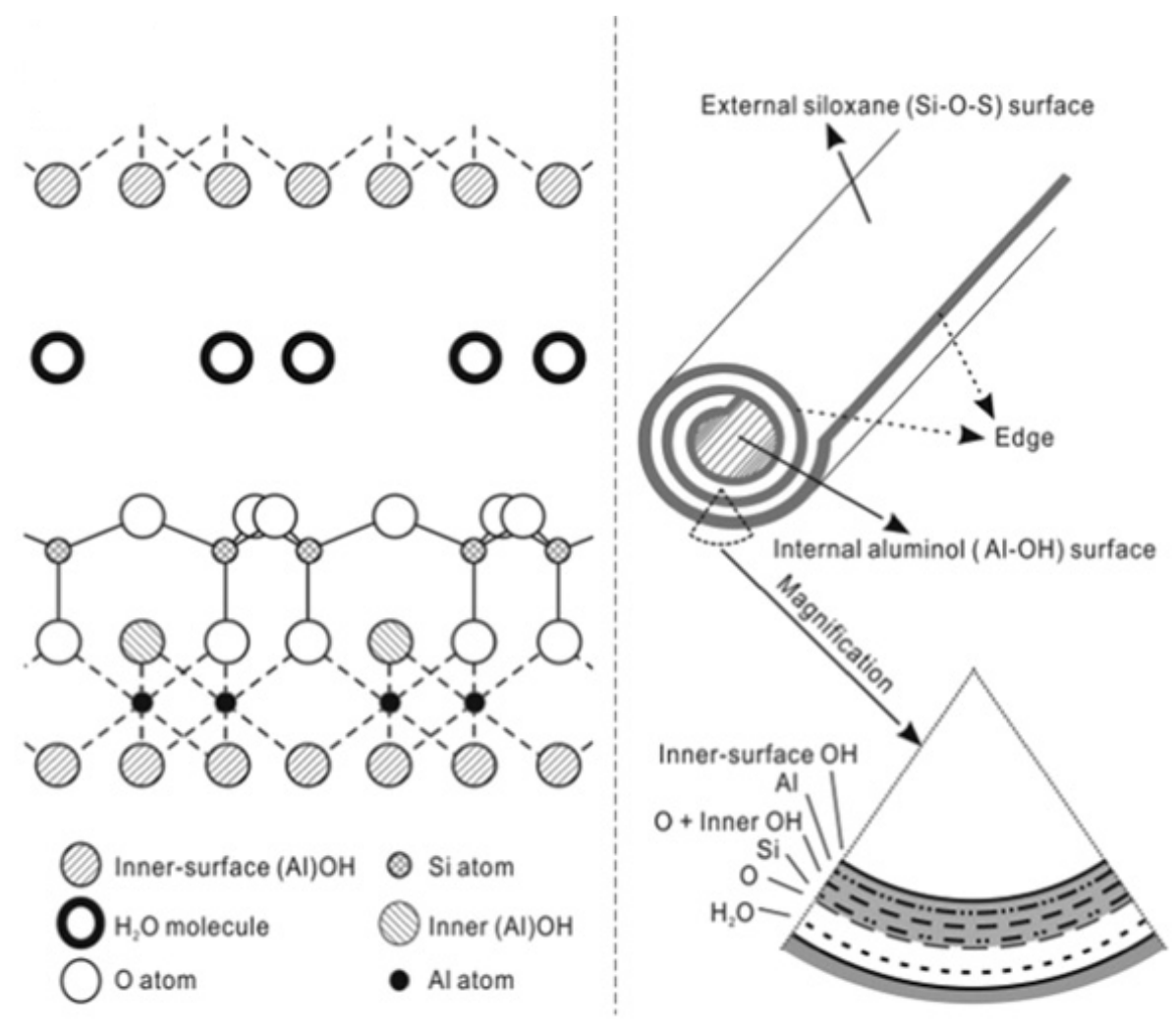

Figure 20. 

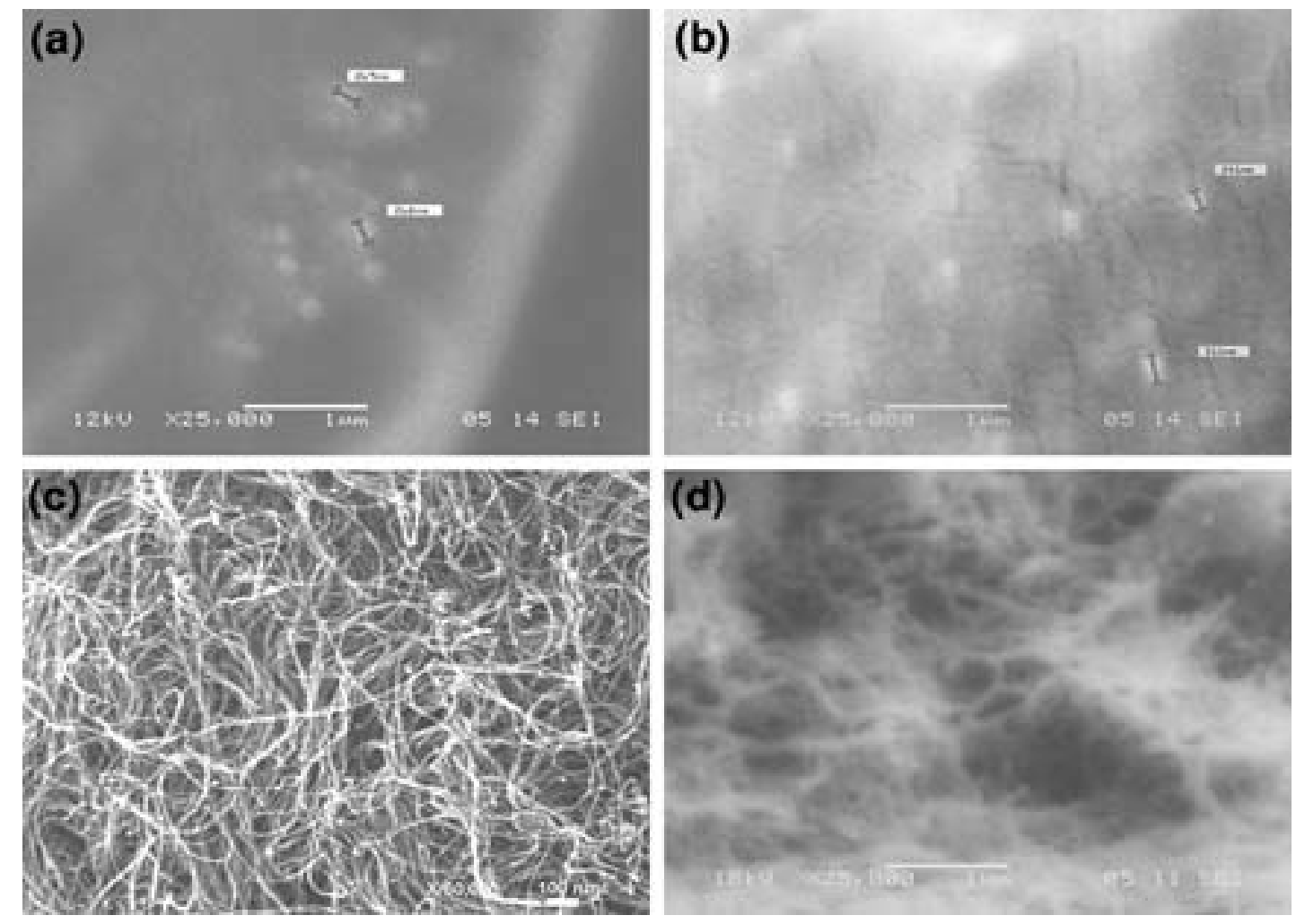

Figure 21. 
a)

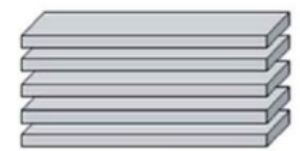

inorganic filler (tactoid)
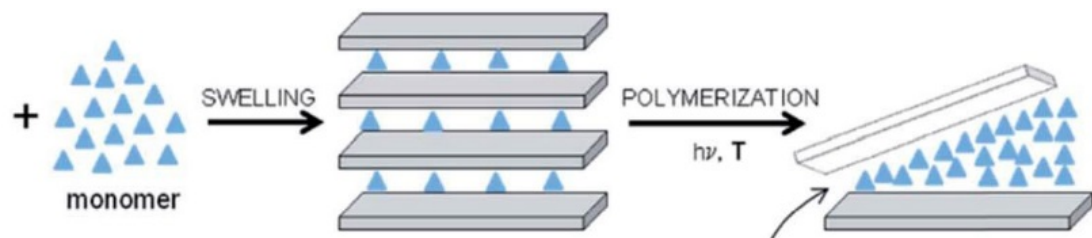

intercalated platelets
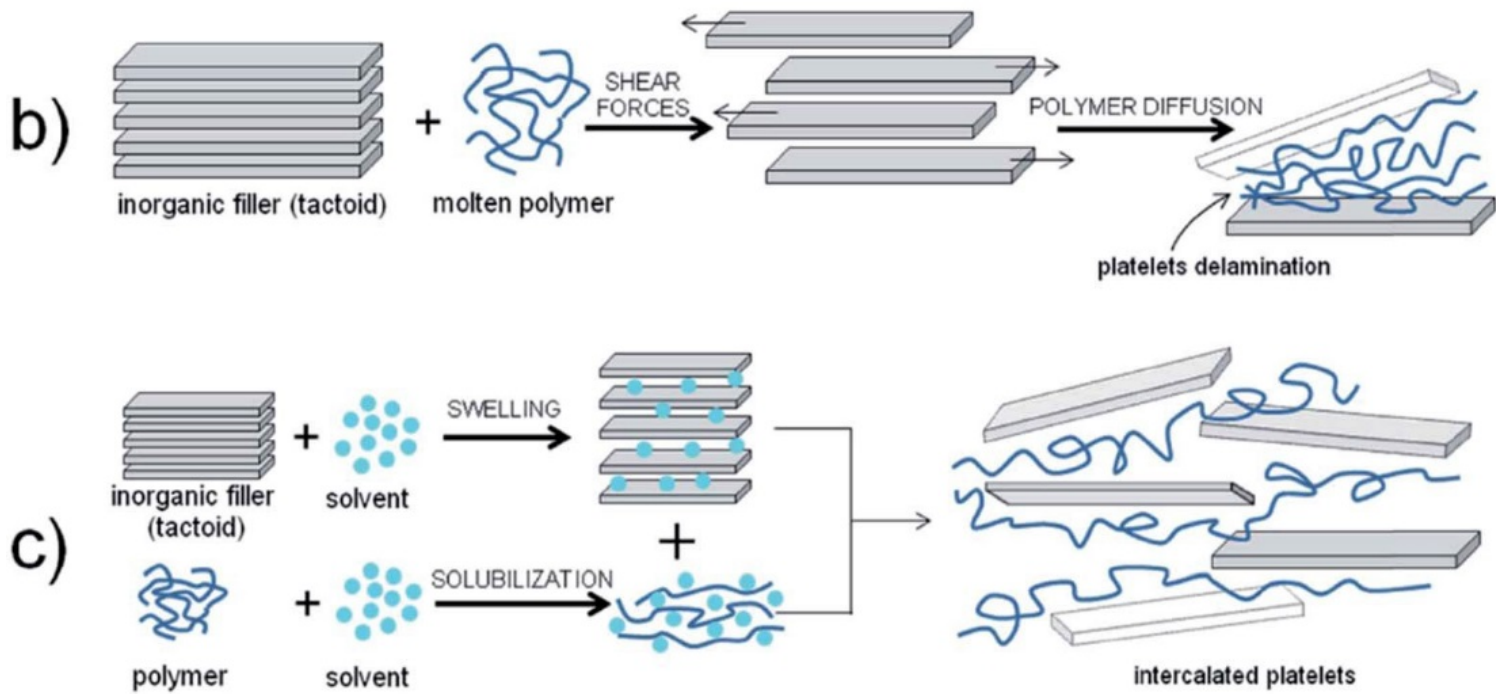

Figure 22. 


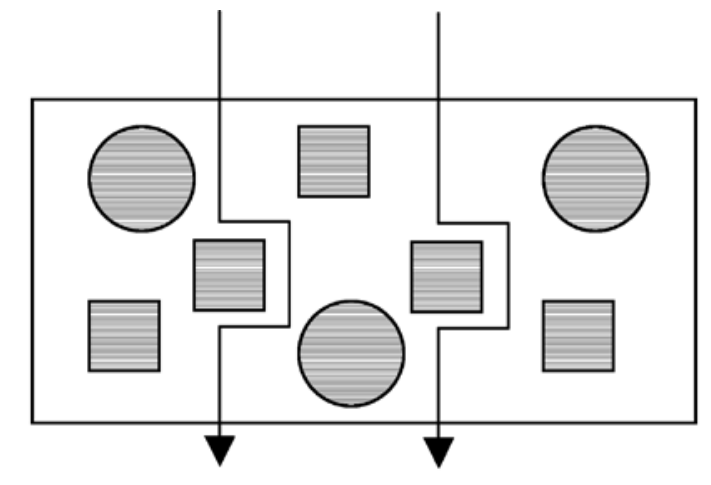

(a) Conventional filler reinforced composites

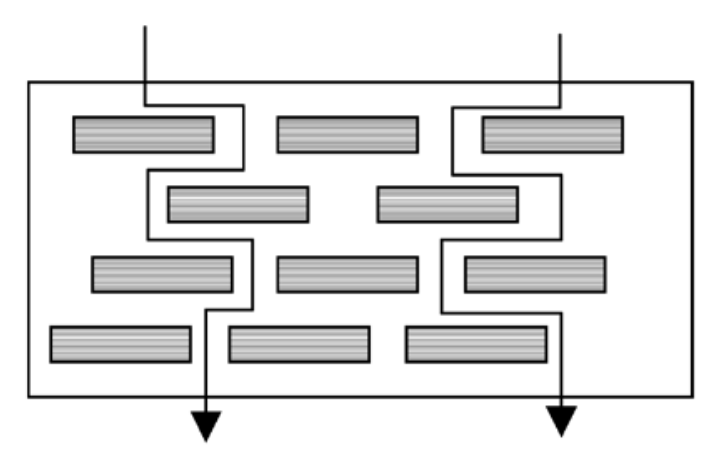

(b) Polymer/Layered silicate nanocomposite

Figure 23. 


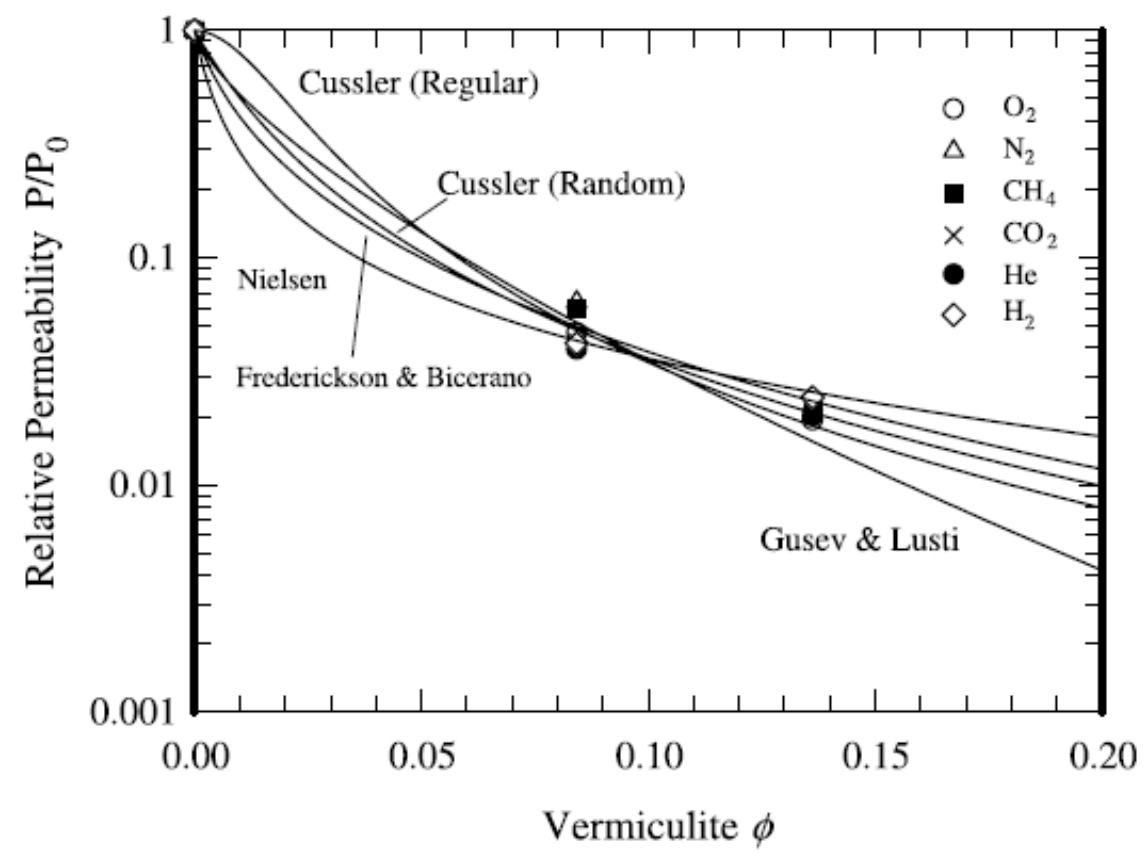

Figure 24. 

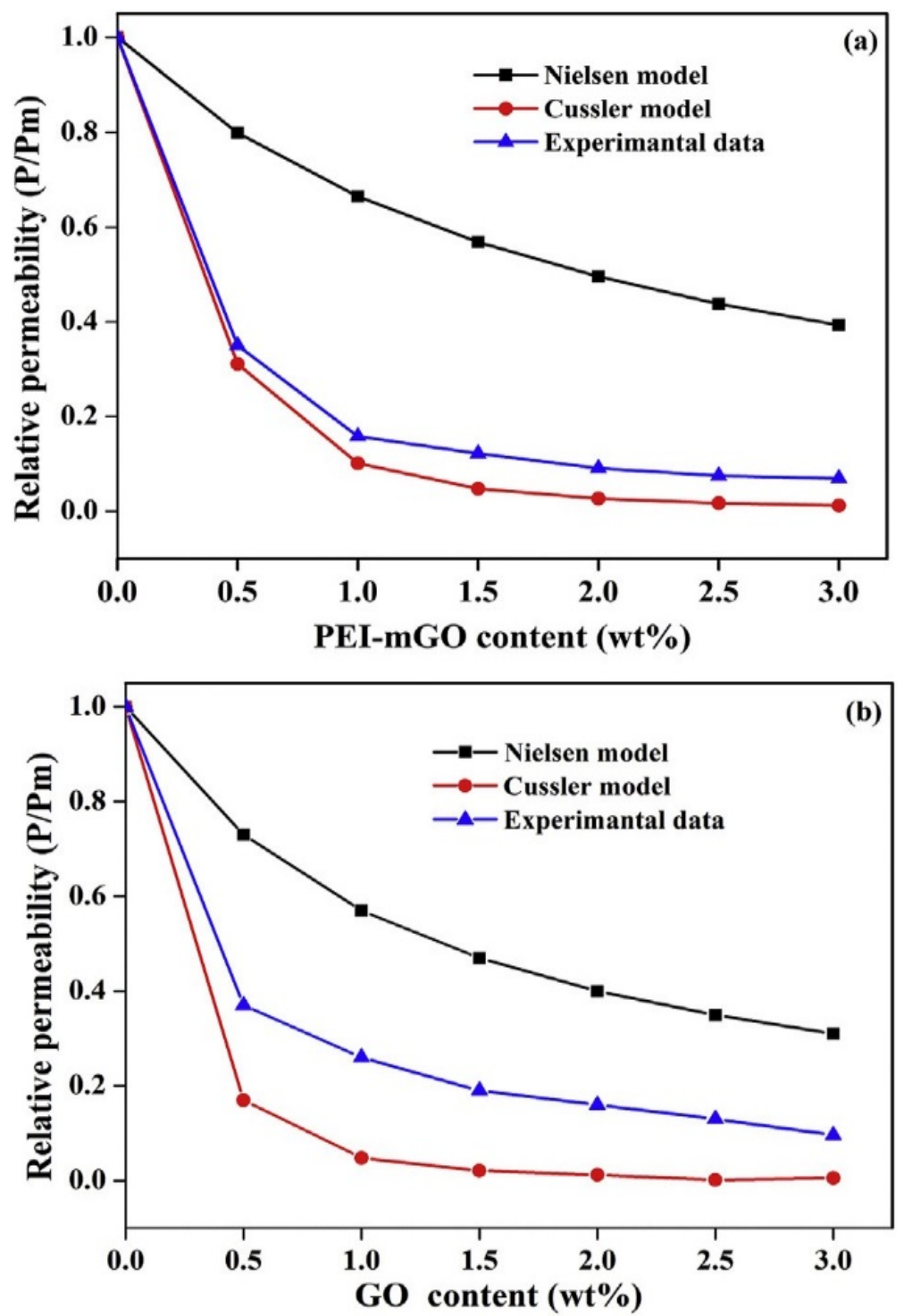

Figure 25. 


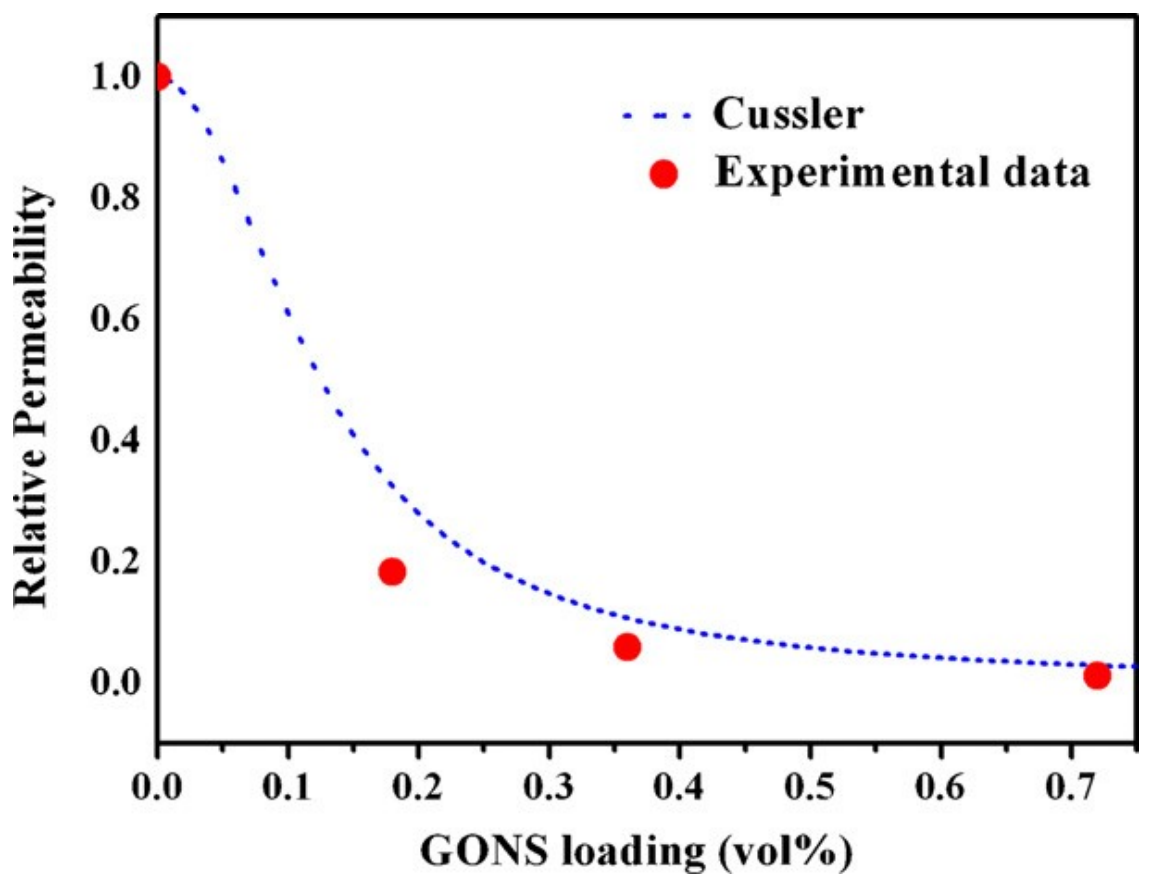

Figure 26. 


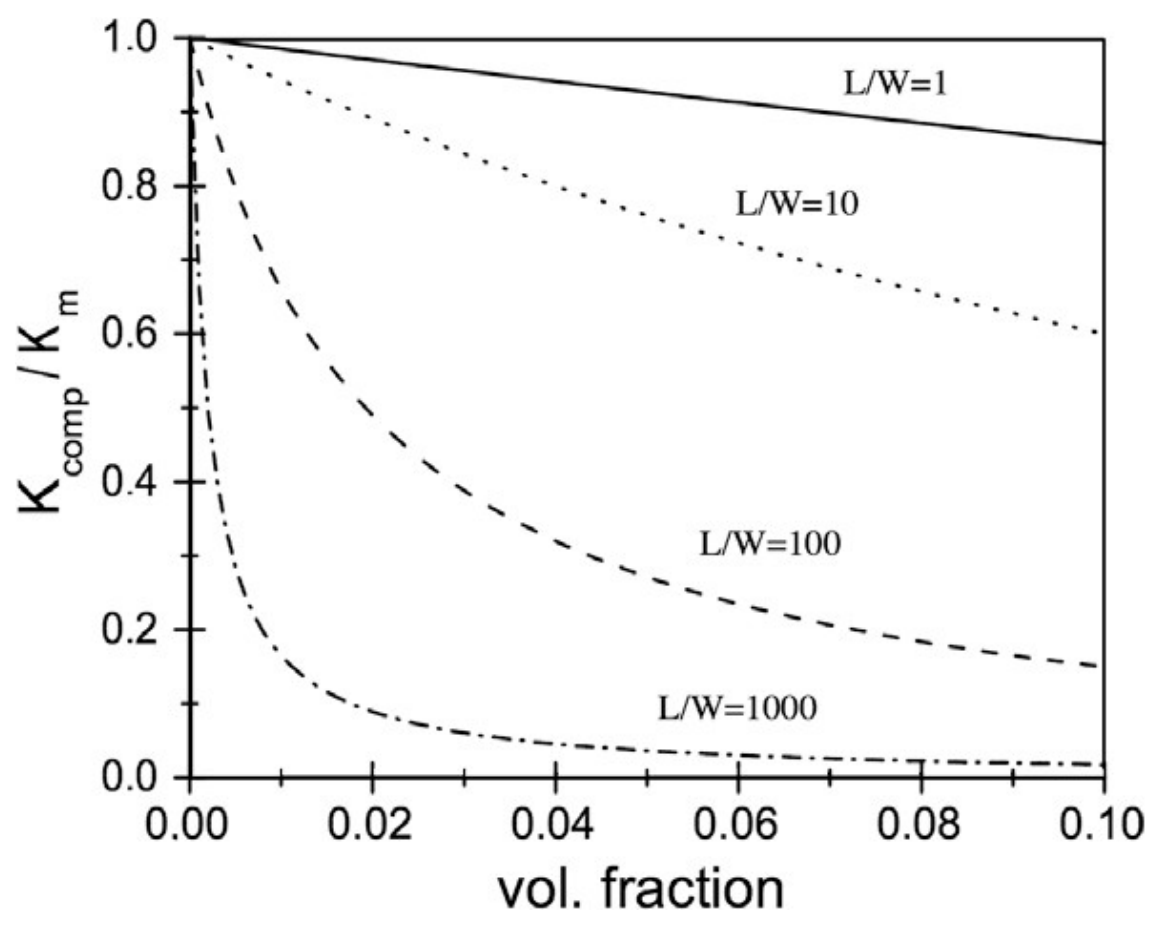

Figure 27. 

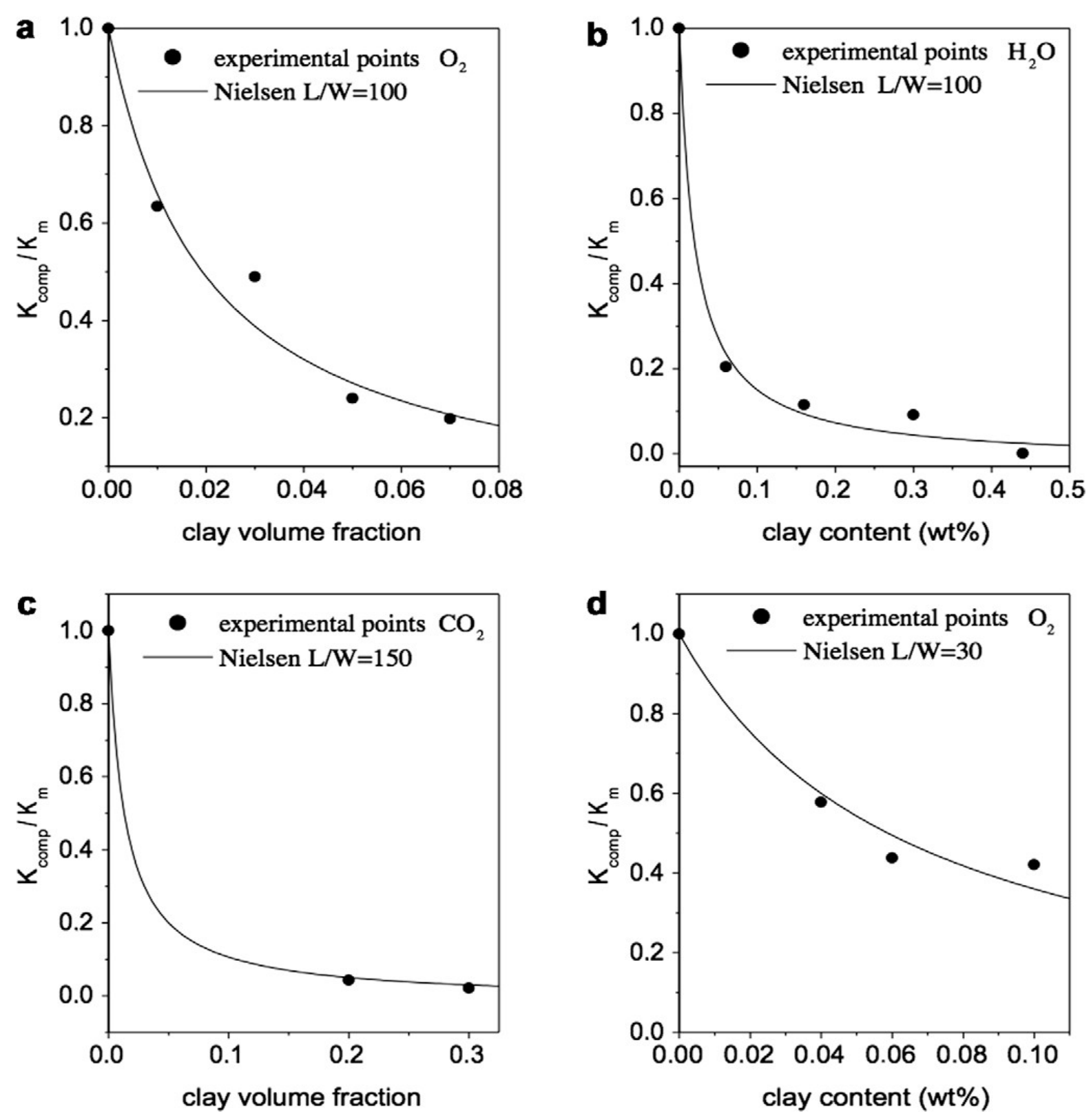

Figure 28. 
Table 1. PVA based packaging material systems with different plasticisers and processing methods

\begin{tabular}{|c|c|c|c|}
\hline Material & Processing method & Plasticisers & Ref. \\
\hline PVA/starch & Solution casting & $\begin{array}{l}\text { 1,4-butanediol, mannitol, } \\
\text { pentaerythritol, xylitol and } \\
\text { 1, 2, 6-hexanetriol }\end{array}$ & [33] \\
\hline PVA & Solution casting & Glycerine & [47] \\
\hline $\mathrm{PVA} / \mathrm{Na}^{+} \mathrm{MMT}$ & Melt extrusion & Polyol & [145] \\
\hline PVA/starch & Solution casting & Glycerol, glutaraldehyde & {$[106]$} \\
\hline PVA/starch & Solution casting & Glycerine, urea & {$[45,74]$} \\
\hline PVA/PLA/chitosan & Hot pressing & Glycerol & [79] \\
\hline $\begin{array}{l}\text { PVA/poly (ethylene-oxide) } \\
\text { (PEO)/CMC }\end{array}$ & Solution casting & & [79] \\
\hline PVA/starch & Twin-screw extrusion & Glycerol & [44] \\
\hline PVA/chitosan/Cloisite (C30B) & Solution casting & & [107] \\
\hline PVA/PLA & Twin screw extrusion & Glycerol & [115] \\
\hline PVA/chitosan & Solution casting & & {$[77,111]$} \\
\hline PVA/graphene nanosheets & Solution casting & & [133] \\
\hline PVA/PEO & Solution casting & & [120] \\
\hline $\begin{array}{l}\text { PVA/halloysite nanotubes } \\
\text { (HNTs)/ cellulose nanocrystals } \\
\text { (CNC) }\end{array}$ & Solution casting & & [171] \\
\hline PVA/starch & Solution casting & Glycerol & $\begin{array}{l}{[36,44,61,} \\
70,131,103, \\
125,136,135, \\
199]\end{array}$ \\
\hline $\mathrm{PVA} / \mathrm{starch}$ & Solution casting & Glutaraldehyde & {$[123,200]$} \\
\hline $\mathrm{PVA} / \mathrm{starch}$ & $\begin{array}{l}\text { Single screw } \\
\text { extrusion }\end{array}$ & Glycerol & {$[32,92,126]$} \\
\hline $\mathrm{PVA} /$ starch/graphene & Solution casting & Glycerol & [93] \\
\hline PVA/cellulose nanofibres & Solution casting & & [173] \\
\hline
\end{tabular}


Table 2. Mechanical properties of PVA nanocomposite films for packaging applications

\begin{tabular}{|c|c|c|c|c|c|c|}
\hline Matrix & Filler type & $\begin{array}{c}\text { Filler } \\
\text { content (\%) }\end{array}$ & $\begin{array}{c}\text { Tensile } \\
\text { strength } \\
(\mathrm{MPa})\end{array}$ & $\begin{array}{c}\text { Young's } \\
\text { modulus } \\
(\mathrm{GPa})\end{array}$ & $\begin{array}{c}\text { Elongation } \\
\text { at break } \\
(\%)\end{array}$ & Ref. \\
\hline PVA & CNWs & $\begin{array}{c}3 \\
6 \\
9 \\
12\end{array}$ & $\begin{array}{l}124 \\
120 \\
110 \\
129\end{array}$ & $\begin{array}{c}2.25 \\
2.35 \\
2.4 \\
2.7\end{array}$ & $\begin{array}{l}14 \\
18 \\
10 \\
13\end{array}$ & [48] \\
\hline \multirow{3}{*}{ PVA } & Chitosan & $\begin{array}{c}0 \\
10 \\
20 \\
30\end{array}$ & $\begin{array}{c}13.5 \\
85.11 \\
62.41 \\
64.93\end{array}$ & $\begin{array}{l}1.623 \\
2.812 \\
2.109 \\
1.822\end{array}$ & $\begin{array}{c}36.8 \\
11.35 \\
15.26 \\
20.09\end{array}$ & \multirow{3}{*}{ [52] } \\
\hline & Chitosan/ $\mathrm{Na}^{+} \mathrm{MMT}$ & $\begin{array}{l}10 / 5 \\
20 / 5 \\
30 / 5\end{array}$ & $\begin{array}{c}122.66 \\
93.54 \\
83.22\end{array}$ & $\begin{array}{l}3.816 \\
3.239 \\
2.299\end{array}$ & $\begin{array}{c}6.43 \\
6.30 \\
16.13\end{array}$ & \\
\hline & Chitosan/OrgMMT & $\begin{array}{l}10 / 5 \\
20 / 5 \\
30 / 5\end{array}$ & $\begin{array}{c}102.02 \\
74.77 \\
82.40\end{array}$ & $\begin{array}{l}3.473 \\
2.289 \\
2.356\end{array}$ & $\begin{array}{c}8.55 \\
7.40 \\
15.10\end{array}$ & \\
\hline PVA/starch & Graphene & $\begin{array}{c}0 \\
0.25 \\
0.5 \\
0.75 \\
1\end{array}$ & $\begin{array}{c}6.67 \\
6.70 \\
10.04 \\
7.95 \\
7.75\end{array}$ & $\begin{array}{l}0.024 \\
0.029 \\
0.053 \\
0.054 \\
0.046\end{array}$ & $\begin{array}{l}27.5 \\
49.6 \\
57.2 \\
46.1 \\
38.9\end{array}$ & [135] \\
\hline PVA/starch & Graphene & $\begin{array}{c}0 \\
0.25 \\
0.5 \\
1.0\end{array}$ & $\begin{array}{l}8.2 \\
8.7 \\
9.3 \\
9.1\end{array}$ & $\begin{array}{c}0.170 \\
0.1794 \\
0.2001 \\
0.1981\end{array}$ & $\begin{array}{l}19.1 \\
21.7 \\
67.3 \\
25.8\end{array}$ & {$[93]$} \\
\hline PVA/chitosan & HNTs & $\begin{array}{c}0.25 \\
0.5 \\
1 \\
3 \\
5\end{array}$ & $\begin{array}{l}42 \\
53 \\
39 \\
31 \\
29\end{array}$ & $\begin{array}{l}1.231 \\
1.425 \\
1.547 \\
1.721 \\
1.812\end{array}$ & $\begin{array}{l}61 \\
52 \\
41 \\
39 \\
30\end{array}$ & [110] \\
\hline PVA & GOs & $\begin{array}{c}0 \\
0.3 \\
0.7 \\
1.0 \\
1.5 \\
2\end{array}$ & $\begin{array}{l}25.4 \\
37.9 \\
32.5 \\
31.5 \\
31.6 \\
37.8\end{array}$ & $\begin{array}{l}0.027 \\
0.037 \\
0.046 \\
0.053 \\
0.068 \\
0.067\end{array}$ & $\begin{array}{l}260 \\
317 \\
286 \\
274 \\
260 \\
294\end{array}$ & [158] \\
\hline \multirow{3}{*}{ PVA } & GOs & $\begin{array}{l}1 \\
5\end{array}$ & $\begin{array}{l}44.6 \\
49.7\end{array}$ & $\begin{array}{l}0.86 \\
0.94\end{array}$ & $\begin{array}{c}458 \\
95\end{array}$ & \multirow{3}{*}{ [162] } \\
\hline & MMTs & $\begin{array}{l}1 \\
5\end{array}$ & $\begin{array}{l}28.3 \\
30.5\end{array}$ & $\begin{array}{l}0.41 \\
0.47\end{array}$ & $\begin{array}{c}103 \\
67\end{array}$ & \\
\hline & GO-MMTs & $\begin{array}{l}1 \\
5\end{array}$ & $\begin{array}{l}68.3 \\
80.7\end{array}$ & $\begin{array}{l}1.27 \\
1.44\end{array}$ & $\begin{array}{c}122 \\
90\end{array}$ & \\
\hline PVA & SWCNTs & $\begin{array}{c}0 \\
0.3 \\
0.6 \\
0.8\end{array}$ & $\begin{array}{c}74 \\
92 \\
103 \\
107\end{array}$ & $\begin{array}{l}2.4 \\
3.1 \\
3.8 \\
4.3\end{array}$ & & [165] \\
\hline
\end{tabular}




\begin{tabular}{|c|c|c|c|c|c|c|}
\hline \multirow{3}{*}{ PVA } & & 0 & 20.6 & 1.80 & & \multirow{3}{*}{ [169] } \\
\hline & DWCNTs & 0.5 & 30.5 & 4.79 & & \\
\hline & MWCNTs & $\begin{array}{l}1 \\
5\end{array}$ & $\begin{array}{l}40.2 \\
30.1\end{array}$ & $\begin{array}{l}10.4 \\
1.22\end{array}$ & & \\
\hline PVA & CNFs & $\begin{array}{l}0 \\
5\end{array}$ & $\begin{array}{c}32.38 \\
33.7\end{array}$ & $\begin{array}{l}0.254 \\
0.536\end{array}$ & $\begin{array}{l}141.80 \\
149.71\end{array}$ & [173] \\
\hline PVA & HNTs & $\begin{array}{c}0 \\
5 \\
10 \\
20\end{array}$ & $\begin{array}{c}34.4^{\mathrm{a}} \\
29.1 \\
27.7 \\
22.0\end{array}$ & $\begin{array}{l}0.245 \\
0.286 \\
0.388 \\
0.466\end{array}$ & $\begin{array}{l}336 \\
297 \\
268 \\
159\end{array}$ & [176] \\
\hline PVA & CNFs & $\begin{array}{c}0 \\
3 \\
5 \\
8 \\
10 \\
15 \\
40 \\
60\end{array}$ & $\begin{array}{l}29.7 \\
35.6 \\
38.4 \\
42.4 \\
44.2 \\
42.9 \\
51.9 \\
55.6\end{array}$ & $\begin{array}{l}0.164 \\
0.228 \\
0.378 \\
0.442 \\
0.476 \\
0.509 \\
0.876 \\
1.022\end{array}$ & $\begin{array}{c}247.8 \\
280.7 \\
255.5 \\
148.8 \\
134.8 \\
51.8 \\
28.5 \\
19.1\end{array}$ & [178] \\
\hline
\end{tabular}

${ }^{a}$ : Tensile strength at fracture 
Table 3. Permeability of PVA systems for packaging applications

\begin{tabular}{|c|c|c|c|c|c|c|c|}
\hline Matrix & Fillers Type & $\begin{array}{c}\text { Filler } \\
\text { content (\%) }\end{array}$ & $\begin{array}{c}\text { Water vapour } \\
\text { permeability } \\
\text { (WVP) }\end{array}$ & Unit for WVP & $\begin{array}{c}\text { Oxygen } \\
\text { permeability } \\
\text { rate }(\mathrm{OPR}) \\
\end{array}$ & Unit for OPR & Ref. \\
\hline $\begin{array}{c}\text { PVA } \\
\text { PVA/starch }\end{array}$ & & $\begin{array}{c}0 \\
1: 1 \\
2: 1\end{array}$ & $\begin{array}{c}2.2 \\
4.97 \\
3.5\end{array}$ & $\mathrm{~g} \cdot \mathrm{mm} / \mathrm{kPa} \cdot \mathrm{h} \cdot \mathrm{m}^{2}$ & & & [41] \\
\hline PVA & GOs & $\begin{array}{c}0 \\
0.15 \\
0.3\end{array}$ & & & $\begin{array}{c}1.27 \times 10^{-13} \\
0.908 \times 10^{-13} \\
0.257 \times 10^{-13}\end{array}$ & $\mathrm{~mol} / \mathrm{s} \cdot \mathrm{m} \cdot \mathrm{Pa}$ & {$[76]$} \\
\hline PVA/starch & CNCs & $\begin{array}{l}0 \\
1 \\
3 \\
5\end{array}$ & $\begin{array}{l}85.3 \\
87.7 \\
85.1 \\
83.4\end{array}$ & $\mathrm{~g} \cdot \mathrm{mm} / \mathrm{kPa} \cdot \mathrm{h} \cdot \mathrm{m}^{2}$ & & & [121] \\
\hline PVA & HTCC & $\begin{array}{c}0 \\
5 \\
10 \\
20 \\
30\end{array}$ & $\begin{array}{c}85.07 \times 10^{-7} \\
1.56 \times 10^{-7} \\
2.14 \times 10^{-7} \\
4.85 \times 10^{-7} \\
7.65 \times 10^{-7}\end{array}$ & $\mathrm{~g} / \mathrm{cm} \cdot \mathrm{s} \cdot \mathrm{Pa}$ & $\begin{array}{c}0.034 \\
0.044 \\
0.063 \\
0.089 \\
0.13\end{array}$ & $\mathrm{~cm}^{3} \cdot \mathrm{mm} / \mathrm{m} \cdot \mathrm{atm} \cdot$ day & [122] \\
\hline PVA & GOs & $\begin{array}{l}0.2 \\
0.3\end{array}$ & $\begin{array}{l}564 \\
664\end{array}$ & $\mathrm{~g} / \mathrm{m}^{2} \cdot$ day & $\begin{array}{c}4.5 \\
11.9\end{array}$ & $\mathrm{~cm}^{3} / \mathrm{m}^{2} \cdot$ day & {$[71]$} \\
\hline PVA & GOs & $\begin{array}{c}0 \\
0.18 \\
0.36 \\
0.72\end{array}$ & $\begin{array}{l}3.99 \times 10^{-15} \\
2.65 \times 10^{-15} \\
2.15 \times 10^{-15} \\
1.28 \times 10^{-15}\end{array}$ & $\mathrm{~g} \cdot \mathrm{mm} / \mathrm{mm}^{2} \cdot \mathrm{s} \cdot \mathrm{Pa}$ & $\begin{array}{c}21.17 \times 10^{-15} \\
3.87 \times 10^{-15} \\
1.24 \times 10^{-15} \\
0.24 \times 10^{-15}\end{array}$ & $\mathrm{~cm}^{3} \cdot \mathrm{cm} / \mathrm{cm}^{2} \cdot \mathrm{s} \cdot \mathrm{Pa}$ & [161] \\
\hline PVA & GOs & $\begin{array}{l}0 \\
1 \\
2 \\
3 \\
4\end{array}$ & & & $\begin{array}{c}14.4 \times 10^{-16} \\
8 \times 10^{-16} \\
7.8 \times 10^{-16} \\
7.1 \times 10^{-16} \\
6.8 \times 10^{-16}\end{array}$ & $\mathrm{~cm}^{3} \cdot \mathrm{cm} / \mathrm{m}^{2} \cdot \mathrm{s} \cdot \mathrm{Pa}$ & [160] \\
\hline
\end{tabular}

HTCC: $N$-(2-hydroxy) propyl-3-trimethyl ammonium chloride chitosan 
Table 4. Transmittance of PVA nanocomposite films

\begin{tabular}{|c|c|c|c|l|}
\hline Matrix & Fillers Type & $\begin{array}{c}\text { Fillers content } \\
(\%)\end{array}$ & $\begin{array}{c}\text { Transmittance } \\
\text { (\%) }\end{array}$ & Ref. \\
\hline \multirow{2}{*}{ PVA } & \multirow{2}{*}{ CNFs } & 37 & 75 & {$[178]$} \\
\hline \multirow{2}{*}{ PVA } & \multirow{2}{*}{ GOs } & 54 & 53 & {$[153]$} \\
& & 0.1 & 97 & \\
& & 1 & 92 & \\
& & 2.5 & 90 & {$[98]$} \\
PVA & \multirow{2}{*}{ Starch } & 5 & 82 & \\
& & 7.5 & 75 & \\
& & 10 & 72 & {$[121]$} \\
\hline \multirow{3}{*}{ PVA/starch } & \multirow{2}{*}{ CNCs } & 1 & 21 & \\
& & 5 & 15 & \\
\hline \multirow{2}{*}{ PVA } & \multirow{2}{*}{ GOs } & 0 & 91 & \\
& & 0.3 & 79 & \\
\hline
\end{tabular}


Table 5. Description of tortuosity factors according to different theoretical models

\begin{tabular}{|c|c|c|c|c|}
\hline Model & Geometry and dispersion condition & Formula & Remark & Ref. \\
\hline \multirow{3}{*}{ Maxwell } & Spherical nanofillers with periodic arrays & $f=1+\frac{1+\emptyset / 2}{1-\emptyset}$ & & \multirow{2}{*}[60]{} \\
\hline & $\begin{array}{l}\text { Cylindrical nanofillers, parallel to the } \\
\text { surfaces }\end{array}$ & $f=\frac{1+\emptyset}{1-\emptyset}$ & & \\
\hline & $\begin{array}{l}\text { Nanoplatelets fillers perpendicular to } \\
\text { diffusion paths }\end{array}$ & $f=1+\frac{l_{p}}{2 t_{p}} \varnothing$ & $\begin{array}{l}l_{p^{-}} \text {length of } \\
\text { platelets nanofillers } \\
t_{p^{-}} \text {thickness of } \\
\text { platelets nanofillers }\end{array}$ & [138] \\
\hline Nilsen & Ribbon nanofillers with regular arrays & $f=1+\frac{\alpha \emptyset}{2}$ & & {$[60]$} \\
\hline \multirow{2}{*}{ Cussler } & $\begin{array}{l}\text { Ribbon nanofillers, perpendicular to } \\
\text { diffusion paths }\end{array}$ & $f=1+\frac{(\alpha \emptyset)^{2}}{4(1-\emptyset)}$ & & [188] \\
\hline & Hexagonal flakes with random arrays & $f=1+\frac{\mu}{4\left[\frac{(\alpha \emptyset)^{2}}{1-\varnothing}\right]}$ & $\mu$ - geometric factor & {$[188,199]$} \\
\hline Aris & Multilayers of nanoplatelets & $f=1+\frac{(\alpha \emptyset)^{2}}{4(1-\emptyset)}+\frac{\alpha \emptyset}{2 \sigma}$ & $\sigma$ - pore aspect ratio & {$[194]$} \\
\hline Gusev-Lusti & Disk nanofillers with random arrays & $f=\exp \left[\left(\frac{d_{p}}{3.47 t_{p}}\right)^{0.71}\right]$ & $\begin{array}{ll}d_{p^{-}} \text {diameter } & \text { of } \\
\text { disks } & \\
t_{\mathrm{p}^{-}} \text {thickness of } \\
\text { disks }\end{array}$ & {$[196]$} \\
\hline Picard & Disk nanofillers with random arrays & $f=1+\frac{0.71 d_{p}}{3.47 t_{p}} \emptyset$ & & {$[188]$} \\
\hline
\end{tabular}


Table 6. Description of relative permeability according to different theoretical models

\begin{tabular}{|c|c|c|c|c|}
\hline Model & Formula & Conditions & Remark & Ref. \\
\hline Nielsen & $\frac{P}{P_{o}}=\frac{1-\emptyset}{1+\frac{\alpha}{2} \emptyset}$ & Ribbon fillers & \multirow{4}{*}{$\begin{array}{l}\alpha=w / t \\
w \text { - width } \\
t \text { - thickness } \\
\text { length is infinite }\end{array}$} & {$[35,63,196]$} \\
\hline \multirow{2}{*}{ Cussler } & $\frac{P}{P_{o}}=\frac{1-\emptyset}{1+\left(\frac{\propto \emptyset}{2}\right)^{2}}$ & $\begin{array}{l}\text { Ribbon fillers } \\
\text { Regular arrangement }\end{array}$ & & {$[63,64,196]$} \\
\hline & $\frac{P}{P_{o}}=\frac{1-\emptyset}{1+\left(\frac{\propto \emptyset}{3}\right)^{2}}$ & $\begin{array}{c}\text { Ribbon fillers } \\
\text { Random arrangement }\end{array}$ & & {$[63,64,196]$} \\
\hline Bharadwaj & $\begin{array}{l}\frac{P}{P_{o}}=\frac{1-\emptyset}{1+\frac{\alpha}{2} \frac{2}{3}\left(S^{\prime}+\frac{1}{2}\right) \emptyset} \\
S^{\prime}=\left(3 \cos ^{2} \emptyset-1\right) / 2\end{array}$ & Ribbon fillers & & {$[35,63]$} \\
\hline Gusev and Lusti & $\frac{P}{P_{o}}=\frac{1-\emptyset}{\exp \left\{\left(\frac{\alpha \emptyset}{3.47}\right)\right\}^{0.71}}$ & Disk fillers & & {$[67,196]$} \\
\hline $\begin{array}{l}\text { Fredrickson and } \\
\text { Bicerano }\end{array}$ & $\begin{array}{l}\frac{P}{P_{o}}=\frac{1-\emptyset}{4\left[\frac{\left(1+x+0.1245 x^{2}\right)}{(2+x)}\right]^{2}} \\
x=\frac{\pi \alpha \emptyset}{2 \ln \left(\frac{\alpha}{2}\right)}\end{array}$ & Disk fillers & $\begin{array}{l}\alpha=d / t \\
d \text { - diameter } \\
t \text { - thickness }\end{array}$ & {$[161,188,201]$} \\
\hline
\end{tabular}


Table 7. Comparison of permeability reduction that predicted by different theoretical models ${ }^{[194]}$

\begin{tabular}{|c|c|c|c|c|c|}
\hline $\begin{array}{c}\text { Volume } \\
\text { fraction }(f)\end{array}$ & Aspect ratio $(a)$ & $\begin{array}{c}\text { Present work based on } \\
\text { finite element model }\end{array}$ & Nielsen & Cussler & $\begin{array}{c}\text { Fredrickson } \\
\text { and Bicerano }\end{array}$ \\
\hline 0.01 & 200 & 0.51 & 0.50 & 0.97 & 0.59 \\
\hline 0.02 & 500 & 0.12 & 0.16 & 0.66 & 0.25 \\
\hline 0.03 & 1000 & 0.0097 & 0.061 & 0.22 & 0.092 \\
\hline 0.05 & 1000 & 0.0013 & 0.037 & 0.091 & 0.047 \\
\hline
\end{tabular}

